Michael Keen

Kai A. Konrad

\title{
International Tax Competition and Coordination
}

Max Planck Institute for Tax Law and Public Finance Working Paper 2012 - 06

July 2012

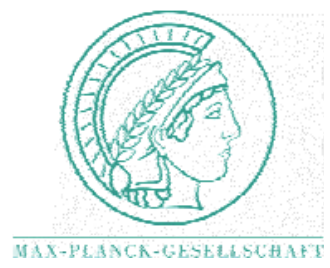

Max Planck Institute for Tax Law and Public Finance

Department of Business and Tax Law

Department of Public Economics

http://www.tax.mpg.de 
Working papers of the Max Planck Institute for Tax Law and Public Finance Research Paper Series serve to disseminate the research results of work in progress prior to publication to encourage the exchange of ideas and academic debate. Inclusion of a paper in the Research Paper Series does not constitute publication and should not limit publication in any other venue. The preprints published by the Max Planck Institute for Tax Law and Public Finance represent the views of the respective author(s) and not of the Institute as a whole. Copyright remains with the author(s).

Max Planck Institute for Tax Law and Public Finance

Marstallplatz 1

D-80539 Munich

Tel: $\quad+498924246-0$

Fax: $\quad+498924246-501$

E-mail: ssrn@tax.mpg.de

http://www.tax.mpg.de 
Draft

\title{
International Tax Competition and Coordination
}

\author{
Michael Keen ${ }^{*}$ and Kai A. Konrad ${ }^{\S}$
}

July 13, 2012

\begin{abstract}
This paper aims to provide a comprehensive survey of the theory of international tax competition. Starting with the standard framework, it visits the non-cooperative equilibrium of tax competition, analyses aspects of partial and regional coordination, repeated interaction, stock-flow-effects, agglomeration effects and time consistency issues in dynamic models. We discuss profit shifting in the Keen-Kanbur model and then survey frameworks to analyze countries' bidding for firms, tax rate differentiation and preferential tax regimes, the role of information exchange and recent work on tax havens. The paper also discusses approaches that replace the benevolent government assumption by selfish (Leviathan) governments or by political processes that determine countries' decisions on their tax policy in an international context.
\end{abstract}

Keywords: International taxation, tax competition

Acknowledgements: We are grateful to Alan Auerbach, May Elsayyad and Dave Wildasin for helpful comments on an earlier draft. Views expressed here are those of the authors and should not be attributed to the IMF, its Executive Board or management.

\footnotetext{
* International Monetary Fund, Fiscal Affairs Department, Washington DC 20431, USA.

E-mail: mkeen@imf.org.

$\S$ Max Planck Institute for Tax Law and Public Finance, Marstallplatz 1, 80539 Munich, Germany, and Social Science Research Center Berlin. E-mail: kai.konrad@tax.mpg.de.
} 


\section{Contents}

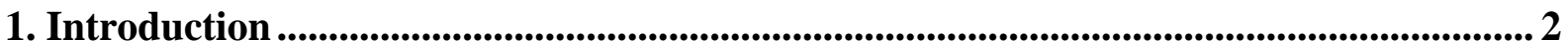

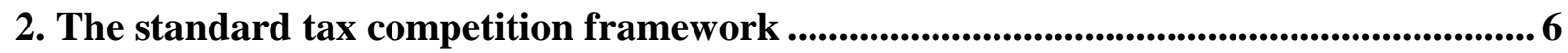

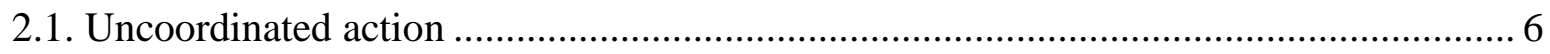

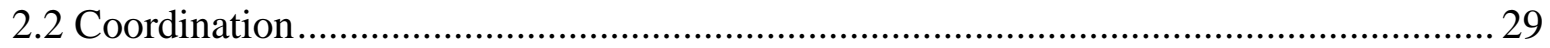

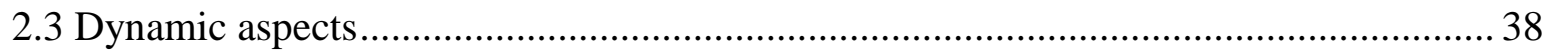

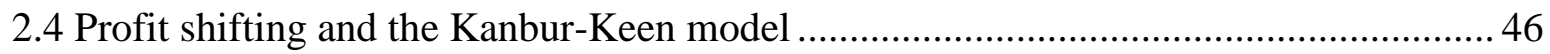

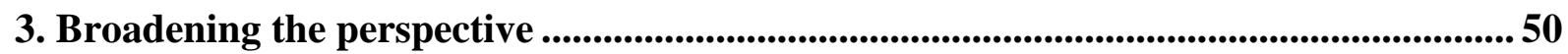

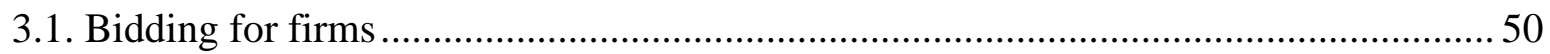

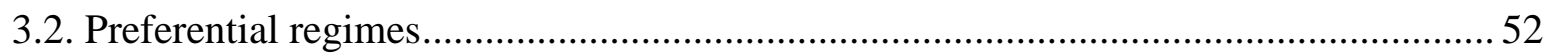

3.3. Information exchange and implementation of the residence principle .........................56

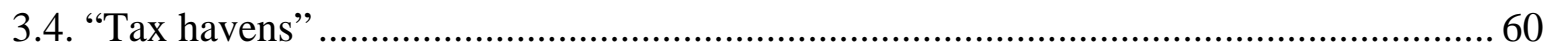

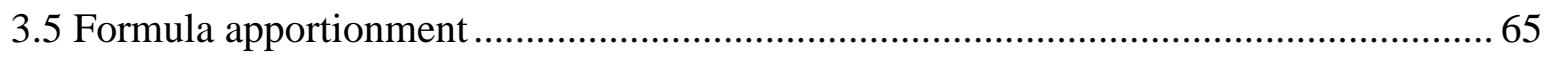

4. Political economy and agency issues............................................................................6 68

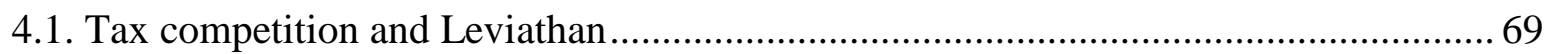

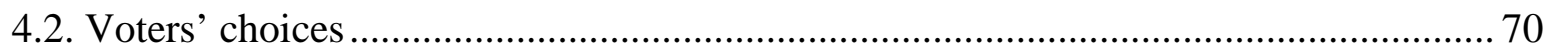

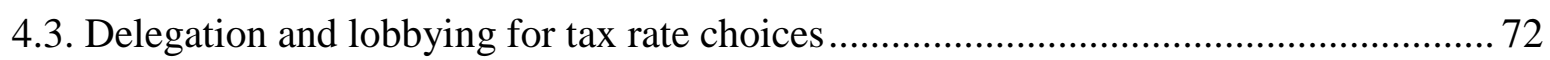

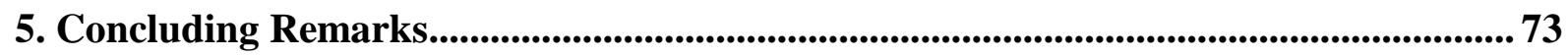

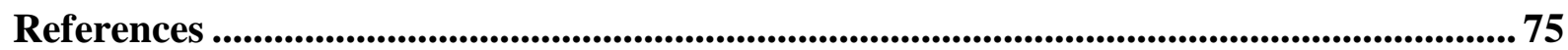




\section{Introduction}

Awareness that national tax policies can induce economic activity to move across international borders is not new. In 1763, Catherine the Great gave to "...Foreigners that have settled themselves in Russia [to] erect Fabricks or Works, and manufacture there such Merchandizes as have not yet been made in Russia..." the right to "sell and export said Merchandizes out of our Empire for ten years, without paying any inland Tolls, Port Duties or Customs on the Borders..."1 It is over the last two decades or so, however, that increased economic integration has made international considerations a central component of tax policy making around the world. Like it or not, national tax policy makers are involved in a game with one another. This class of games is what is meant here by "international tax competition," and it is the aim of this chapter to take stock of what is known of this game, the outcomes it may lead to, and the ways in which it might be beneficially reshaped.

The practical policy agenda on these issues is an active one. Awareness of the constraints that international considerations place on national tax policies is now a commonplace of budget (and campaign) speeches, with the downward trend of statutory corporate tax ratesmost often remarked on for advanced economies, but hardly less marked elsewhere ${ }^{2}$ (Figure 1) - perhaps the paramount prima facie example of international tax competition at work. But there are many other possible instances. These include the widespread demise of inheritance taxation; the reduction in top marginal rates of personal taxation on both labour income (reflecting the mobility of high earners and the tax avoidance opportunities created if that rate strays too far from the corporate rate) and capital income; and the limits placed on cigarette and alcohol excises by the prospect of cross-border shopping and smuggling from lower taxed neighbours. Concern at the pressures consequently imposed on national tax bases has led to proposals for, and, to a much lesser extent, action on coordinated measures to restrict downward pressures on tax rates. When it removed tax-related controls from its internal frontiers, for instance, the European Union (EU) adopted minimum excise duty rates (albeit in some cases of zero) intended to limit downward spiralling of rates In the area of corporate taxation, the Ruding Committee (1992) proposed for the EU a common minimum tax rate, at the now quaint-looking level of 30 percent. $^{3}$ In the later 1990s, effort focused on identifying

\footnotetext{
${ }^{1}$ Weightman (2007, p.33). She had some success, it seems; even James Watt was reportedly tempted.

${ }^{2}$ Arguably it is a more important concern in lower income countries, since they are typically more reliant on the corporate tax as a source of revenue.

${ }^{3}$ Perhaps surprisingly, the committee argues for subsidiarity and flexibility and for leaving ample discretion that can be used for tax competition, and even argues for more transparency and the means to increase capital mobility, that is, provide an environment in which tax competition can be expected
} 
forms of 'harmful tax competition'(distinguishing this simply low rates of tax), notably with a landmark report of the OECD (1998) and the adoption by the EU of a Code of Conduct aimed at rolling back and precluding particular forms of tax incentive. The fate of the OECD initiative reflected the difficulty of agreeing on a delineation of harmful tax design, and came to focus instead on the narrower (but still ambitious) objective of ensuring that countries provide each other with the information needed to enforce their own tax systems. This effort was massively reinforced by leadership from the G20 in the wake of the 2008 crisis. Regional blocs other than the EU-in Central America, East and South Africa and elsewhere-have also sought to reach agreements limiting corporate tax competition among themselves, but, like the EU, with limited success. Coordination is more common on commodity taxation, and the VAT-despite the fact, or perhaps because of it, that the lesser mobility of goods than capital suggests that this is likely to be less important than action on business taxation.

Figure 1: Median statutory corporate tax rates by income group, 1980-2010.

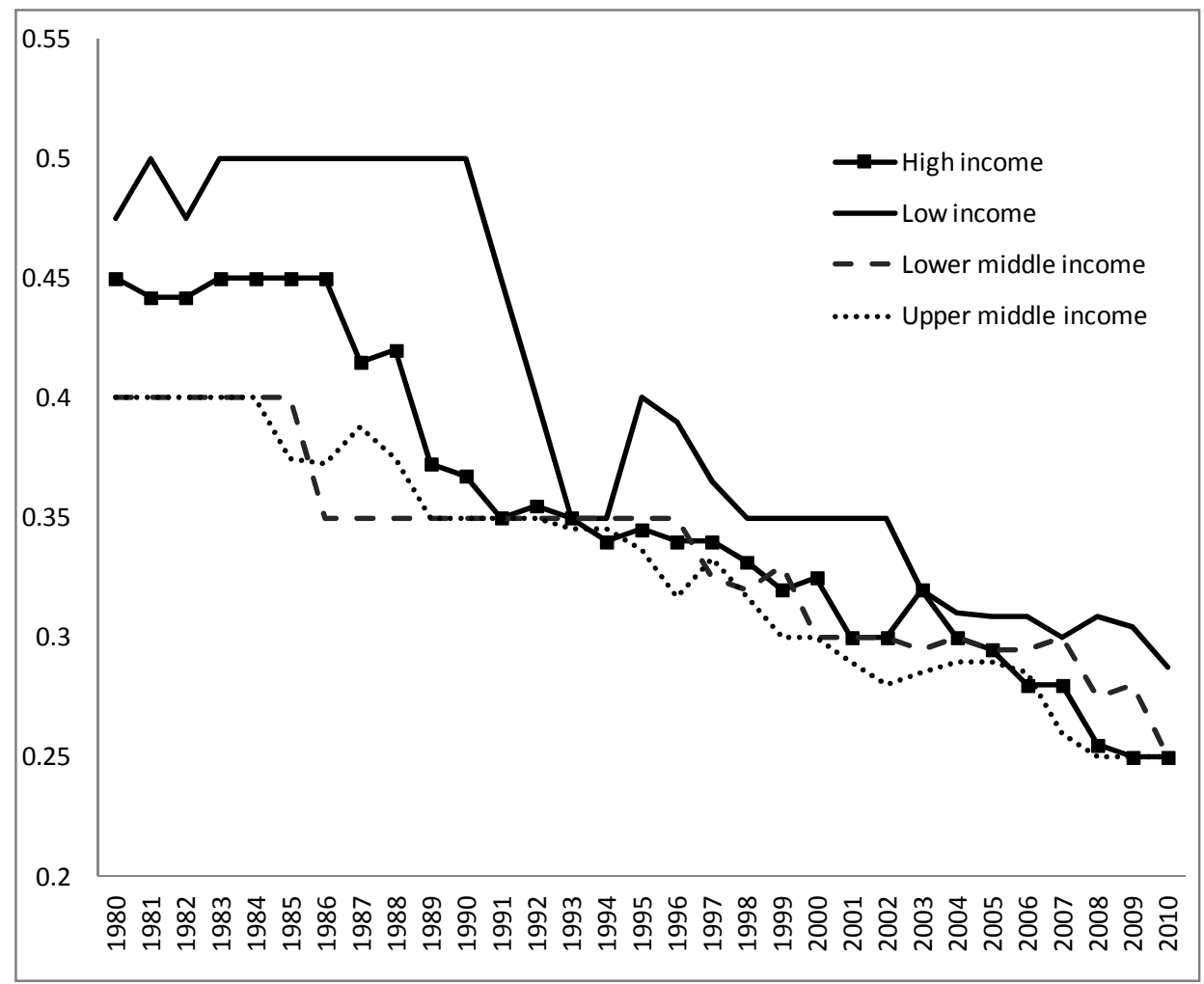

Note: Tax rates from KPMG tax rates online. Countries classified by income, at each date, into four equal-sized groups.

This increased policy focus on international tax competition has been matched by a massive growth of the public economics literature in this area. This chapter does not aim to provide an 
exhaustive review - there are several excellent surveys ${ }^{4}$ - but focuses on theoretical aspects of strategic interactions, and possible policy responses, primarily in relation to the taxation of capital income at business and corporate levels.

These are the areas of taxation in which tax competition concerns have had greatest political salience, and on which most academic attention has focused. In relation to corporate taxation, Figure 1 goes a long way to explaining why. Importantly, it also makes clear that a view of the world in which countries mutually undercut each other in their tax rates in a Bertrand like race to the bottom is too simplistic as a description of the strategic interaction that is associated with tax competition. But this much-used figure also raises, or hides, as many questions as it answers. Is it even obvious in principle, for instance, that tax competition implies downward pressure on rates, rather than upward? And is it necessarily the case that downward pressures on statutory tax rates from international tax competition are undesirable? Who gains, who loses? Might the EU have been wise to adopt the Ruding minimum rates, or would it now simply find itself a ripe target for undercutting by other countries? And the statutory tax rate shown in the Figure is only one among may corporate tax parameters that countries can manipulate. The tax base too is a strategic choice, and indeed many advanced economies have broadened their tax bases at the same time as they have reduced statutory rates $;{ }^{5}$ many of those in sub-Saharan Africa, however, have generally narrowed the base $;^{6}$ can such subtleties be rationalized as responses to international pressures? And countries may, for instance, offer special regimes tailored to particular types of investments: to what extent would one expect them to do so, and does such targeting make tax competition more or less damaging? Other instruments can be deployed, or in addition, to tax parameters, such as the provision of infrastructure or other factor inputs. How do strategic considerations interact across instruments? Not least, the figure also highlights that tax interactions are not a one-shot game: rather, they evolve as a dynamic process in which different countries choose their tax rates repeatedly: How does that affect the nature of the equilibrium and the impact of possible policy interventions?

\footnotetext{
${ }^{4}$ These include Wilson (1999), Gresik (2001), Zodrow (2003), Wilson and Wildasin (2004), Fuest, Huber and Mintz (2005), Zodrow (2010), Genschel and Schwarz (2011) and Boadway and Tremblay (2011).

${ }^{5}$ Indeed corporate tax revenue proved buoyant in these countries, at least until the onset of the 2008 crisis. While base-broadening seems to have contributed to this in many cases, other factors (including particularly high profits in the financial sector) appear also to have played a role. On this, see Devereux, Griffith and Klemm (2002), Auerbach (2006), Clausing (2007), Sørensen (2007), Devereux, Lockwood and Redoano (2008).

${ }^{6}$ See Keen and Mansour (2010).
} 
In focusing on these and related theoretical issues, the chapter emphasizes the analogies between the theory of tax competition and competition models in the theory of industrial organization. This analogy is evident from some of the early contributions describing tax competition as an oligopoly game [Wildasin (1988, 1991), Wilson (1986), Bucovetsky (1991)], and the correspondences will be made transparent throughout.

Doing justice to these issues means that the chapter refers only in passing to important aspects of the wider literature. It does not review econometric work on tax competition, which generally confirms that countries' fiscal policies are indeed interdependent, with many of the findings in line with main hypotheses derived from the theory below. ${ }^{7}$ The models used are a highly stripped down version of a reality that is far more complex in terms of both international tax rules and conventions and the avoidance devices that multinationals may use, accounts of which may be found elsewhere. ${ }^{8}$ The treatment of profit-shifting by multinationals - in essence, the shifting of paper profits between countries-is thus highly stylized. ${ }^{9}$ Nor does this chapter consider in any detail the rather different issues that arise in relation to commodity tax competition, ${ }^{10}$ and it addresses only briefly the nature of tax competition with multi-levelled federal systems. ${ }^{11}$

\footnotetext{
${ }^{7}$ Reflecting the availability of better data and a more homogenous set of jurisdictions, much share of this literature considers fiscal competition on the regional level. An early overview is by Brückner (2003). More recent contributions are Winner (2005), Carlsen, Langset and Ratts $\varnothing$ (2005), Overesch and Rinke (2009), Parry (2003), Revelli (2003), Boadway and Hayashi (2001), Büttner (2003), Mintz and Smart (2004), Binet (2003), Karkalakos and Kotsogiannis (2007), Gérard, Jayet and Paty (2010) and Jacobs, Ligthart and Vrijburg (2010). For a recent survey see also Zodrow (2010).
}

${ }^{8}$ See Gordon and Hines (2002) on the former and Mintz and Weichenrieder (2010) on the latter. Also relevant here is the literature on double tax agreements, which has been primarily focused on whether these have encouraged capital movements: see for example Blonigen and Davies (2004).

${ }^{9}$ Gresik (2001) covers many of the early contributions on transfer pricing issues. The status of the discussion in the legal and economic literature on transfer pricing and other means of profit shifting is set out in the collected volume by Schön and Konrad (2012).

${ }^{10}$ There are resonances between the two literatures-and the Kanbur-Keen (1993) model discussed in Section 2.4 has applications to both-but tax impacts through final consumption and through factor inputs generally require quite different modeling. Central concerns in the analysis of commodity tax competition, which begins with Mintz and Tulkens (1986), are the characterization of, and comparison between, noncooperative equilibrium and potential coordination measures under both origin taxation (under which goods are taxed according to where they are produced) and destination principles (under which they are taxed where consumed. Lockwood (1997) provides an integrated treatment, and a selective survey is in Keen (2001).

${ }^{11}$ See Wilson and Janeba (2005); the survey by Boadway and Tremblay (2011) focuses on fiscal federalism but includes considerations of tax competition. Zodrow (2010) focuses on the empirical evidence both on the sensitivity of capital flows on taxes and the evidence on the strategic interaction 
This still leaves a lot of ground to cover. Section 2 sets out the models and results that have been central to the literature, focusing particularly on the model developed by Zodrow and Mieszkowski (1986) and Wilson (1986). This views tax competition as a game played over the application in each country of a single tax rate applied to the general use of productive capital, an approach that proves instructive but does not capture the possibility that companies and individuals can to some degree decouple—by transfer pricing and other profit-shifting devices, or by use of low-tax jurisdictions offering some degree of secrecy-the income they generate from the tax liability they incur. The section concludes by introducing a second model of tax competition, that of Kanbur and Keen (1993), which has been quite widely used, and which enables a simple first look at profit-shifting and potential policy responses. Section 3 takes a broader perspective, focusing on a series of issues that are prominent in policy debates: these include the use of special regimes targeted at particular firms or activities, and the impact of tax havens and of measures that are or might be adopted in response. Section 4 departs from the assumption of benevolent policy making to turn to considerations of political economy and agency, the key issues being how the political process might temper both the nature of the outcome under international tax competition and, more particularly, the welfare impact of measures of coordination.

\section{The standard tax competition framework}

\subsection{Uncoordinated action}

\section{The workhorse model-Zodrow, Mieszkowski and Wilson}

The formal literature on tax competition is largely rooted in an elegant model developed by Zodrow and Mieszkowski (1986) and Wilson (1986), the influence of which runs through the contributions reviewed in this survey. This ' $\mathrm{ZMW}$ ' model considers a world economy comprised of $n$ 'countries, ${ }^{12} i=1, \ldots n$, each characterized by investment opportunities described by an increasing and strictly concave product-of-capital function $f_{i}\left(k_{i}\right)$. Behind the scenes there may be other factors of production, such as labor, intangibles, and publicly provided inputs; where these are in variable supply and untaxed, they can be taken to have been concentrated out of the production function. In the workhorse model we take all these

between governments in the context of tax competition.

${ }^{12}$ We use this term rather than 'jurisdictions' throughout, although the analysis can of course also be applied to states within a federation (ignoring the presence of the federal government itself); more pedantically, many tax havens are dependencies rather than independent nations. 
factors as exogenously given; they shape the function $f_{i}\left(k_{i}\right)$ but need not be considered in the formal analysis. The downward slope of the marginal product of capital, $f_{i}^{\prime}\left(k_{i}\right)$, is explained by the presence of these hidden exogenous factors. ${ }^{13}$ Each country chooses the per-unit tax $t_{i} \in[0,1]$ that is levied on each unit of capital that is invested in country $i$, so that its tax revenue is $t_{i} k_{i}$. In the basic ZMW framework, the aggregate world capital stock is fixed and denoted by $K$, the net-return on capital is denoted by $\rho$, and, together with price taking behaviour of investors, the capital market equilibrium is determined by

$$
f_{i}^{\prime}\left(k_{i}\right)-t_{i}=\rho \text { for all } i=1, \ldots n,
$$

together with the market clearing condition

$$
\sum_{i=1}^{n} k_{i}=K=\sum_{i=1}^{n} c_{i}
$$

where $c_{i} \geq 0$ denotes the amount of capital that is owned by citizens of country $i$. These equations describe the Walrasian equilibrium outcome in the capital market with perfect competition. Equation (2) is a budget equation: total capital invested must equal to the sum of capital $c_{i}$ owned by citizens of the different countries. Equation (1) describes the market clearing prices: in each country, demand and supply for capital clear at a rate that is equal to the gross marginal return in each firm that rents capital, and therefore also equal to the marginal return of an aggregated production function of the country, $f_{i}^{\prime}\left(k_{i}\right)$. Capital can also flow freely between countries, and an equilibrium in these flows requires that the last unit of world capital that is available yields the same net-of-tax return to the owner of this unit, regardless of where it is used. The net-of-tax return is obtained from the gross-return (the rental price) by deducting the unit tax $t_{i}$ that is deducted at source. And this net-of-tax return is denoted $\rho$.

Equations (1) and (2) jointly determine both the capital allocated to each country and the common net rate of return as functions $k_{i}\left(t_{1}, \ldots, t_{n}\right)$ and $\rho\left(t_{1}, \ldots, t_{n}\right)$ of tax rates in all countries. These, it is dull to show ${ }^{14}$, have the properties that

\footnotetext{
${ }^{13}$ The framework is a special case of a more general model with a country's output as a function $F(K, N, B)$, with $N$ representing an input factor such as labor that is paid a competitive market price (and may be supplied elastically or inelastically) and $B$ representing other fixed factors such as, for instance, national public goods that firms do not have to pay for. Our benchmark model is obtained from this, for instance, if $B$ is absent, $N$ completely inelastically supplied, and $F(K, N)$ is homogenous of degree 1 .

${ }^{14}$ Perturbing the $n-1$ equations corresponding to (2),
}

$$
f_{i}^{\prime}\left(k_{i}\right)-t_{i}=f_{n}^{\prime}\left(K-k_{1}-\cdots-k_{n}\right)-t_{n}, \quad i=1, \ldots, n-1,
$$




$$
\frac{\partial k_{i}}{\partial t_{j}}=\left\{\begin{array}{c}
\zeta_{i}\left(1-\frac{\zeta_{i}}{\sum_{s=1}^{n} \zeta_{s}}\right)<0, \text { for } i=j \\
-\left(\frac{\zeta_{i} \zeta_{j}}{\sum_{s=1}^{n} \zeta_{s}}\right)>0, \text { for } i \neq j
\end{array}\right.
$$

where $\zeta_{i} \equiv f_{i}^{\prime \prime}<0$, and $\partial \rho / \partial t_{i}<0$ for all $\mathrm{i}^{15}$ An increase in the tax rate in any country thus reduces the capital employed there, increases capital employed in all other countriescapital moves until the increased scarcity of capital in $i$ has increased the gross marginal product of capital there and reduced the marginal product of capital in all other countries sufficiently to bring the arbitrage condition back into balance-and reduces the common net rate of return.

In each country there is a single representative consumer-immobile across countrieswith preferences $W_{i}(x, r)=x+G_{i}(r)$ defined over private consumption $x$ and the amount $r$ of some publicly provided good, with $G_{i}$ strictly increasing and strictly concave; ${ }^{16}$ the $G_{i}$ are assumed to satisfy an Inada condition which ensures that, in the absence of other sources of revenue, all countries will charge a strictly positive tax rate $t_{i}$ in equilibrium. Private consumption $x$ is financed by the rents to domestic immobile factors, $f_{i}\left(k_{i}\right)-f_{i}^{\prime}\left(k_{i}\right) k_{i}$ and the net receipts on domestically-owned capital, wherever located, of $\rho c_{i}$. Public provision is financed by receipts $t_{i} k_{i}$ from capital located domestically, and the relative price of the private and publicly provided goods is taken to be fixed and normalized at unity; so $r_{i}=t_{i} k_{i}{ }^{17}$ Welfare in country $i$ is thus given by

$$
W_{i}=f_{i}\left(k_{i}\right)-f_{i}^{\prime}\left(k_{i}\right) k_{i}+\rho c_{i}+G_{i}\left(t_{i} k_{i}\right)
$$

their action spaces and payoff functions (3), each government maximizes its objective function by a choice of its tax rate, taking the (equilibrium) tax rate choices of all other countries as given, and anticipating the implications of their choice for the allocation of capital and the net return to capital.

gives the system $\left(A+f_{n}^{\prime \prime} \iota^{\prime}\right) d k=d t$, where, other than the obvious, $A$ is the diagonal matrix with $j j$ th element $f_{j j}^{\prime \prime}$ and $\iota$ is the column vector of ones. Supposing only one tax rate to change, (2.a) follows on using a result on matrix inversion found, for instance, in Dhrymes (1978, Proposition 33).

${ }^{15}$ Differentiating (1), for any $j \neq i$, gives $\partial \rho / \partial t_{j}=f_{i}^{\prime \prime} \partial k_{i} / \partial t_{j}$, and the conclusion follows from (2.a).

${ }^{16}$ Little of substance is lost by the restriction on the functional form of preferences.

${ }^{17}$ Note that this is, in effect, a model of trade in two goods: a final consumption good and capital. Country $i$ 's exports, given by the excess of production $f(k)$ over its aggregate consumption $x_{i}+r_{i}$ are equal, given individual and public budget constraints, to its net payments on imported capital $\rho\left(k_{i}-c_{i}\right)$. The elegance of the approach derives largely from its collapsing a model of intertemporal trade into a single period. 


\section{Interpretation and limitations}

There are many embellishments of this basic ZMW structure to be found in the literature. Many of these are considered below, though by no means all. One not considered, for instance, is that in which public expenditure enters the production function rather than individual's preferences, reflecting public spending on some form of infrastructure. In terms of strategic interactions and efficiency considerations, this leads to broadly the same conclusions as below. Before putting this model through its paces, however, it is important to see where it inherently does and does not connect with practical policy concerns.

One key issue is the interpretation of 'capital', $k$. This is most naturally thought of as physical productive capital. ZMW is not a model of financial investments, since capital flows are taken to lead directly to changes in production: portfolio investments, or direct investments taking the form of acquisitions, need different handling. The interpretation as physical capital requires of course some suspension of disbelief in terms of the ease with which factories and the like can be shifted from one country to another-raising issues of sunk and adjustment costs that are taken up later. More generally of course, 'capital' here can be read as a metaphor for anything that is mobile internationally and generates real output where it is applied-the ZMW framework has been fruitfully applied, for instance, to issues of labor mobility. Note too that, as a first approximation, 'capital' is considered as a nonlumpy and homogenous good, with foreign- and domestically-owned variants indistinguishable. ${ }^{18}$

On the tax side, several important elements of reality are abstracted from by specifying tax paid as simply $t_{i} k_{i}$.

First, tax is practice levied on some combination of the rents that capital earns, $f(k)-$ $f^{\prime}(k)$ and the marginal return to capital $f_{i}^{\prime} k_{i}$, not on capital itself. Allowing for a distinct tax on rents that accrue to the domestic citizen is straightforward: this could be seen as an additional source of revenue, with the tax on capital $k$ levied only in so far as additional revenue is needed.. What this treatment of rents does mean, however, is that the tax rate $t_{i}$ is best thought of as an indicator of the 'marginal effective tax rate' on capital invested in country $i$-the additional tax paid on a real investment, reflecting both the statutory tax base and the base of the tax-rather than the statutory tax rate alone. Even this though, is not quite right. This is because of the latter aspect above, tax in the ZMW being levied on capital rather than its marginal return. The distinction here is similar to that between a specific and ad valorem tax in the context of commodity taxation. In that context, and here to, the distinction

\footnotetext{
${ }^{18}$ Mintz and Tulkens (1996) is an exception.
} 
is immaterial in terms of the decisions of competitive firms. Lockwood (2004) shows, however, that the distinction does matter in terms of strategic tax setting, with tax competition likely to be more aggressive in the more realistic case in which it is the return to capital that is taxed: intuitively, if country $i$ reduces its tax rate, this causes a larger inflow of capital because the reduction in the marginal return it induces reduce the tax paid per unit of capital and so leads to an inflow additional to that which would arise if tax per unit of capital were fixed. Two other aspects of the modelling of the tax system are likely event more fundamental. The first is that tax liability follows mechanically from real investment decisions; in practice, however, firms have a variety of devices, through transfer pricing, financial decisions and organizations structures, for disentangling the two. These issues, at the heart of much international tax debate, cannot be addressed in the ZMW setting. The second is that the assumption of taxation only by the source country (where the productive capital is located) is apparently at odds with core features of the international tax architecture. Several countries have applied instead the 'residence principle' in taxing foreign direct investment (and almost all do so for portfolio investment), by which, while the source (or 'host') country has primary taxing rights the home country (where the parent company is formally resident) also taxes income arising abroad, with a credit (non-refundable in practice) for taxes paid abroad. This is still, most notably, the system applied by the U.S. Residence taxation can have profound implications for the strategic issues with which we are concerned here, since it means that in some circumstance the tax applied by the host country is entirely irrelevant for the foreign investor; and issues consequently arise as to when countries would choose to apply the residence or source (also known as 'exemption' or 'territorial') system. These issues are addressed in Gordon and Hines (2002) and Fuest, Huber and Mintz (2005). Arguably, however, the ZMW assumption of source taxation is a reasonable characterization of reality: additional taxes payable in the residence country can generally be deferred, for instance, by delaying repatriation of profits (this being a large part of what tax havens enable companies to do), and in some cases-more at the personal level rather than corporate-are liable to outright evasion by simply failing to declare taxable income to the authorities of the residence country. There has, moreover, been a trend towards territorial systems, with both the U.K. and Japan having moved in this direction. The strong residence elements in the international tax architecture should not, however, be forgotten-there are over 2,000 double tax treaties whose purpose is largely to clarify and coordinate taxing rights of residence and source countries-and will be referred to occasionally below when the implications are especially important. 
Clearly too governments have other tax instruments at their disposal, including at personal level, as well as a range of administrative instruments, including their audit and tax enforcement strategies ${ }^{19}$, their choice of restrictions limiting profit shifting ${ }^{20}$, choice of public infrastructure (Keen and Marchand, 1997). ${ }^{21}$ Several of these are examined below.

\section{Equilibrium and social optimality}

Returning to the model itself, maximizing in (3) for each $i_{s}$ taking the tax rates of all other countries as given, gives the necessary conditions

$$
\frac{\partial W_{i}}{\partial t_{i}}=-f_{i}^{\prime \prime}\left(k_{i}\right) k_{i} \frac{\partial k_{i}}{\partial t_{i}}+\frac{\partial \rho}{\partial t_{i}} c_{i}+G_{i}^{\prime}\left(k_{i}+t_{i} \frac{\partial k_{i}}{\partial t_{i}}\right)=0, i=1, \ldots, n
$$

so that, in considering an increase in its tax rate, each government weighs the reduction in rents to immobile factors consequent on the capital outflow this would cause, and any increase in revenue, against the reduced net income that it would earn on its capital endowment. A Nash equilibrium vector of tax rates is a solution to the system (4).

A central question of interest is whether this equilibrium has any social optimality properties. To address this it is useful first to consider how welfare would be affected in each country if all were to raise their tax rates by some common and small amount $d t_{i}=d t$. From (1) and (2), this would have no effect on the allocation of capital, so $d k_{i}=0$, and would reduce the net return $\rho$ by the full amount of the tax. And so, recalling (3), the effect of such a reform on welfare in country $i$ is given by

$$
d W_{i}=d G-c_{i} d t=\left(G_{i}^{\prime} k_{i}-c_{i}\right) d t
$$

Noting that (1) implies, $\partial \rho / \partial t_{i}=f_{i}^{\prime \prime}\left(\partial k_{i} / \partial t_{i}\right)-1$, the necessary condition (4) implies that in equilibrium

\footnotetext{
${ }^{19}$ Boadway and Keen (1998) show how a commitment to lax auditing can be used to as a means to overcome the time consistency problem in capital income taxation. Baretti, Huber and Lichtblau (2002) find evidence for the strategic choice of tax enforcement activities in the context of German fiscal federalism.

${ }^{20}$ See, for example, Peralta, Wauthy and van Ypersele (2006) and the section on tax havens further below.

${ }^{21}$ An early discussion of the choice of instruments and its potential implications for the nature of fiscal competition is Wildasin (1991).
} 


$$
G_{i}^{\prime} k_{i}-c_{i}=\left[\left(k_{i}-c_{i}\right) f_{i}^{\prime \prime}-G_{i}^{\prime} t_{i}\right] \frac{\partial k_{i}}{\partial t_{i}}
$$

With this in mind, it is helpful to consider in turn two cases.

\section{Identical countries}

Suppose all countries are symmetric as regards production opportunities $\left(f_{i}()=.f_{j}(.) \equiv f().\right)$, ownership of capital $\left(c_{i}=K / n\right)$, and public goods preferences $\left(G_{i}()=.G_{j}(.) \equiv G().\right)$. Then in equilibrium the employment of capital $k_{i}$ must be the same in all, and this amount must then be the same as he endowment of capital in each. Thus $k_{i}=c_{i}$, and using (6) in (5) gives

$$
d W_{i}=-G_{i}^{\prime} t_{i} \frac{\partial k_{i}}{\partial t_{i}} d t>0
$$

The Nash equilibrium is thus Pareto inefficient: All countries would benefit from a small, uniform increase in all tax rates. This is the central result in the case against untrammelled international tax competition.

In this case, the Nash equilibrium can be very directly compared with the social optimum. With identical countries, the latter is simply the combination of tax rates and transfers between countries that maximizes the sum of all their utilities. A necessary condition for this first-best outcome is the efficient provision of public funds, which, in an interior solution, is described by the condition

$$
G^{\prime}(.)=1 \text { for all } i=1, \ldots n \text {. }
$$

This requires some amount $T=\Sigma_{i} T_{i}$ of public funds, which needs to be raised by taxation. As the global capital stock is assumed completely inelastic, this stock is a non-distortionary tax base, and $T$ should be taken from this capital stock. To generate this revenue while maintaining production efficiency, which requires equalizing marginal products of capital across countries (without which, aggregate output could be increased by reallocating capital between them), tax rates must be the same in all countries, $t_{i}=t$ for all $i=1, \ldots n$, and fulfil the global public budget constraint $t K=T$. Hence, the first-best set of tax rates is

$$
t_{i}=\frac{G^{-1}(1)}{k^{-}}, \text {for } i=1, \ldots, n
$$


The Nash equilibrium outcome generically differs from this. In this case, the first order condition (4) implies

$$
G^{\prime}(t * c)=\frac{1}{1+E_{k}}<1
$$

where $E_{k} \equiv \partial \ln \left(k_{i}\right) / \partial \ln \left(t_{i}\right)(<0)$ denotes the elasticity of capital employed in $i$ with respect to its own tax rate, evaluated at the Nash equilibrium. Relative to the social optimum, there is thus under-provision of the public good, and too low a tax rate, in the Nash equilibrium. There is production efficiency: all countries charge the same tax rate, so the allocation of capital is first best. But decentralized tax-setting means that countries fail to properly exploit what is, from the collective perspective, a perfectly inelastic tax base, access to which makes the first best feasible.

\section{Asymmetric countries}

The simplicity of the symmetric case, and sharpness of the results to which it leads, has made symmetry a common assumption in the literature. But it is worth stressing how unrealistic it is. The implication, for instance, is that there is no capital movement in equilibrium, and no gain from allowing capital to move; indeed there is a loss, given the inefficient tax-setting (if border were closed, each country would recognize the inelasticity of the tax base, and achieve the first-best) from allowing capital to move at all. While the asymmetric case is thus inherently more interesting, it is also much more complex.

The diversity of national interests that can then arise is evident from substituting (6) into (5). This shows that country $i$ gains from a small, collective increase in tax rates if and only if $\left(k_{i}-c_{i}\right) f_{i}^{\prime \prime}-G_{i}^{\prime} t_{i}<0$. This is sure to be the case when $k_{i}>c_{i}$; that is, for a capital importing country. For a capital exporting country, however, the reduction in after-tax capital income may more than outweigh the value of the increased tax revenue.

Social optimality also becomes more complex in the asymmetric case. Consider, for instance, the characterisation of Pareto-efficient tax structures: ones, that is, from which no country can be made better off without making any other worse off (and from which a selection might then be made if some social welfare function is available). It follows from results of Keen and Wildasin (2004) that if there are three or more countries, then, in the absence of lump sum international transfers, such Pareto efficient allocations may feature production inefficiency: marginal products of capital, that is, may differ across countries at a 
(constrained) Pareto efficient allocation. That is, Pareto efficient international tax structures may well involve tax rates that vary across countries.

One implication is that the case for the residence principle, sometimes presented as the preferred international tax regimes on the grounds that it eliminates the production inefficiency associated with the source principle, is weaker than often thought: it can lead to Pareto inefficient outcomes. The qualification has some policy importance, given the focus of current initiatives - discussed later-on strengthening the enforcement of residence taxation.

\section{Comparative statics}

For the symmetric case, (10) immediately implies that the equilibrium tax rate is lower-and hence the inefficiency greater, the larger (in absolute terms) is the elasticity of each country's tax base with respect to its own tax rate. Probing further, that elasticity can be shown, from (2.a), to be given by

$$
E_{k}=\left(1-\frac{1}{n}\right)\left(\frac{t^{*}}{c f^{\prime \prime}}\right)
$$

Substituting this into (10), it is straightforward to show that the equilibrium tax rate $t^{*}$ is lower the larger is the number of countries and the flatter is the marginal product of capital (the smaller, that is, is $\left|f^{\prime \prime}(c)\right|$ ). This as intuition would suggest: there is no distortion, of course, if $n=1$; and a flatter marginal product schedule means that small tax differences induce larger capital flows

For the symmetric case, some instructive comparative statics results can be derived by linearizing the production functions $f_{i}\left(k_{i}\right)$, as in Wildasin (1991) and as has become popular more recently. Taking now

$$
f_{i}^{\prime}\left(k_{i}\right)=\max \left\{a_{i}-k_{i}, 0\right\} \text { with } a_{i}>0
$$

and assuming that capital is not abundant

$$
K<\sum_{i=1}^{n} a_{i} \equiv A
$$

this turns the capital market equilibrium becomes

$$
a_{i}-k_{i}-t_{i}=\rho \text { for all } i=1, \ldots n \text {. }
$$


For the case $n=2$ the capital market equilibrium can be depicted as in Figure 2. This shows the linearly declining marginal productivity of capital for the two countries as bold lines, and the net-of-tax return for capital owners for different allocations of the aggregate capital stock $K$ as broken lines. The intersection of the broken lines marks the equilibrium allocation of capital, for which (14) holds, and the net return $\rho$ that results from the tax rate choices $t_{1}$ and $t_{2}$ in the capital market equilibrium.

Figure 2: Capital market equilibrium in the two-country model.

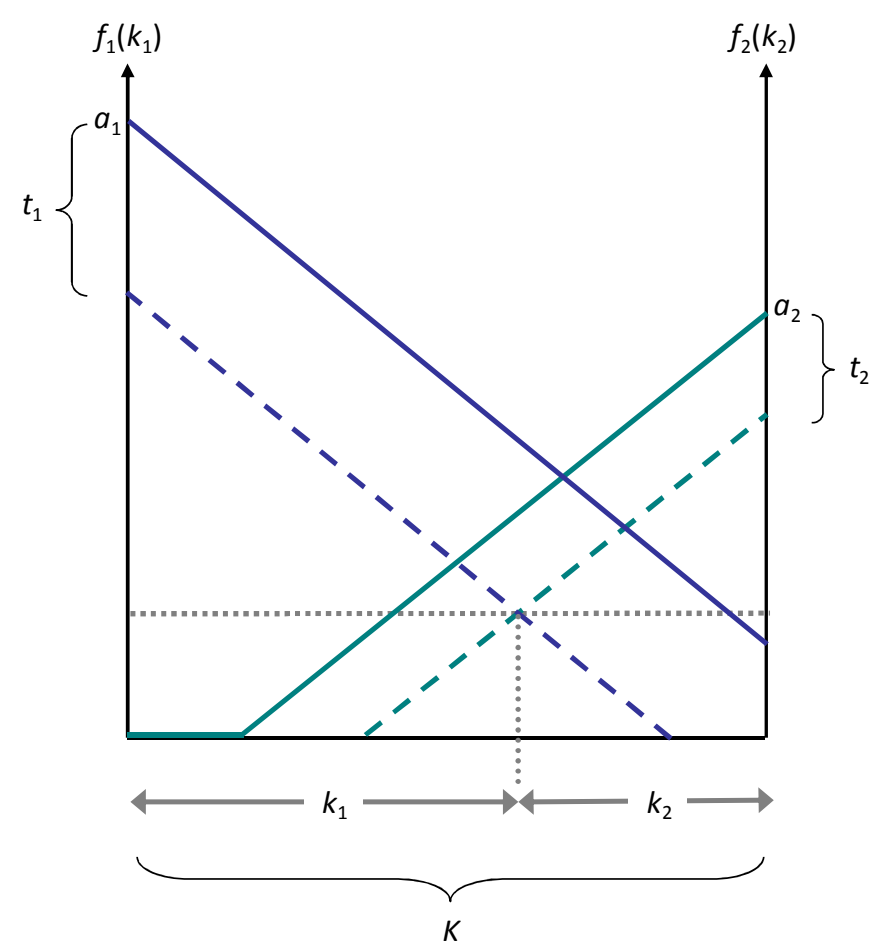

Suppose too that $G_{i}\left(t_{i} k_{i}\right)$ takes the form

$$
G_{i}= \begin{cases}\left(1+\lambda_{i}\right) t_{i} k_{i} & \text { for } t_{i} k_{i} \leq \bar{G} \\ \left(1+\lambda_{i}\right) \bar{G} & \text { for } t_{i} k_{i}>\bar{G}\end{cases}
$$

so that the private evaluation of the public good is strictly proportional to the amount of tax revenue, up to some point beyond which further increases have no value. The public expenditure generates some surplus, which can be seen as the shadow price of public funds, with $\left(1+\lambda_{i}\right)>1$. The upper limit $\bar{G}$ is assumed to be sufficiently high not to affect the taxcompetition equilibrium, but makes sure that the government would wish to confiscate all capital in the case of autarchy. 
In this parametric version, which has been used more recently by a number of authors (including Bucovetsky (2009), taking $f_{i}^{\prime \prime}=-1$ for all $i$ in (2.a) implies that the private market reactions to tax rate changes are

$$
\begin{gathered}
\frac{\partial k_{i}}{\partial t_{i}}=-\frac{n-1}{n} \\
\frac{\partial k_{j}}{\partial t_{i}}=\frac{1}{n}
\end{gathered}
$$

from which, and, as a consequence of (2),

$$
\frac{\partial \rho}{\partial t_{i}}=-\frac{1}{n}
$$

in the "interior range"- which needs to be determined further, as corner solutions are likely. This structure allows closed form solutions for a range in which tax rates are not "too different" from each other. Using that (14) holds for all $i$ inside the interior range, summing yields $A-K-\sum_{i=1}^{i=n} t_{i}=n \rho$. Accordingly, $a_{i}-k_{i}-t_{i}=A / n-K / n-\sum_{i=1}^{i=n} t_{i} / n$, or, solving for $k_{i}$

$$
k_{i}\left(t_{1}, \ldots, t_{n}\right)=\frac{K}{n}-\frac{A}{n}+a_{i}+\frac{\sum_{j=1}^{j=n} t_{j}}{n}-t_{i} .
$$

In what follows we define the average tax rate

$$
\frac{\sum_{j=1}^{j=n} t_{j}}{n}
$$

Tax revenue in country $i$ becomes

$$
T_{i}\left(t_{1}, \ldots, t_{n}\right)=\left(\frac{K}{n}-\frac{A}{n}+a_{i}+\frac{\sum_{j=1}^{j=n} t_{j}}{n}-t_{i}\right) t_{i}
$$

and the net-return on capital becomes

$$
\rho\left(t_{1}, \ldots, t_{n}\right)=\frac{A-K}{n}-\frac{\sum_{j=1}^{j=n} t_{j}}{n}
$$


This can be used to calculate closed form solutions for reaction functions of countries for the "interior range". Inserting into the general first-order condition yields

$$
t_{i}=\frac{\left(K-A+n a_{i}\right)\left(1+n \lambda_{i}\right)-c_{i} n}{n\left(n+2 n \lambda_{i}-\lambda_{i}\right)}+\frac{1+\lambda_{i} n}{1+n \lambda_{i}+(n-1)\left(1+\lambda_{i}\right)} \frac{\sum_{j=1}^{j=n} t_{j}}{n}
$$

and, expressing $t_{i}$ as a function of all other tax rates only,

$$
\begin{gathered}
t_{i}\left(1-\frac{1+\lambda_{i} n}{1+n \lambda_{i}+(n-1)\left(1+\lambda_{i}\right)} \frac{1}{n}\right)=\frac{\left(K-A+n a_{i}\right)\left(1+n \lambda_{i}\right)-c_{i} n}{n\left(n+2 n \lambda_{i}-\lambda_{i}\right)} \\
+\frac{1+\lambda_{i} n}{1+n \lambda_{i}+(n-1)\left(1+\lambda_{i}\right)}\left(\frac{\sum_{j \neq i} t_{j}}{n}\right)
\end{gathered}
$$

The function (24) can be used to make a few general observations:

(1) Tax rates are strategic complements: $t_{i}$ is a function of the sum of the tax rates chosen by all other countries, and the optimal reply to a given sum of these other tax rates is increasing in that sum. This implies that any exogenous change that increases $\Sigma_{j \neq i} t_{j}$ will cause $i$ to choose a higher tax rate, too. Strategic complementarity of single tax rates is a seemingly intuitive and natural property of competition frameworks with price competition, but it cannot be taken for granted in the most general framework set out above.

(2) Differences in capital endowment' Suppose all countries are identical as regards the shadow price of public goods $\left(\lambda_{i} \equiv \lambda\right)$, and their local opportunities for production $\left(a_{i}=a\right)$, but differ in their ownership of capital $\left(c_{i} \neq c_{j}\right)$. Let $t^{*}=\left(t_{1}^{*}, \ldots, t_{n}^{*}\right)$ be an interior equilibrium. For this equilibrium it holds that $t_{i}^{*}<t_{j}^{*}$ if $c_{i}>c_{j} \cdot{ }^{22}$ Intuitively, the capital tax reduces the incomes of the owners of the capital. As far as this influences capital used in the own country, this is not a matter of concern, as the loss of capital owners is to the benefit of the own tax office. However, if $c_{i}>c_{j}$ at $t_{i}=t_{j}$ country $i$ is a capital exporter and part of the tax on the capital that is owned by its citizens' accrues to the tax office of the other country. Accordingly, when deciding about their tax rate, capital rich countries that would be capital exporters for homogenous tax rates face a welfare cost of higher taxes that countries with no

${ }^{22}$ To confirm this more formally, we can write the reaction functions for $i$ and $j$ for given equilibrium tax rates of all other countries as $t_{i}=R+B t_{j}-D c_{i}$ suggesting that these functions cross for $t_{i}>t_{j}$ if $c_{i}<c_{j}$. 
or very little capital ownership do not face. This, in turn, makes capital rich countries less aggressive in their tax policy. A more general analysis of tax competition with differences in capital ownership is offered by Wilson (1991) and Peralta and van Ypersele (2005).

(3) Differences in 'size' Suppose all countries are identical as regards the shadow price of public goods $\left(\lambda_{i} \equiv \lambda\right)$, and their ownership shares in the aggregate capital stock $\left(c_{i} \equiv K / n\right)$. Let $t^{*}=\left(t_{1}^{*}, \ldots, t_{n}^{*}\right)$ be an interior equilibrium. For this equilibrium it holds that $t_{i}^{*}>t_{j}^{*}$ if $a_{i}>a_{j} \cdot{ }^{23}$ Intuitively, starting in $t_{i}=t_{j}$, we have $k_{i}>k_{j}$ but $\partial k_{i} / \partial t_{i}=\partial k_{j} / \partial t_{j}$. That is, for the same tax rates in both countries, more capital is used in country $i$ than in country $j$, but the change in tax base that is induced by a deviation from $t_{i}=t_{j}$ is the same for both countries. If a country lowers its tax rate starting from $t_{i}=t_{j}$, it attracts more capital, but it taxes the existing capital at a lower rate. The first effect is the same for both countries, but the second effect is more harmful for country $i$. Accordingly, the incentives for a reduction in own tax rate are stronger for the country that has the less productive sector and hence, attracts less capital. For the implications of size differences for the tax competition outcome see also Bucovetsky (2009).

(4) Differences in valuation of public goods. Suppose all countries are identical in production facilities $\left(a_{i} \equiv a\right)$, and ownership shares in the aggregate capital stock $\left(c_{i} \equiv K / n\right)$. Let $t^{*}=\left(t_{1}^{*}, \ldots, t_{n}^{*}\right)$ be an interior equilibrium. For this equilibrium it holds that $t_{i}^{*}>t_{j}^{*}$ if $\lambda_{i}>\lambda_{j}{ }^{24}$ Intuitively, country $i$ values public goods more highly than country $j$, but their opportunity costs as regards private incomes of their capital owners and tax-base effects are the same. Consider now a situation in which the tax rates are the same in all countries, and in which countries are on the left-hand-side of the Laffer curve (so that a higher own tax rate increases own tax revenue). In this case, all countries have the same sacrifice from an increase in their own tax rate, but country $i$ enjoys a greater benefit than country $j$.

\footnotetext{
${ }^{23}$ For a proof note that, for given equilibrium values of all tax rates other than $t_{i}$ and $t_{j}$, the reaction functions of the two countries differ only by a different intercept. The intercept for $i$ is higher than for $j$ if $a_{i}>a_{j}$.

${ }^{24}$ Equation (24) can be solved for $t_{i}\left(t_{j}\right)=\alpha_{i}\left(\lambda_{i}\right)+\beta_{i}\left(\lambda_{i}\right) \Sigma_{s \notin\{i, j\}} t_{s}+\beta_{i}\left(\lambda_{i}\right) t_{j}$. For a given equilibrium, $\Sigma_{s \notin\{i, j\}} t_{s}^{*}$ is the same for both countries $i$ and $j$. Hence, $\alpha\left(\lambda_{i}\right)+\beta\left(\lambda_{i}\right) \Sigma_{s \notin\{i, j\}} t_{s}^{*}$ constitutes the intercept, and $\beta\left(\lambda_{i}\right)$ the slope of the reply functions. Both $\alpha$ and $\beta$ are strictly increasing in $\lambda_{i}$. Accordingly, for $\lambda_{i}>\lambda_{j}$, the intercept of $t_{i}\left(t_{j}\right)$ and $t_{j}\left(t_{i}\right)$ must occur for $t_{i}>t_{j}$.
} 
(5) Increase in number of countries. As $n$ increases, the reaction of country $i$ to a change in the average tax rate of all other countries becomes smaller.

In order to use a graphical tool, it is useful to turn to the case with $n=2$. For this case the reply function becomes

$$
t_{i}=\frac{\left(1+2 \lambda_{i}\right)\left(K-A+2 a_{i}\right)-2 c_{i}}{3+4 \lambda_{i}}+\frac{1+2 \lambda_{i}}{3+4 \lambda_{i}} t_{j}
$$

for $i=\{1,2\}$. This reply function in Figure 3 is drawn for the case in which $\lambda_{1}=\lambda_{2}=.5$ (i.e., $\left.\frac{\partial t_{i}}{\partial t_{j}}=\frac{2}{5}\right)$.

Figure 3: Nash equilibrium as the intersection of optimal reply functions in the linear model.

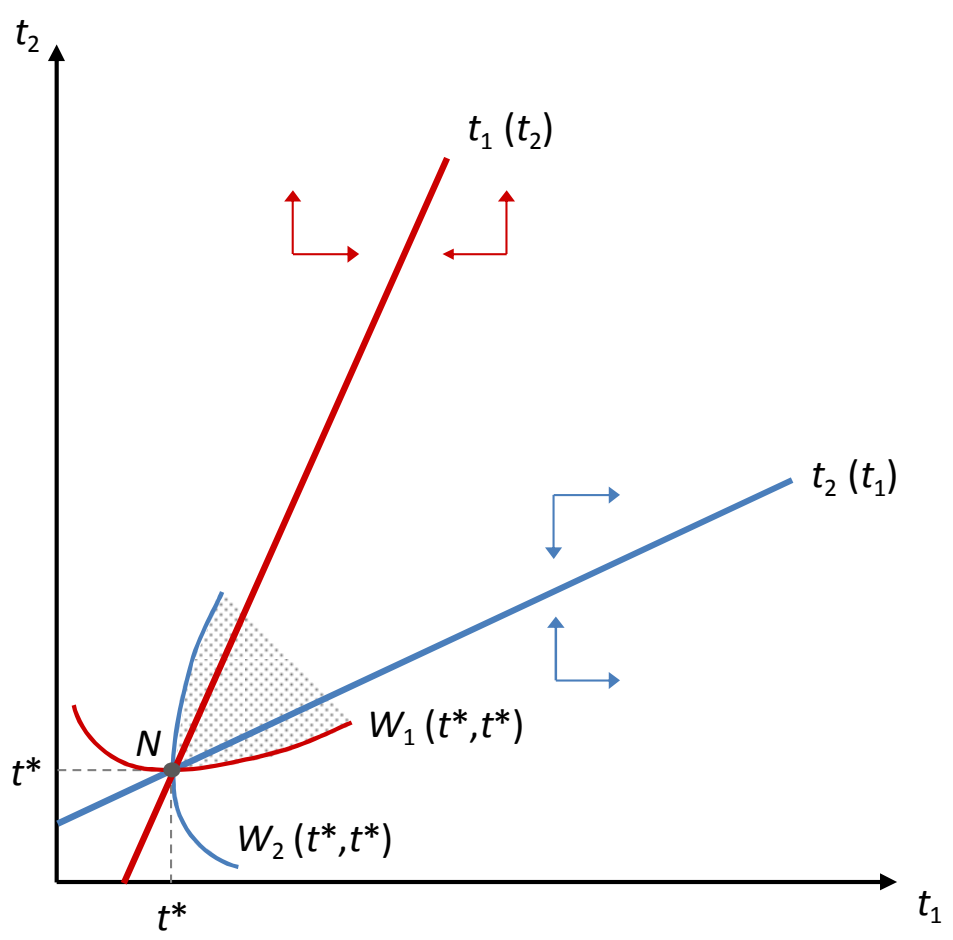

It shows the Nash equilibrium with tax rates $\left(t^{*}, t^{*}\right)$ where the two reply functions intersect, and the iso-welfare curves $W_{1}\left(t^{*}, t^{*}\right)$ and $W_{2}\left(t^{*}, t^{*}\right)$ at the Nash equilibrium. The iso-welfare curves for country 1 intersect $t_{1}\left(t_{2}\right)$ with a slope of zero: by the definition of $t_{1}\left(t_{2}\right)$, the country is at its optimum for a given $t_{2}$; hence, a small deviation in $t_{1}$ has only a second order effect for welfare along the curve $t_{1}\left(t_{2}\right)$. A similar argument explains the slope of $W_{2}\left(t^{*}, t^{*}\right)$ along $t_{2}\left(t_{1}\right)$. The curves $W_{1}\left(t^{*}, t^{*}\right)$ and $W_{2}\left(t^{*}, t^{*}\right)$ form a lens (the shade in Figure 3 ) that describes the set of tax rate pairs $\left(t_{1}, t_{2}\right)$ that, if implemented, yield a strict welfare improvement for both countries even in the absence of any transfers between them. 
The diagram with reply functions can also be used to analyse asymmetries. Consider, for instance, reply functions as in Figure 4 that map the case of a more asymmetric distribution of capital ownership and symmetry otherwise. It shows an equilibrium in which the country with the higher stock of capital (country 1 here) chooses a substantially lower tax rate than the capital poor country, in line with the intuition that the capital poor country has a lower opportunity cost of taxing capital, because the owners of this capital are citizens of another country, and hence, their sacrifice is not part of the welfare considerations in the capital poor country. Note that the lens describing pairs of tax rates that yield a Pareto improvement compared to the Nash equilibrium at $\left(t_{1}^{*}, t_{2}^{*}\right)$ need not have an intersection with the line $t_{1}=t_{2}$ : there need not be a common tax rate that improves welfare for both countries compared to the Nash equilibrium. More generally, even if countries could commit on a common harmonized tax rate, starting from a Nash equilibrium between sufficiently asymmetric countries there may exist no common harmonized rate that makes all countries better-off.

Figure 4: Asymmetric countries in the linear model.

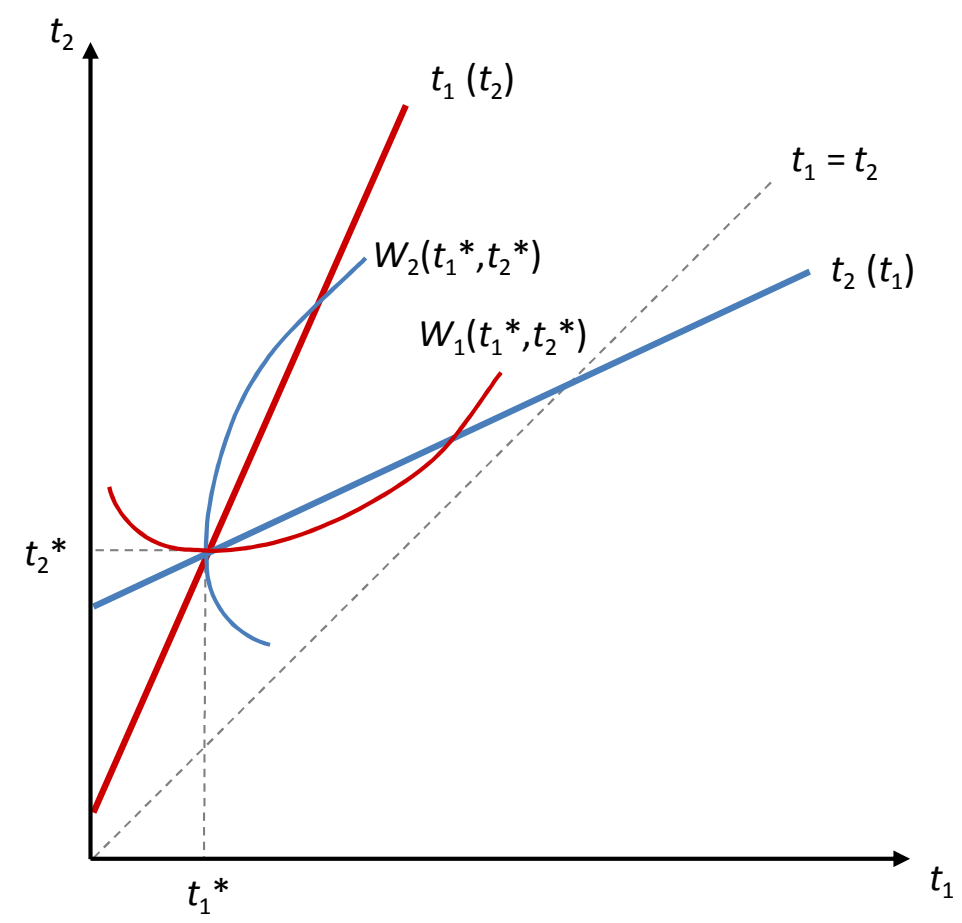

(6) Tax rates in the Nash equilibrium can be more dispersed than the tax rates that maximize joint welfare. To see this, consider $n=2$ and let $\lambda_{1}=0$ and $\lambda_{2}=2$, and let the two countries be perfectly symmetric otherwise, i.e., $a_{1}=a_{2} \equiv a$, and $c_{1}=c_{2} \equiv c$. In this case the tax rates that maximize joint welfare must yield the same marginal productivity of capital in both countries; but for an interior solution, by (12), $f_{1}^{\prime}=f_{2}^{\prime}$ requires $a-k_{1}=a-k_{2}$. This condition 
holds in the capital market equilibrium only if $t_{1}=t_{2}$. On the other hand, as is evident from (25), for $\lambda_{1}=0$ and $\lambda_{2}=2$, the equilibrium tax rates are $t_{1}=\frac{2}{7} c$ and $t_{2}=\frac{6}{7} c$.

\section{Sequential decision making}

Timing is an essential aspect in strategic games. Most analyses of tax competition assume that countries choose their actions simultaneously. And given that there is no obvious reason why one government should be able or be forced to commit to a tax rate earlier than others countries, this seems a natural assumption. There is, however, some evidence that tax reforms in different countries do not all occur simultaneously. The results of Altshuler and Goodspeed (2002), for instance, suggest that sequential choices existed since the 1986 US tax reform between the US and European countries, with the USA acting as a Stackelberg leader and European countries acting as followers vis-a-vis the USA and simultaneously vis-a-vis each other. ${ }^{25}$ This raises the question of how the possible sequentiality of choices among governments can change the outcome. The question has been addressed in theoretical contributions by Wang (1999) for indirect taxes (in the setting of the Kanbur-Keen model discussed in section 2.4 below) and Kempf and Rota Graziosi (2010) who address endogenous timing, using the workhorse model with capital taxes at source.

Figure 5 illustrates the Stackelberg leadership case. It shows the same reply functions for the linear variant of the workhorse model as in Figure 2, and the Nash equilibrium that emerges from simultaneous tax-rate choices. Suppose now that, for some reason, country 1 has to choose a tax rate $t_{1}$ first and country 2 is the follower who observes this choice and chooses $t_{2}$ on the basis of this observation. In this case, country 1 anticipates that whatever $t_{1}$ it selects country 2 will choose $t_{2}\left(t_{1}\right)$ in line with its reply curve. Hence, by choosing $t_{1}$ and anticipating subgame perfect play, the country can essentially choose from all combinations $\left(t_{1}, t_{2}\left(t_{1}\right)\right)$ that are graphically described by the reply function $t_{2}\left(t_{1}\right)$. If country 1 optimizes, it chooses the point along $t_{2}\left(t_{1}\right)$ that maximizes the country's objective function. Graphically, such a point is found where an iso-payoff curve for country 1 is tangent to $t_{2}\left(t_{1}\right)$, as it is drawn in Figure 5. A conclusion that follows is that, in a Stackelberg equilibrium, both countries choose higher taxes if they choose sequentially. The intuition for this result comes from the strategic complementarity of tax rates. Starting from the Nash equilibrium, if country 1 chooses a tax rate that exceeds the Nash equilibrium tax rate, then this does not yield an advantage for the country if the other country continues to choose the Nash equilibrium tax rate. And this would happen in the simultaneous game, because country 2 would have no

\footnotetext{
${ }^{25}$ Stackelberg leadership of the federal government is also commonly assumed in the literature that discusses tax competition within a federation [see, e.g., Hayashi and Boadway (2001)].
} 
reason to anticipate this deviation from $t_{1}=t^{*}$. However, if country 1 chooses first and country 2 can observe this choice, country 2 re-optimizes its choice and finds that, given $t_{1}>t^{*}$, its optimal tax rate choice is also higher. By $t_{1}>t^{*}$, country 1 induces a higher $t_{2}$, and it is this strategic effect that benefits country 1. Consequently, in the Stackelberg equilibrium, both countries end up with higher tax rates, and both countries are better-off than in the Nash equilibrium: this too is clear from Figure 5, as both countries are on higher iso-payoff curves at the Stackelberg equilibrium than at the Nash equilibrium.

Figure 5: Stackelberg equilibrium.

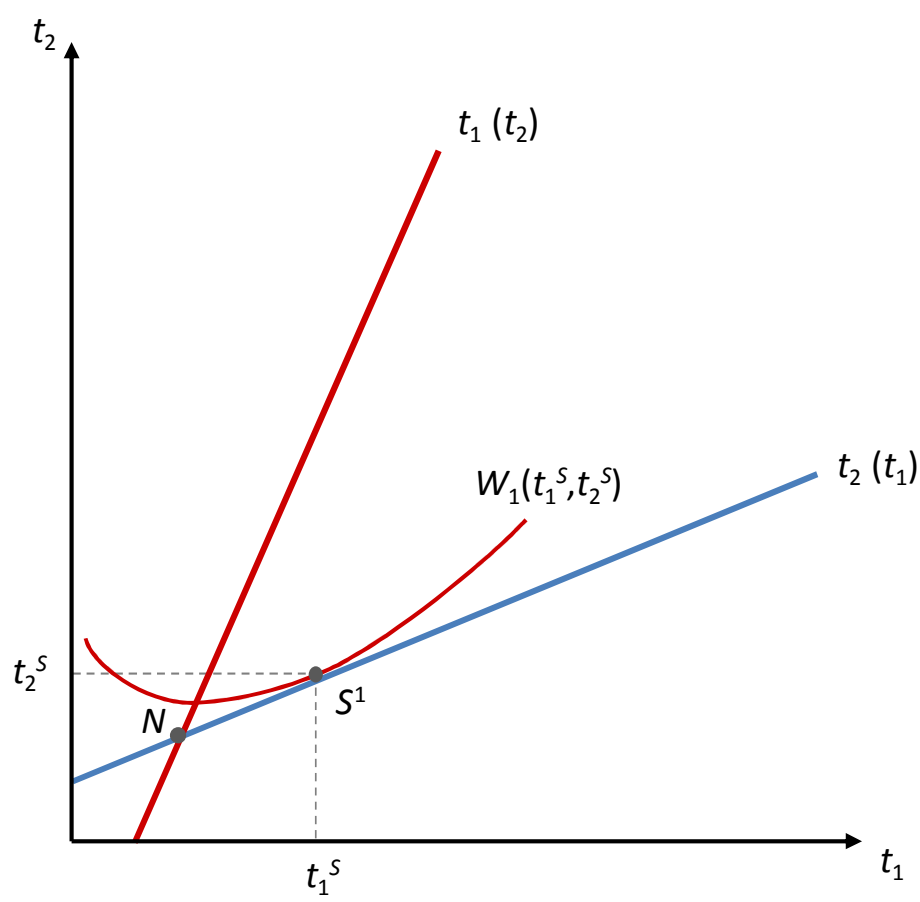

While sequential choice is in the interest of all countries, it requires commitment. As the Stackelberg follower is seemingly at an advantage, the commitment problem is one of staying flexible and out-waiting the other country. Procedural rules, the timing of government formation and so on may yield some differences in the timing in different countries. But the cyclicity of most of these institutional procedures does not clearly answer the question who has to move first.

A solution to this problem comes from the theory of endogenous sequential choices. This theory has been developed in the context of duopoly first by Hamilton and Slutsky (1990) and applied to the context of tax competition duopolies by Kempf and Rota Graziosi (2010). A Stackelberg leader-follower outcome can typically be obtained as the outcome of a game which is augmented by an earlier stage in which each country first chooses its timing of choice (what Hamilton and Slutsky call "the extended game with observable delay"). Let there be two points of time for tax rate choices: $h \in\{e($ arly $), l($ ate $)\}$, with the point $l($ ate $)$ 
occurring after the point $e($ arly) in the time line. First, let each country simultaneously choose whether it would like to choose and fix its tax rate at time $e$ or $l$. One can then show that there is a subgame perfect equilibrium in which one country, say, country 1 , chooses $h_{1}=e$ and the other country 2 chooses $h_{2}=l$, and with the Stackelberg game just discussed as the continuation game. To confirm this, we need to show that, assuming subgame perfect play in all possible continuation games, $h_{1}=e$ and $h_{2}=l$ are mutually optimal replies. Suppose that, for whatever reason, country 1 assumes that country 2 chooses $l$. Then country 1 has essentially two options. It can also choose $h_{1}=l$. In this case both countries choose their tax rate at time $l$ and simultaneously. They end up in the Nash equilibrium $\left(t^{*}, t^{*}\right)$. Alternatively, country 1 can choose $h_{1}=e$. In this case they end up in the sequential subgame with country 1 the Stackelberg leader and country 2 the follower (with an equilibrium $S^{1}$ in Figure 6). As has just been discussed, this outcome is superior to the Nash equilibrium outcome for country 1. Hence, $h_{1}^{*}\left(h_{2}=l\right)=e$. Turn now to country 2 . One needs to confirm that, given $h_{1}=e$, country 2 prefers $h_{2}=l$. Suppose the country 2 anticipates $h_{1}=e$. Then the country has essentially two options. It can choose $h_{2}=e$. This yields simultaneous tax rate choices in the continuation game, and the equilibrium is the Nash equilibrium with tax rates $\left(t^{*}, t^{*}\right)$. Country 2 can choose $h_{2}=l$ instead. In this case the subgame is the Stackelberg game discussed above, and country 2 is better off in the Stackelberg equilibrium than in the Nash equilibrium.

Figure 6: Endogenous sequencing in the tax rate choices.

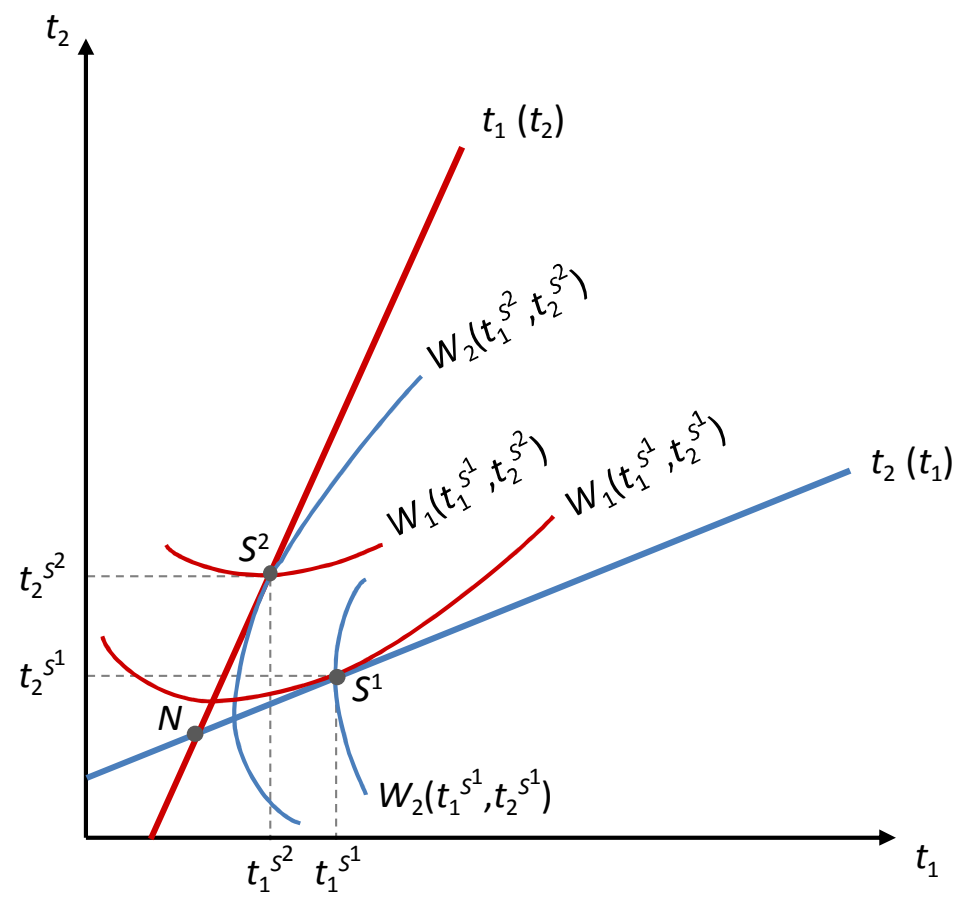


Two difficulties remain with this concept. One is the coordination problem. As was argued in the context of Figure 5, both countries prefer the Stackelberg game to the Nash game. But they typically prefer being in the position of Stackelberg follower, i.e., be the country that chooses $h=l$, if the other country chooses $h=e$. If the countries cannot coordinate on who becomes follower and who becomes leader, they may randomize independently about their commitment choices. This leads to a symmetric equilibrium with mixed strategies at the stage in which they choose timing. In some of the subgames the mixed strategies lead to $(e, e)$ or $(l, l)$, in which case a Nash game follows as the continuation game, and in some of the subgames they manage to end up with $(e, l)$, leading to the Stackelberg equilibrium $S^{1}$ (in Figure 5), or $(l, e)$ leading to the Stackelberg equilibrium $S^{2}$ in the continuation game. Kempf and Rota Graziosi (2010) use an equilibrium selection argument (the risk-dominance criterion) to argue that - focussing on country differences in capital productivity - the less productive country is more likely to be the leader. If the countries become sufficiently asymmetric, this order of moves can even become Pareto dominant.

The second problem that remains is to explain what makes the commitment feasible and credible at the stage when countries commit on their timing. In an institutional context in which tax reforms are feasible only at some time windows within an electoral cycle, for instance, the choice of the timing of elections may induce some sequential ordering of decision making.

\section{The strategic role of internal governance structure}

The analysis so far has abstracted from the complex multi-player decision making process which leads to national tax policy choices, reducing this process to national decisions as if these were made by single players taking them in the interest of their citizens. In fact, many countries have multilayered governance systems, with each government drawing with different taxes on partially overlapping tax bases, and are often complemented by systems of intergovernmental grants. 
Figure 7: Different prototypes of governance.

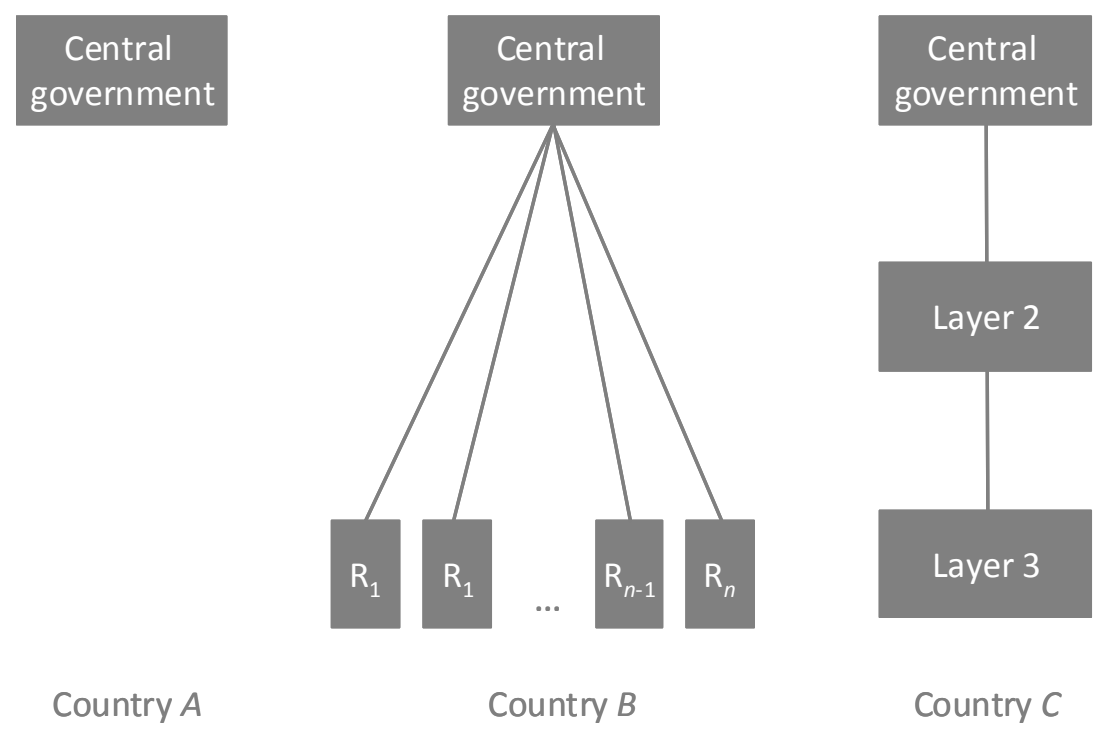

Figure 7 shows three prototype countries with very different federal structures that may compete with other countries. The prototype country $A$ is a fully centralized country in which the choices about tax rates and the tax system are made on the most central level. This country resembles most closely the type of players usually considered in the context of tax competition in other sections of this survey. Country $B$ has one central government and a considerable number of regional governments. Country $C$ has several parallel governments, all drawing on the same national tax base, but no horizontal competition between regions inside the country. The additional layers of government should generally cause even higher tax rates, as more decision makers independently extract tax revenue from the same tax base. Country $C$ suffers only from vertical tax competition inside the country.

Consider country $B$ more closely. Suppose the central and local governments each choose independently a unit tax on capital at source. The capital that is applied in region $i$ will then be taxed both by the central government and by the local government. In each region these unit taxes add to the total tax burden on capital in the respective region. The central government uses these revenues on behalf of the population in the whole country. Accordingly, this part of the tax revenue that is generated in a region benefits the citizens from this region as well as citizens from other regions, and the tax rate choice of the central government will be guided by the preferences of the citizens in all regions. In contrast, the regional governments presumably care more about the own, regional tax revenue, and attribute a shadow price to central tax revenue that is too low if considered from a countrywide welfare perspective. When the region decides about its tax rate, it anticipates that this will make some tax base flow away or cause other distortions that generally diminish the revenue accruing to the central level. However, it attributes too low a shadow price to this loss 
in federal revenue. The region has insufficient incentives to take these side effects appropriately into account. As a result the regions may pursue a tax policy that is too aggressive and charge too high taxes, thereby distorting the composition of regional versus central tax revenue and the provision of local and central public goods that are funded by these revenues. Also, the double taxation of the same tax base by the different layers of government may cause an aggregate tax burden resulting in country $B$ that is too high. These effects of vertical tax competition and its interplay with horizontal tax competition between regions and between nations has been analysed and is well understood by now [see Keen and Kotsogiannis (2002, 2004), and Wrede (1999)].

Within federations, particularly if regions have some tax autonomy, there are often systems of interregional or vertical intergovernmental transfer systems in place. These systems have often been analysed in isolation. These analyses can lead to policy conclusions about the disincentive effects of such systems to implement effective systems of tax enforcement in the different regions, and to conclusions about other negative incentive effects of such systems. It is therefore interesting to note that horizontal and vertical transfer systems inside a federal country can and partially do counterbalance the internal forces of vertical and horizontal tax competition inside a country and can partially correct for the problems caused by interregional or vertical tax competition [see, e.g., Fenge and Wrede (2007), Kelders and Koethenbuerger (2010) and Kotsogiannis (2010)].

The incentives for vertical and horizontal internal tax competition play also a role if a country competes with other countries in the context of international tax competition. For instance, due to the vertical tax externalities inside the country of type $C$ and horizontal tax externalities inside this country being absent in this structure, this country has a tendency to choose a higher tax rate on capital than a country of type $A$, when competing with each other. This is sustained also in a framework with international tax competition with countries of types $A$ and $C$. The internal governance structure of a country has strategic effects. It affects the tax rate choices in the country. And as this is anticipated in other countries, it changes the equilibrium choices in other countries as well. Wilson and Janeba (2005) and Kessing, Konrad and Kotsogiannis (2009) highlight this latter strategic effect in different competition frameworks. A structure that induces vertical tax competition can be advantageous or disadvantageous, and which it is also depends on the nature of tax competition. As the choice of governance structure is a long-term decision and cannot be adjusted in the short run as easily as the tax rate, the governance structure could be used as a commitment device by which countries can position themselves in a framework of international tax competition. To illustrate this, consider a source based tax on capital applied in the respective country. More 
independent vertical tiers of governance lead to a higher effective tax rate chosen in this country. This higher overall tax rate will be anticipated by other countries. Provided that tax rates are strategic complements, this higher overall tax rate will induce the competitors to this country to also choose higher tax rates. This strategic effect is similar to the commitment of a Stackelberg leader who may also benefit from it. However, this advantage becomes small in the context of many competitors, and smaller than the negative side effect of deviating from what would have been the tax rate chosen from the perspective of unitary state. Hence, if the number of competitors of the country is sufficiently large, the overall effect will typically work to the disadvantage of this country in the context of capital taxation at source.

\section{Pure profits and international portfolio diversification}

An important issue which is eliminated from the picture in the workhorse model is the treatment of pure profits and the ownership shares in these. The assumption there is that aggregate production is a function of internationally mobile capital and other, internationally immobile factor inputs. If some of these inputs are attached to the location and can costlessly be used, then the ownership of the production facilities in a country may include entitlements in pure profits. Following the ideas outlined in Huizinga and Nielsen (1997, 2002, 2008) and Fuest (2005), we strip down their frameworks to consider a pure source tax on capital, with a firm sector that generates pure profits. Production in each country occurs with a technology that uses only capital as the variable factor, but also applies a fixed factor (other than labor), which can be thought of as a natural public good that is available in the respective country. In this case, $\left(f_{i}\left(k_{i}\right)-f_{i}^{\prime}\left(k_{i}\right) k_{i}\right)$. measures pure profits that accrue to the owners of the production facilities in country $i$. Let $\alpha_{i j}$ be the share that is owned by entrepreneurs in country $i$ in the production facilities in country $j$. If national governments strictly maximize the aggregate rents of the inhabitants of a country, then the welfare function (3) becomes

$$
W_{i}=\sum_{j=1}^{n} \alpha_{i j}\left(f_{j}\left(k_{j}\right)-f_{j}^{\prime}\left(k_{j}\right) k_{j}\right)+\rho c_{i}+G_{i}\left(t_{i} k_{i}\right)
$$

Governments may be tempted to tax pure profits; but practically speaking it is difficult to identify pure profits and to implement such a tax. Here we report about the implications of such pure profits accruing to foreigners for the optimal capital tax, under the assumption that rents themselves cannot be taxed.

Assuming an interior equilibrium characterized by the first-order conditions, this equilibrium is determined by 


$$
\frac{\partial W_{i}}{\partial t_{i}}=\sum_{j=1}^{n} \alpha_{i j}\left(-f_{j}^{\prime \prime}\left(k_{j}\right)\right) k_{j} \frac{\partial k_{j}}{\partial t_{i}}+\frac{\partial \rho}{\partial t_{i}} c_{i}+G^{\prime}\left(t_{i} k_{i}\right)\left(k_{i}+t_{i} \frac{\partial k_{i}}{\partial t_{i}}\right)=0
$$

Comparing this with equation (4) above, the relocation of capital away from country induced by an increase in its tax rate $t_{i}$ has different welfare effects in the presence of international portfolio investment. First, the country $i$ bears only the share $\alpha_{i i}$ of any loss in rents $\left(f_{i}\left(k_{i}\right)-f_{i}^{\prime}\left(k_{i}\right) k_{i}\right)$ on domestically employed capital as its citizens own only a share $\alpha_{i i}<1$ of these rents, making an increase in $t_{i}$ more favorable than for $\alpha_{i i}=1$. Second, the inhabitants in $i$ benefit from the increase in production rents that accrue in other countries, proportional to the shares $\alpha_{i j}$ which they own in these rents. As an increase in $t_{i}$ increases these production rents, this effect also makes an increase in $t_{i}$ more beneficial than for $\alpha_{i j}=0$. Starting from the values $\left(t^{*}, \ldots, t^{*}\right)$ that characterize a Nash equilibrium for $\alpha_{i i}=1$ and $\alpha_{i j}=0$ for the case of fully symmetric countries, the first-order welfare effect of an increase in the country's own tax rate is

$$
\left(\alpha_{i i}-1\right)\left(-f^{\prime \prime}\left(\frac{K}{n}\right)\right) \frac{K}{n} \frac{\partial k_{i}}{\partial t_{i}}+\sum_{j \neq i} \alpha_{i j}\left(-f^{\prime \prime}\left(\frac{K}{n}\right)\right) \frac{K}{n} \frac{\partial k_{j}}{\partial t_{i}} .
$$

This welfare effect of the tax rate increase is positive for $\alpha_{i i} \in(0,1)$ and $\alpha_{i j} \in(0,1)$ and makes it beneficial for a country to unilaterally increase its own tax rate starting from levels $\left(t^{*}, \ldots, t^{*}\right)$ that characterize the symmetric Nash equilibrium for $\alpha_{i i}=1$ and $\alpha_{i j}=0$. Taking into consideration the strategic complementarity of tax rates, this implies that international portfolio diversification should generally lead to higher taxes in equilibrium. International portfolio diversification thus weakens tax competition and leads to higher equilibrium tax rates than in the benchmark case. ${ }^{26}$

This analysis suggests a strategic relationship between the degree of international firm ownership and the strength of tax competition forces. A high degree of international ownership reduces the incentives for a race to the bottom. As each single portfolio investor is small and may therefore safely disregard the effect of own portfolio choice for the outcome of tax competition, overall changes in portfolio choices that are driven by other considerationssuch as the openness of capital markets, incentives for international risk diversification, transaction cost of international portfolio diversification and so on-may influence the strength of tax competition. If the portfolio investors in a country could coordinate on a joint

\footnotetext{
${ }^{26}$ Huizinga and Nicodème (2006) interpret their empirical findings on the relationship between international ownership and corporate taxes a being in line with this finding.
} 
portfolio policy and if the national capital owners are less interested in the public good than the policy maker (or the median voter), then they could choose to reduce their international investment activities. Indigenization-encouraging national ownership in national firms and their profits-is a well-known means to reduce the government's incentive to generate tax revenue from them. ${ }^{27}$

The indigenization effect that is explored here is well-known from other contexts. For instance, it has been argued that indigenization or joint ventures with host country citizens reduces the incentives of the national government in the host country to expropriate or nationalize foreign direct investment. Konrad and Lommerud (2001) show that the problem of ex-post opportunistic behavior can also be moderated if the host country government has incomplete information about the true profitability of the FDI project, and if a large share of the foreign company is owned by citizens of the host country. Key to their argument is that this incomplete information shields an information rent of the firm from being extracted, even if the host government applies the most sophisticated extortionary means to extract as much revenue as possible. Similarly, it has been argued that a country with sovereign debt should be less inclined to default on its government debt if this debt is mainly held by nationals [Broner, Martin and Ventura (2010)].

\subsection{Coordination}

The benchmark model of tax competition reveals that the tax rate choice of a country can have several external effects for other countries. First, a higher tax rate in one country typically drives out capital from this country into other countries. This benefits these other countries by broadening the capital tax base there and increasing their tax revenues. This effect is known as the tax base effect. Second, the tax increase makes capital more abundant in other countries, causing an expansion of production there. This may also benefit these other countries. Further, the increase in the tax rate reduces the net return on capital, imposing a burden on capital owners, not only in this respective country, but also the owners of capital in other countries. Generically, these different external effects do not cancel each other out. Hence, the tax competition equilibrium can be expected to be inefficient. Countries may coordinate their tax policies in order to overcome these inefficiencies. In this section we first discuss coordination in which all countries cooperate. We then turn to cases of regional coordination and partial coordination.

\footnotetext{
${ }^{27}$ The trade-off between risk diversification and the incentives for tax revenue extraction in the context of international ownership of fixed resources is developed already in Wildasin and Wilson (1998).
} 


\section{Full coordination and harmonization}

Using the benchmark model of tax competition, we can illustrate the potential and also the problems of tax coordination. Figure 2 shows a whole area of combinations of taxes $\left(t_{1}, t_{2}\right)$ for which welfare in both countries is higher than in the Nash equilibrium. For identical countries, there is a whole range of harmonized taxes $\left(t_{1}=t_{2}\right)$ for which both countries are better-off. If countries can negotiate a cooperative outcome, they should end up in the core. Which set of pairs of tax rates are inside this core depends on whether international transfers are feasible. More generally, in a framework with complete information and full commitment, with governments that maximize a well-specified welfare function of their respective country as players, it is an application of standard welfare theory that there exists a planning solution that is at least as good as any decentralized equilibrium outcome. And if the decentralized solution suffers from externalities between the players, it generically holds that an appropriately chosen central planner solution exists that yields a strictly higher welfare in each of the countries than in the decentralized outcome.

Of course, the central planner solution is a Nirvana outcome. It typically requires too much. For instance, it requires the absence of problems of asymmetric information and it typically requires full commitment - that is, the ability to write and implement fully binding contracts on all matters of relevance. It also requires that these contracts are written prior to any possible unilateral action by which a single player can tilt the cooperative outcome to his own favor. In an international context with sovereign countries being the decision makers, full commitment and its enforcement is probably the most serious hurdle, but information problems can also be an obstacle. The set of Pareto efficient outcomes is useful as an efficiency benchmark, however, as the welfare outcomes for more plausible institutional frameworks can be compared with this benchmark. In what follows we consider some of these institutional frameworks that involve elements of coordination.

\section{Limits to coordination}

As one possible limitation of the amount of cooperation, countries may be unable to coordinate on specific tax policies, but may be able to coordinate on a range of possible taxes. One example of such types of limited cooperation is the EU agreement on a lower limit of VAT taxes. Lower and/or upper limits for possible tax rate choices leave countries some flexibility to react to structural or macroeconomic developments or changes in the shadow price of public funds in their countries and may be more appealing for the countries' decision makers than a fully rigid system of coordinated taxes that can be changed and adjusted to their 
needs only by a unanimous renegotiation agreement. It might seem that imposing such minimum taxes must make those countries thereby forced to raise their tax rates worse off. This, however, is not the case: lower (or upper) bounds on tax rates can have surprising consequences for welfare in the resulting tax competition equilibrium.

Starting from an asymmetric Nash equilibrium $N$ with $\left(t_{1}^{*}, t_{2}^{*}\right)$ in the fully uncoordinated situation with $t_{1}^{*}<t_{2}^{*}$, a common lower bound of $t_{i}=t_{0}<t_{1}^{*}$ does not change the Nash equilibrium with simultaneous tax rate changes. A bound $t_{0}$ in the interval $\left(t_{1}^{*}, t_{2}^{*}\right)$, between the two Nash equilibrium rates, generally binds country 1 and induces it to choose this lower bound. This is illustrated in Figure 8: the new best reply function $t_{1}\left(t_{2}\right)$ is kinked at $t_{0}$; the best response for country $2, t_{2}\left(t_{1}\right)$ also has a kink, but this is a range that is irrelevant for the equilibrium. The change of $t_{1}$ from $t_{1}^{*}$ to $t_{0}$, taken in isolation, would benefit country 2 , but would reduce welfare in the low tax country 1 . Country 2 , however, will not continue to choose $t_{2}^{*}$ in the new equilibrium. Using the Nash equilibrium conjecture $t_{1}=t_{0}$ it will choose its optimal reply $t_{2}\left(t_{0}\right)$. Strategic complementarity of tax rates suggests that this optimal reply is a tax rate that is higher than $t_{2}^{*}$. This change should be beneficial for both countries. A new equilibrium for the lower bound $t_{0}$ is $N^{0}$. The overall welfare effect for country 1 in this equilibrium compared to the unconstrained Nash equilibrium is therefore unclear in general.

Consider though a marginal increase in $t_{1}$ from $t_{1}^{*}$ to $t_{0}=t_{1}^{*}+\varepsilon$. This has a zero first-order effect for the welfare of country 1 , as $W_{1}\left(t_{1}^{*}, t_{2}^{*}\right)$ has a slope of zero at $N$. However, this marginal increase in $t_{1}$ induces an equilibrium reaction by country 2 . Country 2 increases $t_{2}$ by $\mathcal{E}$ times the slope of $t_{2}\left(t_{1}\right)$. This increase in $t_{2}$ has a first-order marginal effect for country 1 's welfare. Thus there is always a lower bound that is sufficiently close to $t_{1}^{*}$ that increases both countries' welfare. In the context of Figure 8 the range in which both countries' welfare is increased can be determined more precisely. Both countries' welfare is increased if $N_{0}$ on the upper right to $N$ is to the left of the tax rate $\hat{t}$ at which $t_{2}\left(t_{1}\right)$ and $W_{1}\left(t_{1}^{*}, t_{2}^{*}\right)$ intersect. Hence, any lower bound $t_{0} \in\left(t_{1}^{*}, \hat{t}\right)$ induces an increase in both countries' welfare, whereas lower bounds in the range $t_{0} \in\left(\hat{t}, t_{2}^{*}\right)$ reduce the welfare of country 1 . $^{28}$

\footnotetext{
${ }^{28}$ Peralta and Ypersele (2006) show, however, that this result need not hold more generally in related models. In their framework with three countries, a minimum tax reform that introduces a lower bound only need not be unanimously accepted by all countries, whereas a combination of a lower and an upper bound may be unanimously accepted.
} 
Figure 8: A lower bound on tax rates.

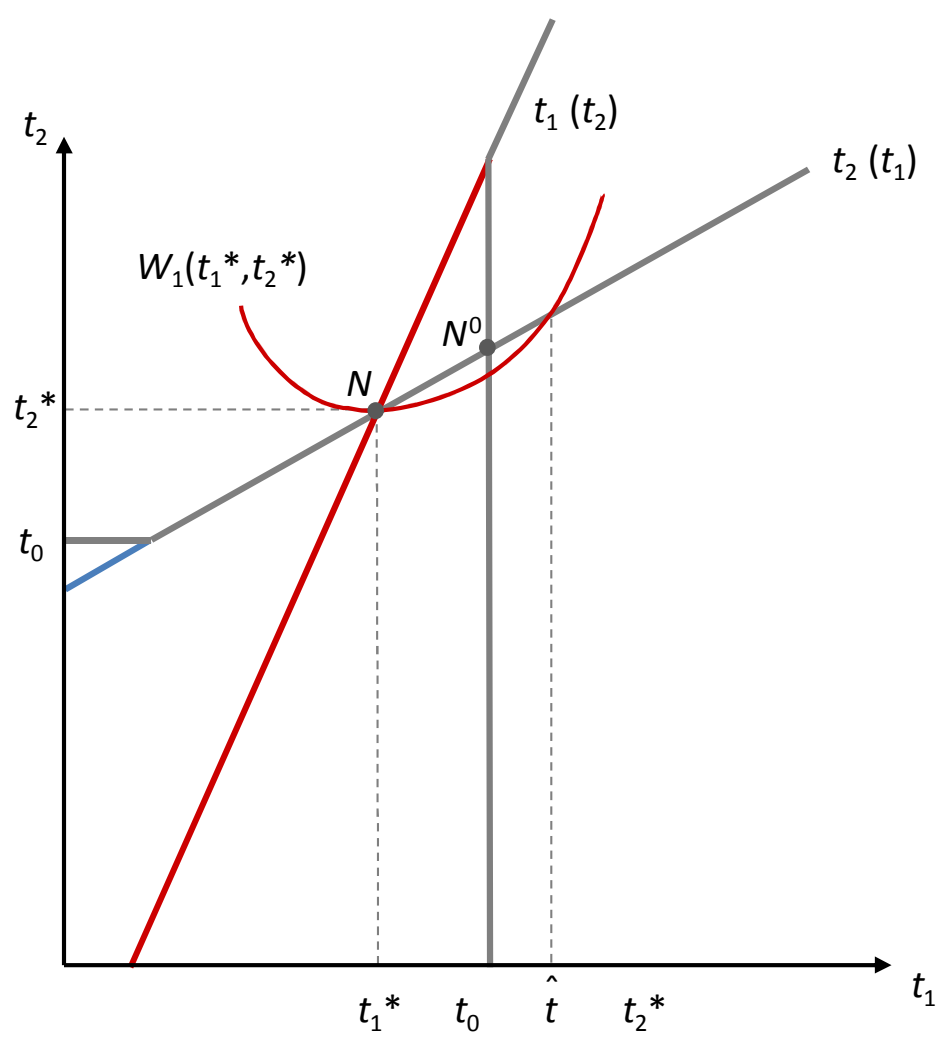

The welfare impact of minimum taxes when countries choose sequentially is considered by Wang (1999). He uses the Kanbur-Keen model discussed below, but the same insights can be seem using the linear model illustrated in Figure 9a. Focusing on the asymmetric case and taking the larger country 1 to be the Stackelberg leader, the initial Stackelberg equilibrium in the absence of any minimum taxes is at $S^{1}$, the point of tangency between country 1's isowelfare curve $W_{1}\left(t_{1}^{S}, t_{2}^{S}\right)$ and country 2 's reply function, which has $t_{1}^{S}>t_{2}^{S}$. Imposing a minimum tax $t_{0}$ with $t_{1}^{S}>t_{0}>t_{2}^{S}$ may cause the tax rate of the Stackelberg leader to drop and, for a broad range of parameters and under quite general conditions, causes welfare to increase for the leader and decrease for the follower. Figure 9a depicts one typical case that generates this outcome: a minimum tax $t_{0}$ that is slightly higher than $t_{2}^{s}$ leads to reply functions $\hat{t}_{1}\left(t_{2}\right)$ and $\hat{t}_{2}\left(t_{1}\right)$ - they follow the original reply functions for higher tax rates but have a kink at $t_{0}$. If country 1 chooses its most preferred point $\left(t_{1}, t_{2}\right)$ along the reply function $\hat{t}_{2}\left(t_{1}\right)$ of country 2 subject to $t_{1} \geq t_{0}$ as well, this most preferred point is $\hat{S}$. As a consequence, this minimum tax causes the Stackelberg leader to choose a tax rate that is considerably lower than $t_{1}^{S}$. This was not attractive in the absence of the minimum tax, because the follower reacted to such a choice by an even much lower tax. The minimum tax prevents such a reaction and this makes 
$t_{1}=t_{0}$ attractive for the Stackelberg leader. As is suggested by Figure 9a, this makes the leader better-off, but may reduce the payoff for the follower.

Figure 9a: Effects of a binding minimum tax in a Stackelberg equilibrium.

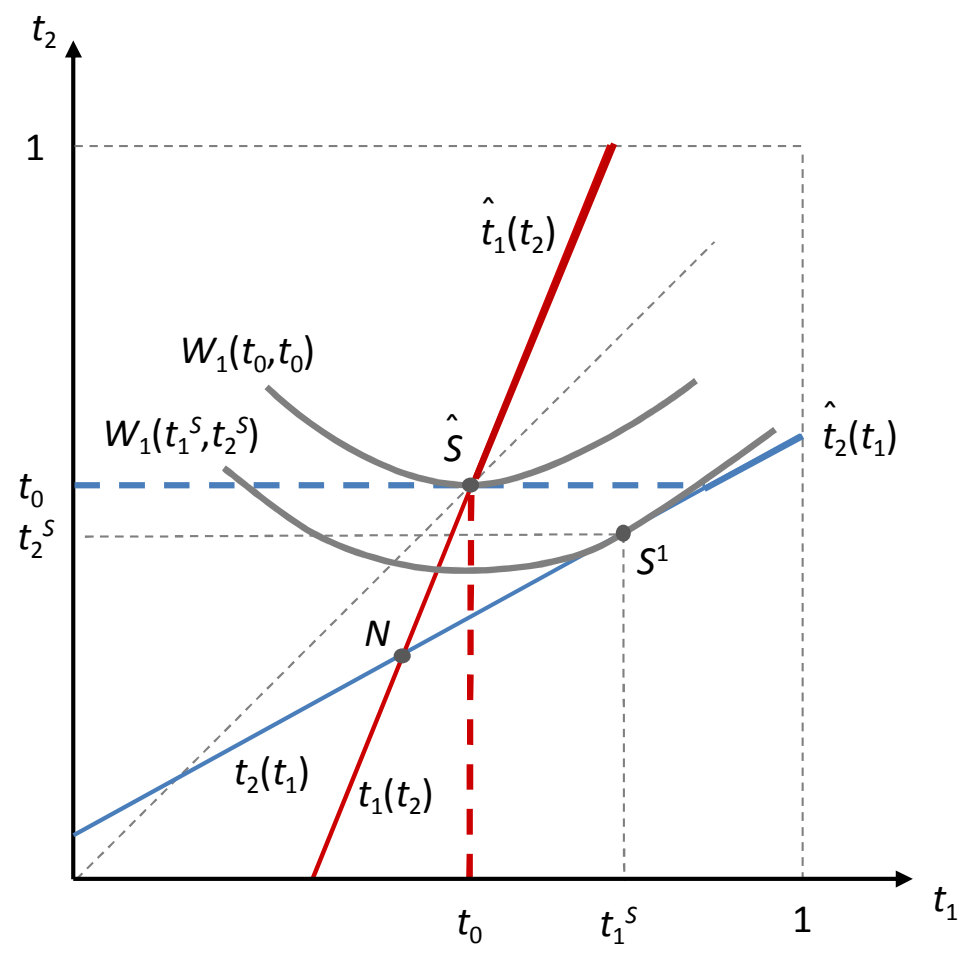

Konrad (2009) goes one step further and considers a minimum tax $t_{0}<t_{2}^{S}$, i.e. a tax that is even lower than the lower of the two tax rates chosen in the unconstrained equilibrium. One might expect this to have no effect. But in the Stackelberg case even such seemingly unconstraining floors change the nature of the equilibrium and may actually induce all countries to reduce their tax rates, compared to the tax rates in the unconstrained Stackelberg equilibrium: it can lead, that is, to a Pareto-worse outcome. The intuition for this result can be gained from Figure $9 \mathrm{~b}$ which is similar to Figure 9a. It shows again the unconstrained reply functions $t_{1}\left(t_{2}\right)$ and $t_{2}\left(t_{1}\right)$ as the dashed lines, and a Stackelberg equilibrium $S^{1}$, again with country 2 as the follower. A floor on the tax rate as low as $t_{0}$ induces kinks in the reply functions. With a lower bound of $t_{0}$, the reply functions $\hat{t}_{1}\left(t_{2}\right)$ and $\hat{t}_{2}\left(t_{1}\right)$ are drawn as closed lines with these kinks. Also, the range of possible tax rates is constrained now, as tax rates lower than $t_{0}$ are ruled out. In the Stackelberg equilibrium, country 1 chooses the point along $\hat{t}_{2}\left(t_{1}\right)$ for the range $t_{i} \geq t_{0}$ that maximizes country 1's payoff. While $S^{1}$ was optimal for country 1 in the unconstrained situation, now $\hat{S}$ is the new equilibrium and yields higher payoff for country 1 . Intuitively, without a floor, a choice of $\hat{t}_{1}=t_{0}$ would induce a very low tax rate chosen by country 2 in the unconstrained situation. However, as country 2 cannot 
reduce its tax rate below $t_{0}$, the reaction induced by the choice of $\hat{t}_{1}=t_{0}$ is much less drastic than in the unconstrained situation. This makes such a choice more attractive. As a result of this discrete change in the nature of the equilibrium, the Stackelberg leader is better-off and the follower is worse-off in the constrained equilibrium.

Figure 9b: Effects of a minimum tax that is lower than the lowest equilibrium tax rate in the Stackelberg equilibrium.

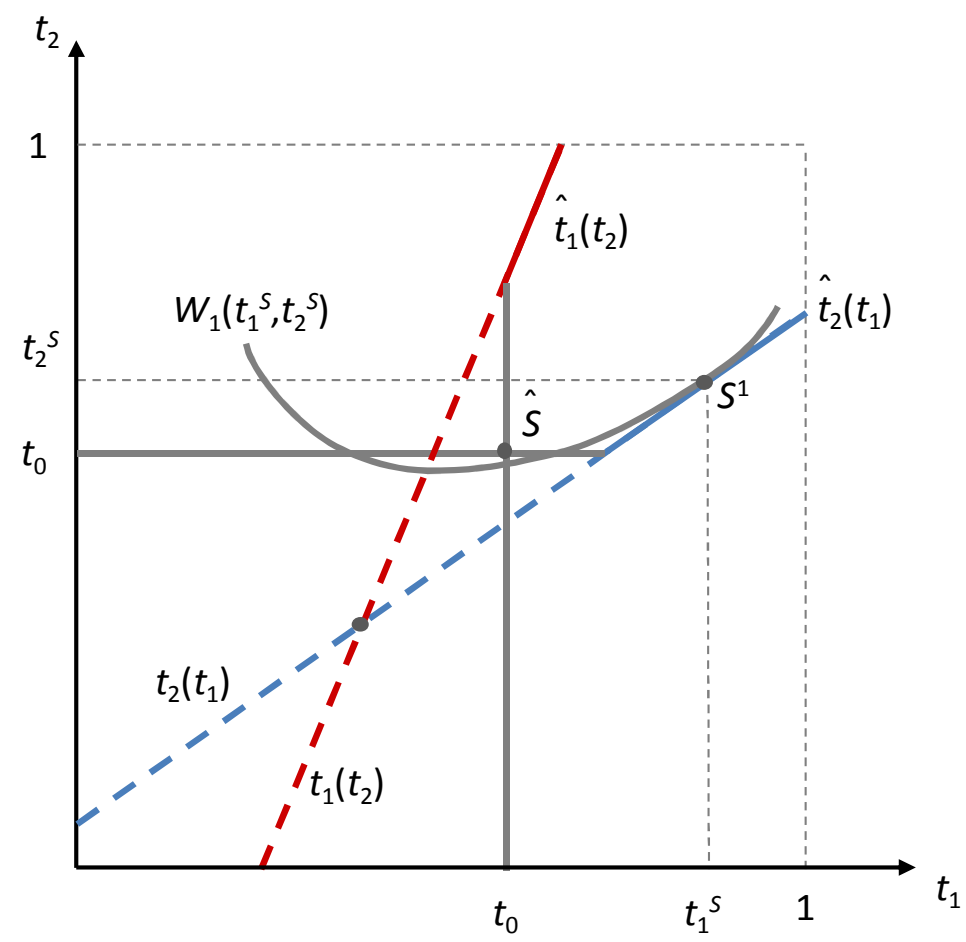

Intuitively, in both these Stackelberg cases, he lower floor on tax rates limits the possible reactions which the follower can choose. Without such limits, if the leader chooses a tax as low as $t_{0}$, the follower chooses an even much lower tax and this harms the leader. With this limit this adverse reaction is ruled out, making this lower tax rate choice attractive for the leader. Had the Ruding Committee proposal of a 30 percent minimum tax rate been adopted, for instance, EU members setting a higher rate could have reduced their rate secure in the knowledge that no other country would undercut them by going below 30 percent. The results for the Stackelberg case provide an important qualification to the strong case that emerges from the Nash game that setting a minimum tax rate modestly higher than the lowest observed is Part-improving.

\section{Coordination in tax alliances}

A simultaneous coordination of all countries is hard to envisage, as there is no supra-national agency that could enforce such an agreement. However, supra-national structures such as the 
European Union may enable their members to commit to joint action. But is in the interest of subsets of countries to coordinate only among themselves? Non-participating countries' equilibrium tax rates may well be different from those they set in the fully non-cooperative Nash equilibrium. Even though participating countries benefit from joint action in the absence of such strategic effects on non-participants (at least, they cannot do worse), it is not clear a priori if, once those effects come into play, the overall outcome of this coordinated action is beneficial for them. Since almost all international tax coordination that one can conceive of in practice is likely to involve only a subset of countries, and such coordination is high on the agenda of many regional trading blocs, the issue is a critical one.

This problem has been addressed formally by Konrad and Schjelderup (1999), and the general question can be addressed in a modified version of the reaction curve diagram for the linear model. In this subsection, we extend this model to three symmetric countries, labelled 1, 2 and 3. We assume that the symmetric Nash equilibrium in pure strategies exists and denote the uniform equilibrium tax rate $t_{1}=t_{2}=t_{3}=t^{*}$. We ask if countries 1 and 2 could gain if, rather than maximizing their own welfare individually and ending up in this Nash equilibrium, they join forces and credibly and publicly agree on choosing a common tax rate $t_{1}=t_{2} \equiv t_{A}$ that maximizes their joint welfare $W_{A} \equiv W_{1}+W_{2}$, where $W_{i}$ is defined as in (3) for all countries $i=1,2,3$.

A first question is whether they can increase their welfare by both choosing a slightly higher tax rate, assuming first that country 3 still chooses $t_{3}=t^{*}$. Formally, at $\left(t_{1}, t_{2}, t_{3}\right)=\left(t^{*}, t^{*}, t^{*}\right)$,

$$
\frac{\partial\left(W_{1}+W_{2}\right)}{\partial t_{A}}=\frac{\partial\left(W_{1}+W_{2}\right)}{\partial t_{1}}+\frac{\partial\left(W_{1}+W_{2}\right)}{\partial t_{2}}=\frac{\partial W_{2}}{\partial t_{1}}+\frac{\partial W_{1}}{\partial t_{2}}>0
$$

where use is made of the first-order conditions $\partial W_{i} / \partial t_{i}=0$. Intuitively, if both countries 1 and 2 slightly increase their tax rate starting at the non-cooperative Nash equilibrium, the direct first-order effect of the increase in their own tax rate on their own welfare is zero, because the deviation occurs at the local optimum. However, country 1 gains from country 2's tax rate (and vice versa) due to a tax-base effect. The increase in $t_{2}$ drives capital away from country 2 and part of this capital relocates to country 1 . This is a first-order effect. The same applies for $t_{1}$ and country 2's welfare. Of course, country 3 benefits even more than the two countries, as country 3 has a first-order tax base effect from the increase in each of the tax rates $t_{1}$ and $t_{2}$. Clearly though participants gain in the absence of some form of response from the rest of the world. 
Country 3 forms Nash conjectures about the collective choice of $t_{A}$ by countries 1 and 2, and conjectures that this tax rate will be higher than $t^{*}$. Country 3 will therefore choose a different tax rate and we have to search for the new equilibrium. The new equilibrium is obtained as a set of taxes $\left(t_{A}, t_{A}, t_{3}\right)$ that fulfils two conditions. First, given country 3 's Nash conjecture that countries 1 and 2 both choose $t_{A}$, country 3 chooses the $t_{3}$ that maximizes $W_{3}\left(t_{A}, t_{A}, t\right)$ for this conjecture. Moreover, the joint tax rate $t_{A}$ is the argument $t \in(0,1)$ that maximizes the sum of $W_{1}\left(t, t, t_{3}\right)+W_{2}\left(t, t, t_{3}\right)$ given the Nash conjecture about $\mathrm{t} 3$. Whether or not the coordinated choice of countries 1 and 2 improves their joint welfare in the new equilibrium will crucially depend on the new equilibrium value of $t_{3}$. However, as a consequence of strategic complementarity of the tax rates, the optimal reply of country 3 to the conjectured size of $t_{1}=t_{2}=t_{A}>t^{*}$ is the choice of $t_{3}>t^{*}$. This higher tax rate benefits countries 1 and 2 . Hence, the overall welfare effect for countries 1 and 2 is positive. This analysis can easily be extended to more than three symmetric countries, with a subset of these forming an alliance.

The consideration of regional cooperation has its correspondence in the work on merger of $m$ firms in an oligopoly with $n>m$ firms and price competition [see Deneckere and Davidson (1985)]. Merger between firms in this context means that they maximize their joint profits by a coordinated choice of their prices. If the products of all firms are strategic substitutes, the merging firms typically choose higher prices, and the strategic effect of this increase on bystanding firms is that they also increase their prices. Overall, the merger increases profits of all firms. The assumption of price competition is important in this context, as quantity competition comes to opposite conclusions about the profitability of a merger for the merging firms [see, e.g., Salant, Switzer and Reynolds (1983)].

The logic of regional tax coordination plays a role in a number of further studies. Conconi, Perroni and Riezmann (2008) essentially analyse partial tax coordination in a context with downward pressure on tax rates due to tax competition on the one hand side and upward pressure on tax rates due to time consistent confiscatory taxation. Coordination by a suitably chosen size of the subgroup may be used to find the right balance for this trade-off. Haufler and Wooton (2006) apply a related logic in a competition for direct investment. Sørensen (2004a) explores a similar logic, focussing on the amount of redistributive taxation, rather than on the provision of public goods. His analysis also offers simulations of the welfare effects of regional (subgroup) versus global coordination, compared to fully uncoordinated tax competition. His results suggest that the beneficial effect of coordination among a subset of all countries is small in comparison to the benefit for the country that is not part of the coordinating subgroup. Simulation results with a similar flavour which allow for asymmetries 
between the countries are by Parry (2003) and Brochner, Jensen, Svensson and Sørensen (2007) and Vrijburg and de Mooij (2010) highlight the importance of asymmetries between countries for whether tax rates are strategic complements or substitutes.

In the case of Europe and potentially other supra-national entities, the set of candidate countries that may enter into a regional coordination agreement is given exogenously or has been determined by other factors outside the context of the tax competition problem. Where this is not the case, the formation of subgroups becomes a challenging theoretical question. Members of the coordinating subgroup benefit, but their gains are typically smaller than those of outsiders. If there are $n$ countries, the formation of a subgroup of 2 is a Pareto improvement to no group formation at all. But which country should voluntarily give in and join the subgroup, and which country can happily stay outside and enjoy even higher benefits? Moreover, an enlargement of the group from $m$ to $m+1$ may be a further Pareto improvement up to some group size. However, among symmetric countries, if the number of countries is sufficiently large, this process typically comes to a natural stop: if, for instance, the subgroup consisted of $n-1$ countries already, the one remaining outsider is typically better-off as a free-rider than by joining the alliance. The process of alliance formation and the question of alliance stability is a matter that is typically very sensitive to the assumptions made about the formation process.

\section{Partial coordination}

The analysis of global tax coordination and of tax coordination in a region or a strict subset of the set of all countries considered here looked at the case in which governments have exactly one instrument, and in which coordination is about the choice of this instrument. Countries often have more than one instrument and also several targets. Partial coordination in such contexts can mean that all countries agree on restrictions as regards some, but not all of their instruments. Keen and Marchand (1997), for instance, consider coordination of tax rates in a framework in which countries can continue to compete along another dimension, which is their decision about infrastructure investment, and which works like an input subsidy. Fuest and Huber (1999) consider a framework with four tax or subsidy instruments. These analyses suggest that one may not expect too much from coordination negotiations, even if they yield some positive results in terms of partial coordination. If countries have more instruments than goals, some of the instruments may be redundant, and coordinated action that fixes the value of this instrument at some level can be undone by changes in the other variables. And even if the instruments are not redundant in a strict sense, and instruments are only imperfect 
substitutes, coordinated action that fixes the value of one instrument may imply that the substitute instrument may be used more strongly for the competition.

\subsection{Dynamic aspects}

Tax competition takes place, in practice, in a dynamic framework. This has several implications. Where there is an unknown, possibly infinite number of repetitions, the results for infinitely repeated games may become relevant for describing the outcome of tax competition. A second aspect of these dynamics is that decisions are made sequentially. Some early decisions may generate stock effects that determine the environment in which later decisions take place. More to the point: the capital stock is the result of earlier decisions on savings and consumption, and this may generate time consistency problems for the optimal tax policy which may interact with the effects of tax competition. A third aspect is the relationship between stocks and flows and the trade-off between taxing the stocks or attracting the flow of new capital. We consider these three aspects in turn.

\section{Infinitely repeated interaction}

Tax laws change from time to time, and there is no reason for an end to this process. This makes the folk theorems of infinitely repeated games potentially relevant in thinking about tax competition. One can ask whether the benefits of coordination or tax harmonization can be obtained in a fully non-cooperative game due to the infinite repetition. Analyses of this problem are Cardarelli, Taugourdeau, and Vidal (2002), Catenaro and Vidal (2006), Kessing, Konrad and Kotsogiannis (2006) and Kiss (2011). The last of these considers a symmetric setup with $n$ countries and uses simple trigger strategies to generate efficient tax harmonization as a non-cooperative equilibrium outcome, the main point being that introducing a minimum tax that is higher than the tax in a static Nash equilibrium may destabilize an existing efficient equilibrium.

The following multi-period version of the linear model with two countries illustrates why. Generalizing the linear framework to an infinitely repeated game with the static game as a state game, the local strategies of countries in a given period $s=0,1, \ldots$ are their tax rate choices $t_{1}^{s}$ and $t_{2}^{s}$ which may generally be functions of the whole history. Let $W_{i}\left(t_{1}^{s}, t_{2}^{s}\right)$ be the period payoff of country $i$ in period $s$ if the tax rates are $t_{1}^{s}$ and $t_{2}^{s}$ in that period, and let

$$
\sum_{s=k}^{\infty} \delta^{s} W_{i}\left(t_{1}^{s}, t_{2}^{s}\right)
$$


be the discounted present value of payoffs for all periods from period $k$ on that emerge from a series of tax rate choices $\left(t_{1}^{k}, t_{2}^{k}\right),\left(t_{1}^{k+1}, t_{2}^{k+1}\right), \ldots$, with $\delta$ is the discount factor that is invariant over time and the same for both countries. Further, let $\left(t^{*}, t^{*}\right)$ be the static symmetric Nash equilibrium tax rates, and let $\left(t^{o}, t^{o}\right)$ be the efficient tax rates that implement the symmetric first-best Pareto optimum. Suppose countries follow the following simple local strategies of choosing $t^{O}$ in the first period and then, for all further periods, choosing $t^{O}$ if both players have chosen $t^{O}$ in the previous period but $t^{*}$ if one of the players has not chosen $t^{O}$ in the previous period. These strategies constitute an equilibrium with $\left(t_{1}^{s}, t_{2}^{s}\right)=\left(t^{o}, t^{o}\right)$ for all $s=0,1, \ldots$ if the condition

$$
\sum_{s=0}^{\infty} \delta^{s} W_{i}\left(t^{o}, t^{o}\right) \geq W_{i}\left(t_{i}\left(t^{o}\right), t^{o}\right)+\sum_{s=1}^{\infty} \delta^{s} W_{i}\left(t^{*}, t^{*}\right)
$$

is fulfilled, where $t_{i}\left(t^{o}\right)$ is the tax rate that maximizes $i$ 's period payoff for a given choice of $t^{O}$ for the respective other country. The left-hand side of (31) is the present value of the sum of all payoffs of country $i$ if both countries choose the efficient taxes $t^{o}$ forever. The righthand side consists of two terms. The first is the period payoff of country $i$ chooses the optimal deviation tax rate $t_{i}\left(t^{o}\right)$ that maximizes its period payoff. The second term is the present value of the sum of all payoffs from all future periods, in which both countries choose the tax $t^{*}$ that characterizes the static non-cooperative Nash equilibrium. If (31) holds, then both countries prefer to stick to $t^{O}$ rather than to defect. This condition is more likely to be fulfilled if the discount factor $\delta$ is higher. Note that in this equilibrium $t^{*}<t_{i}\left(t^{o}\right)<t^{O}$ was used in equation (31), which is a consequence of strategic complementarity of the tax rates.

Suppose now that countries enter into a binding agreement in period 0 , which states that none of them will ever use a tax rate lower than some $t_{\min }$, with $t_{\min } \in\left(t^{*}, t_{i}\left(t^{o}\right)\right)$. Such an agreement changes the equilibrium of the static game. The Nash equilibrium of the static game is no longer $\left(t^{*}, t^{*}\right)$ as $t_{i}=t^{*}$ is infeasible. Instead, reversion to the static noncooperative Nash equilibrium will imply that the countries both choose $t_{\min }$. Applying this to the logic of infinitely repeated interaction, note that the minimum tax rate does not affect the left-hand side of (31). Also, $W_{i}\left(t_{i}\left(t^{o}\right), t^{o}\right)$ will not be affected. However, reversion to the static Nash equilibrium is less harmful for the two countries. It yields a present value of the discounted sum of period payoffs $W_{i}\left(t_{\min }, t_{\min }\right)$. Accordingly, if a country deviates from $t^{o}$, its immediate gain is the same as without a minimum tax, but the present value of future payoffs does not drop by that much. The relevant condition for whether an equilibrium with sustained cooperation on efficient tax rates exists becomes 


$$
\sum_{s=0}^{\infty} \delta^{s} W_{i}\left(t^{o}, t^{o}\right) \geq W_{i}\left(t_{i}\left(t^{o}\right), t^{o}\right)+\sum_{s=1}^{\infty} \delta^{s} W_{i}\left(t_{\min }, t_{\min }\right) .
$$

This, in turn, implies that a minimum tax that exceeds the Nash tax rate tightens the condition on the discount factor. The result by Kiss (2011) is an application of the topsy-turvy principle which is known from industrial organization: an institutional change that causes an improvement for the static non-cooperative Nash equilibrium may be harmful for the stabilization of collusive outcomes in infinitely repeated games. Intuitively this is so because such a change reduces the punishment that players experience in future periods if they defect from the collusive path.

\section{Endogenous savings and time consistent taxation}

So far we considered the world capital stock as exogenous. In a dynamic perspective, the current capital stock is the outcome of consumption and savings choices made in earlier periods. This was noted early on in the context of capital income taxation, and its implications for international capital taxation have been explored (Gordon 1986). A simple strategic setting can be used to analyse optimal and time consistent tax choices of countries $i=1,2, \ldots n$ in a dynamic framework with two periods, $\theta=0$ and $\theta=1$, this setting is a natural extension of the workhorse model and a simplified version of the two-period framework analysed by Huizinga (1995). In each country, a(representative) individual is born in period 0 with an endowment of capital $\kappa$, and decides how much to save $\left(c_{i}\right)$ and how much to consume $\left(\kappa-c_{i}\right)$ in this period. At the beginning of period 1, the sum of these savings $\Sigma_{i} c_{i}$ determine the world capital stock $K$; period 1 is very similar to the economy in the static workhorse model. Capital market clearing internationally requires

$$
\sum_{i} c_{i}=\Sigma_{i} k_{i}
$$

These investments determine aggregate output $f\left(k_{i}\right)$. The remuneration for capital is determined on a competitive market with its marginal product: $f^{\prime}\left(k_{i}\right)$. The government in country $i$ levies a source-based unit capital tax $t_{i}$, leading to an international capital market equilibrium with market clearing (33) and common same net return on capital

$$
\rho=f^{\prime}\left(k_{i}\right)-t_{i} \text { for all } i=1, \ldots, n \text {. }
$$

Finally, we assume $G_{i}\left(t_{i} k_{i}\right)$ to be as in the linear model above (equation (15)) This public good is produced and used only in the period $\theta=1$, reducing the role of the public sector to that period for simplicity. Overall, assuming additively separable period utilities with concave 
consumption utility $u\left(\kappa-c_{i}\right)$ in period $\theta$, the objective functions of a welfarist government is then

$$
W_{i}=u\left(\kappa-c_{i}\right)+f\left(k_{i}\right)-f^{\prime}\left(k_{i}\right) k_{i}+\rho c_{i}+G_{i}\left(t_{i} k_{i}\right)
$$

It consists of three components. The first is utility of period-0 consumption of private goods, where we assume that $u$ is an increasing and concave function. The second is utility of private consumption in period 1 , where this consumption enters linearly, making welfare quasi-linear and thereby sterilizing the analysis with respect to income effects. This private consumption is equal to output net of the remuneration of capital used in the country, plus the net-of-tax capital income of citizens in the country. The third component is $G_{i}\left(t_{i} k_{i}\right)$, utility from the public good that is produced from the tax revenue $t_{i} k_{i}$. This welfare is a straightforward extension of welfare in the benchmark model, simply adding utility from private consumption in a previous period.

Before analysing the equilibrium outcome for $n>1$, we discuss two benchmark outcomes for $n=1$. This reduces the problem to a special case of the analysis of Kydland and Prescott (1980) which they used to show the pitfalls of time consistent capital taxation. The optimal tax program considered from the perspective of period 0 , prior to a savings choice, consists of a choice $t$ such that the marginal opportunity cost of extracting one additional revenue unit from capital taxation equals the shadow price of public funds, which is equal to $(1+\lambda)$ here. The representative individual chooses savings according to

$$
u^{\prime}\left(\kappa-c_{1}\right)=f^{\prime}\left(c_{1}\right)-t_{1}
$$

use being made here of $k_{1}=c_{1}$ for $n=1$. This first-order condition implies that $c_{1}$ is a decreasing function of $t_{1}$.

The government takes this relationship $c_{1}\left(t_{1}\right)$ into consideration when choosing $t_{1}$ optimally. The first-order condition for the government leads to

$$
1+\lambda=\frac{1}{1+\frac{t_{1}}{c_{1}} \frac{\partial c_{1}}{\partial t_{1}}}
$$

an elasticity rule that just balances the benefit of additional public good against the marginal excess burden from the distortion of the consumption-savings decision. Typically, this condition singles out one tax rate that induces the second-best optimal amount of savings. 
Once the individual savings decisions have been made, however, $c_{1}$ becomes exogenous and fixed, so that the marginal welfare cost of taxing capital is equal to $1<1+\lambda$. The welfare maximizing government chooses its tax rate at the beginning of period 1. Assuming that a unit tax exceeding full expropriation is not feasible, the welfare optimum is attained either at $t_{1}=1$ if $c_{1} \leq \bar{G}$, or at $t_{1}$ that solves $t_{1} c_{1}=\bar{G}$ if $c_{1}>\bar{G}$. But this high tax rate will be anticipated by the individuals already in period 0 and its anticipation will generally discourage savings. Even though the ex-post optimal tax does not change the capital stock at the point when it is introduced, it imposes an excessive excess burden due to its anticipation. The confiscatory tax can reduce savings, thereby causing a maximum distortion in the savings-consumption decision without generating any revenue. In particular, in an economy in which aggregate savings are formed by many individuals, there is typically an equilibrium in which $c_{1}=0$. Hence, the time consistent capital tax is too high from a welfare point of view. Ex-post optimal taxation leads to excessive taxation in the single economy.

Return now to $n>1$. As has been shown in the benchmark analysis, tax competition has a tendency to drive down tax rate levels. Kehoe (1989) argued that this competition effect may be desirable in a situation in which the government cannot credibly commit on a capital tax early on and suffers from the Kydland and Prescott (1980) time consistency problem. If we open up for tax competition between a set of such identical economies, this competition will drive down equilibrium tax rates compared to these excessive levels. Can tax competition with tax rate choices based on existing savings lead to the same equilibrium outcome as the ex-ante optimal program of capital taxation in the solitary economy? ${ }^{29}$

The answer is: possibly, but the outcome is generically still inefficient. To see that efficiency may be restored, consider first the downward sloping function $c_{1}\left(t_{1}\right)$. Denote the ex-ante optimal tax rate as $t^{s}$ and the respective savings as $c^{s}$. In a solitary economy, these savings are identical with the capital stock $k^{s}$. Now turn to the case of $n$ symmetric, identical countries with tax competition and tax rates chosen at the beginning of period 1 . Suppose that the citizens in each of these countries expect that the tax rate that is to be chosen at the beginning of period 1 will be $t^{s}$. Then there is an equilibrium in which the individually optimal consumption choices in period 0 induce savings in each country equal to $c^{s}$.

But is there is a symmetric Nash equilibrium in the tax competition game that really induces $t^{s}$ as the tax rate? For this, note that the situation in period 1 is essentially the same as

\footnotetext{
${ }^{29}$ Means to overcome this problem other than tax competition have also been discussed. Boadway and Keen (1998), for instance, show that commitment on a lax audit policy can thereby reduce the tax rate that is ex-post optimal and so mitigate the time consistency problem.
} 
in the static tax competition problem that has been solved in the benchmark case, with capital endowments $c_{i}=c^{s}$ in each of the $n$ countries. The elasticity formula (10) characterizing the equilibrium tax rate in a symmetric tax competition equilibrium now becomes, for a given stock of capital $k^{*}=c^{s}$, and replacing $G^{\prime}$ by $(1+\lambda)$,

$$
1+\lambda=\frac{1}{1+\frac{t^{*}}{c^{s}} \frac{n-1}{n} \frac{1}{f^{\prime \prime}\left(c^{s}\right)}}
$$

which typically has one solution $t^{*}\left(c^{s}, n\right)$. If it so happens that $t^{*}=t^{s}$, then the expectations of the individuals that induced their savings of $c^{s}$ were justified and tax competition can indeed implement the ex-ante efficient outcome with $t^{s}$ and $c^{s}$. For $n=1$, we return to the case of excessive ex-post efficient taxation for the case of the solitary economy, with $t^{*}>t^{s}$. However, $t^{*}\left(c^{s}, n\right)$ is a downward sloping function of $n$. Assuming away the indivisibility problem for $n$, and depending on the shape of the production function $f$, for sufficiently large $n$ the solution to (38) may just be equal to $t^{s}$. In this case the forces of tax competition happen to exactly compensate for the ex-post inefficiently high incentives to confiscate capital. More generally, the pressure of competition allows the country to credibly commit to a tax rate that is lower than the high tax rate on capital that would be the time consistent solution in the solitary economy.

Kehoe's (1989) result is in the tradition of Lipsey and Lancaster (1956). In a world with several distortions, they may reinforce or counterbalance each other. It is only fortuitously, however, that a combination of some degree of tax competition and of time-consistent capital taxation will only accidentally lead to efficient taxation. Generically the outcome will be inefficient. In particular, if countries are asymmetric, it will typically be the case that the degree of tax competition that is just desirable from the perspective of one country will be suboptimal for other countries. And there is one further problem with the notion that tax competition can ease the time consistency problem in taxing capital income, This is that it relies on the idea that the world capital stock is fixed once the savings decisions are made, but this capital remains mobile internationally once it has been formed and can be shifted between the countries as a reaction to the tax rate choices. It is true that single investors can sell their assets in one country and purchase assets in another country. Capital is, hence, mobile on the individual level. However, on the aggregate country level, at a given year, most of the capital assets in one country are fixed and essentially immobile and can be taxed at source. ${ }^{30}$

\footnotetext{
30 Andersson and Konrad (2003) explore a similar logic in the context of human capital investments, arguing that the international mobility of human capital can cure the problems created by time-consistent taxation of human capital that emerged in a closed economy.
} 
An analysis that develops a more credible mechanism but remains in the spirit of Kehoe (1989) is that of Janeba (2000). He considers the following hold-up problem that essentially resembles the problem of time consistent taxation. A firm faces an exogenously given block demand. It can sell up to $m$ units of a homogenous product for a given price, which can be normalized to 1 per unit sold, up to the maximum number of $m$. Any additional output can be sold only at a price of zero. The production technology of the firm is characterized by a capacity cost equal to $\gamma \in(0,1 / 2)$ per unit of capacity, zero variable cost up to the capacity limit. Suppose the firm can invest only in one location, say, country $A$, and let $\mu_{A}$ be the capacity that it chooses to build up in this country at a cost of $\gamma \cdot \mu_{A}$. Suppose governments are interested in tax revenue only. The government can levy a unit tax $t_{A}$ on goods produced inside the country. The country has to choose $t_{A}$ at a time when the capacity investment is made, but prior to the firm's output choice. In this case the following hold-up problem emerges. The firm's producer rent net of taxes is $x\left(1-t_{A}\right)$ for any $x$ up to the block demand $m$, and equal to $m\left(1-t_{A}\right)$ for even higher output. Anticipating that the firm will maximize this net producer rent, the government optimally chooses a tax $t_{A}$ that equals, or is just an epsilon below the selling price: $t_{A}=1$, reducing the net producer rent to zero. However, anticipating this high tax, the firm will not invest in capacity, as its equilibrium payoff is equal to losses that are equal to the size of the investment cost $\gamma \mu_{A}$.

Suppose now that the firm can also build up capacity $\mu_{B}$ in country $B$, also with a marginal capacity cost of $\gamma$. Governments in $A$ and $B$ must decide on a tax rate $t_{A}$ (resp. $t_{B}$ ) per unit produced inside the country, and they must choose these tax rates once the capacity investment is made, but before the production decision is made. Janeba (2000) shows that the firm would then be wise the firm to build capacity of $m$ in both countries, giving it twice the capacity which is sufficient to cover the block demand. For then it becomes evident to each government that the firm will produce the whole quantity $m$ in the country that has the lower tax, and zero in the country that has the higher tax. Given this option to shift the whole production to the country with the lower tax, when countries choose their tax rates $t_{A}$ and $t_{B}$ they face cut-throat competition. The equilibrium tax rates they choose in the equilibrium are $t_{A}=t_{B}=0$. And this removes the hold-up problem. But not for free. In this outcome the firm incurs additional costs that are equal to the size of the excess capacity, however. The point is that the hold-up problem would not be removed without excess capacity, even if the firm allocates some capacity in each of the countries. Without excess capacity the threat of relocating production is empty.

Unlike physical capital, human capital is mobile ex-post. It is embodied in persons, but the persons are mobile. 


\section{Stock effects and agglomeration}

In a dynamic framework there is a critical distinction is between the stock of capital invested in a country, which is typically embodied in physical capital and very expensive or impossible to relocate, and the flow of additional net investment in a given period. Countries must then distinguish between two effects of setting a high tax rate. A high tax rate will generate considerable revenue from the existing, 'old' stock of capital. But it may also discourage investors to build up new capital in this country (Wildasin 2003). The competition for new capital occurs via the choice of the tax rate in a given period, and new capital is more likely to flow into countries with a lower tax rate. The choice of a low tax rate makes a country an attractive location for new investment, but brings in little tax revenue in the ongoing period.

This is the trade-off for the tax policy of a government that would like to generate a large present value of revenue from taxation of the stock of capital in a sequence of periods. In a strategic environment, a large stock of old capital can be a disadvantage for a country that competes for new capital with other countries: A country which has a large stock of capital has a higher opportunity cost from a reduction in its tax rate in the ongoing period than a country which has less old capital. The country with a large stock sacrifices more current tax revenue than the other country [Janeba and Peters (1999), Marceau, Mongrain and Wilson (2010)]. For this reason, some countries may decide to extract as much as possible from the given stock of capital invested there, and leave it to other countries to attract the new investment, and this may lead to capital rich countries with high taxes and a lack of investment dynamics, and young emerging countries with low taxes and dynamic investment.

There exists an important countervailing force to this divergence in tax rates, however, if a large installed capital base has positive externalities for new investors. Such agglomeration advantages may make it attractive for new investment to locate in the country that has the large capital base, even if the tax rates are higher there than in other countries without capital agglomerations of comparable size. Baldwin and Krugman (2004) analyzed the tax competition outcome in a framework with such agglomeration advantages. They show that an optimal tax policy of the country with large agglomeration advantages can be limit taxation (in analogy to limit pricing in competition policy): setting a tax rate that constitutes a strictly positive net fiscal burden for new investors, but is sufficiently low such that this burden is smaller than or just equal to the benefits from joining the agglomeration, compared to investing in a competitor country without such agglomeration advantages, even if this competitor country chooses a zero tax. If this equilibrium exists, it can perpetuate agglomeration advantages. 
Whether such a perpetuated equilibrium with limit taxation exists, and under what conditions the equilibrium is one with capital-rich high-tax countries which exploit their existing capital and suffer from lack of new investment on the one side, and capital-poor lowtax countries with strong growth is analysed by Konrad and Kovenock (2009). They show that both outcomes are possible, and which outcome emerges in the equilibrium depends on the size of the agglomeration benefit for newly attracted capital, and on the quantity of newly attracted capital in comparison to the stock of existing capital that cannot escape from taxation. They also consider the case in which existing capital and new capital can be taxed at different rates, or in which newly attracted capital receives tax holidays. In this case the agglomeration is more stable, but also the tax revenue is very small in the long run, as there is strong competition for the newly attracted capital. Empirically, asymmetric equilibra in which one country or region chooses a high-tax strategy and extracts from the existing immobile capital base and the other country or countries compete for new investments in Russia has been the motivation for the analysis by Cai and Treisman (2005) who study this type of asymmetric equilibrium.

\subsection{Profit shifting and the Kanbur-Keen model}

As the preceding sections make clear, the workhorse ZMW model has proved extremely versatile and informative. In one important respect, however, it (and the variants discussed so far) is inherently limited as an approach to thinking about international tax competition. This is because the tax base over which countries are assumed to compete is mechanically tied to real activity. In practice, both companies and individuals have a range of ways in which they can rearrange their affairs so as to reduce the total tax they pay with only limited effect on the pre-tax income they receive. Companies can shift paper profits to low tax jurisdictions, for instance, by transfer pricing (that is, manipulating prices charged within the group-for instance, by providing highly-priced management services to a subsidiary in a high tax country from another located in a low tax country), by financial structuring (by 'thin capitalization,' for instance: lending from a subsidiary in a low tax country to subsidiaries in high tax ones, the interest deduction being worth more than the tax paid on interest received by the other), or by judicious choice of organizational form (exploiting mismatches in the way different countries view the same entity for tax purposes). Individuals can choose to hold investments through accounts in low tax jurisdictions, and evade or defer tax due in their home countries. Quantifying these effects is difficult, but there is little doubt that the sums at stake are large. 
The aim here is not to review such avoidance or evasion schemes-on the corporate side an excellent treatment is in Mintz and Weichenrieder (2010)_but rather to consider how profit shifting activities affect the way in which one should think about strategic aspects of international tax competition. For this, the model of Kanbur and Keen (1993) is a useful start. This was initially exposited as a model of commodity tax competition, and, although that is not the topic of this review, it will be helpful to construct it in the same way, and then reinterpret it as one of profit shifting.

The framework is a spatial one, with two countries, $i=1,2$, each of length unity, located on a line with a border between them in the middle. The population is distributed uniformly in each, but population sizes $h_{i}$ differ. Consumers buy only one unit of some good, which they can do either where they are located, paying the local tax, or by travelling to the border to buy at the tax-inclusive price of the other country. In the latter case they incur unit transport costs of $\delta$. Suppose then that $t_{1}<t_{2}$, where $t_{i}$ denotes the unit tax in country $i$. Then all consumers in low-tax country 1 will simply buy at home. In high-tax country 2 , a consumer living a distance of $s$ from the border will find it worthwhile to purchase abroad if and only if $t_{1}-\delta s<t_{2} ;$ in aggregate, a proportion

$$
s^{*} \equiv \frac{t_{2}-t_{1}}{\delta}
$$

of country 2 consumers will thus shop abroad. Revenues in the two countries are then:

$$
R_{1}=t_{1}\left(h_{1}+h_{2}\left(\frac{t_{2}-t_{1}}{\delta}\right)\right) ; R_{2}=t_{2} h_{2}\left(1-\left(\frac{t_{2}-t_{1}}{\delta}\right)\right)
$$

reflecting the revenue gain to the low tax country from sales to a proportion $s^{*}$ of the $h_{2}$ consumers in country 2, and the corresponding loss to the latter. Each government is assumed to maximize its tax revenue, taken as given the tax set by the other. In the region ${ }^{31}$ where $t_{1}<t_{2}$ the best responses are readily calculated to be

$$
t_{1}\left(t_{2}\right)=\frac{1}{2}\left(\delta \theta+t_{2}\right) ; t_{2}\left(t_{1}\right)=\frac{1}{2}\left(\delta+t_{1}\right)
$$

\footnotetext{
${ }^{31}$ As discussed in Kanbur and Keen (1993), considered over the full range the best response functions differ in structure between the larger and smaller countries, with as discontinuity in the latter case.
} 
where $\theta \equiv \frac{h_{1}}{h_{2}}$.These intersect at tax rates

$$
t_{1}=\delta\left(\left(\frac{2}{3}\right) \theta+\frac{1}{3}\right) ; t_{2}=\delta\left(\left(\frac{1}{3}\right) \theta+\frac{2}{3}\right)
$$

which is consistent with the maintained assumption that $t_{1} \leq t_{2}$ if and only if $\theta \leq 1$ meaning that it is the smaller country that sets the lower tax rate in equilibrium.

Several embellishments of this framework are to be found in the commodity tax literature. $^{32}$ To see how a simple model of profit shifting can lead to the same formal structure, consider a multinational that earns 'true' profits ${ }^{33}$ in each of two countries of $\Pi_{i}, \mathrm{i}$ $=1,2$. Profit declared in country $i$, and taxed there at a proportional rate $t_{i}$ differs from true profit, however, to the extent that the company uses transfer pricing and other devices to shift profit between them. Suppose, as above, that $t_{1}<t_{2}$ so that the incentive is to shift profits into country 1 , and denote by $S$ the fraction of real profit in country 2 that is shifted to country 1 . Such shifting is not costless, however, involving some organizational cost, distortion of activities or risk of penalty. Assuming this cost to take the form $(1 / 2 \delta) S^{2} \Pi$ and not to be deductible in either country, ${ }^{34}$ the firm's net profit is then

$$
\Pi=\Pi_{1}+\Pi_{2}-t_{1}\left(\Pi_{1}+S \Pi_{2}\right)-t_{2}\left(\Pi_{2}+S \Pi_{2}\right)-\left(\frac{1}{2}\right) \delta S^{2} \Pi_{2}
$$

\footnotetext{
${ }^{32}$ Nielsen (2001), for instance, shows that essentially the same results hold if countries instead have uniform population densities but differ in length. Ohsawa (1999) extends the analysis to the case of three countries located on a line, showing that (in the absence of size differences) tax rates will be higher in the periphery (because the intermediate country attracts cross-border shoppers from two countries by setting a lower rate, but the others from just one). With a federal structure in mind, Agrawal (2011) locates states (corresponding to countries in the analysis above) along a circle and allows for tax differentiation across towns within states. Keen (2002) provides a review.

${ }^{33}$ The concept of 'true' profits allocable to particular countries is problematic in itself. The centerpiece of international tax practice is the principle of valuing intra-group transactions t 'arms-length' prices that would be paid between unrelated parties. Since competitive markets from which such prices can be found often do not exist - a fact in itself linked with the existence of the multinationals - this is in practice highly contentious. For present purposes, however, a broad distinction between profits associated with real activity in particular and those shifted with the tax-minimizing intention of shifting the distribution rather than the total of group profits is clear enough.
}

${ }^{34}$ This is for convenience rather than realism. In practice, costs may well be tax-deductible in one country or the other, and the cost may reflect penalties that in turn depend on the applicable tax rate. The extent of profit-shifting may then depend on tax rates through more than just the absolute difference between them. 
Maximizing with respect to $S$, the proportion of profits shifted from country 2 to country $1, s^{*}$ is exactly as in (39) above; and revenues in the two countries are precisely as in (40), with true profit $\Pi_{i}$ relacing population size. Conclusions drawn from the commodity tax form of the model can thus be translated directly into results on profit shifting.

Prominent among these is that it is the country which is 'smaller', not necessarily (as in the commodity tax variant) in terms of population or geographical size but in the sense of hosting lower aggregate profits from real activities, which sets the lower tax rate in equilibrium. This is strong prediction that, as will be seen, resonates closely with a central features. The intuition underlying it is straightforward: a country that is small in this sense loses little revenue from its own tax base by cutting its tax rate; but it can gain a good deal by attracting taxable profit from the rest of the world.

Many other of the implications drawn from the Kanbur-Keen model are also broadly similar to those derived earlier for the ZMW model, with the closed forms available enabling particularly sharp expression. These include the finding that setting a uniform rate anywhere between the rates that emerges in the Nash equilibrium always harms the small, low tax country, whereas imposing a minimum tax anywhere in that range is Pareto-improving. There is though one important difference: whereas the tax rates in the ZMW model are, as noted, best interpreted as marginal effective rates, capturing the combined impact of tax rates and tax base on the additional liability associated with investing a little more, the relevant tax rates in considering profit shifting are best thought of as corresponding to statutory rates, since the shifting has no impact, for instance, on depreciation allowances claimed. Thus it is quite possible, for instance, that countries might wish to lower the statutory rate in order to manipulate profit-shifting while expanding tax bases so as to protect revenue from real investments. This, indeed, seems broadly consistent with the developments in advanced economies noted in the Introduction.

With this important difference between them, the confluence of results is nonetheless reassuring, in the sense that the insights into equilibrium outcomes and broad policy responses seem reasonably robust to the mix between real and paper shifting of tax bases. But they also point to the importance of asymmetries, and the difficulties this creates for coordinating beneficial outcomes. It is a general feature of tax competition models that small countries matter a good deal—a sharp contrast, for example, to the literature on tariff wars, in which it is the large countries that are potential winners from trade wars. This has powerful implications for designing feasible reforms in this area, a point taken up in the next section. 


\section{Broadening the perspective}

The benchmark model of tax competition considers a tax base 'capital' as a continuously divisible quantity that flows between countries, with these flows affecting the marginal product of capital in all of them. This describes changes in the capital endowments at the intensive margin and assumes a perfectly competitive market for capital inside each country. From the point of industrial economics, countries operate much like companies which are price setters and compete with each other for aggregate demand, where this demand may be fixed (as in an oligopoly with block demand), or where aggregate demand may also react to the prices offered. From the point of view of formal structure, the main difference is the different objective function of governments where these do not simply maximize tax revenue, but national welfare that consists of a set of components. This model of competition does not exhaust practically relevant models of competition, and some of these alternative concepts also matter in the context of tax competition. In what follows we discuss several other concepts, where this selection is clearly incomplete. Governments may make bids for lumpy investment, trying to attract firms much like in an auction. Governments may apply the concept of "third-order tax discrimination" when they compete for tax bases with different mobility. Information exchange between countries may be an important element of tax competition. Also geography, and proximity in particular, may play a role for tax competition. All these concepts play a role in understanding the phenomenon of tax havens which we address at the end of this section.

\subsection{Bidding for firms}

Where countries compete for foreign direct investment, this is often not a competition for additional capital that is then used at the intensive margin, but for individual firms: that is, it is competition at the extensive margin and makes the taxed subjects strategic players. The literature has attributed considerable attention to this fact.

A number of contributions consider the bidding for firms by countries that benefit from attracting the firm or a larger share of its capital in their country. Ferrett and Wooton (2010a) provide a simple and fairly general framework of two countries bidding for one firm. They consider two countries $A$ and $B$ who can make bids $y_{A}$ and $y_{B}$ to attract a firm from the rest of the world. Let $\pi_{A}$ and $\pi_{B}$ be the gross profits of the firm from locating in $A$ and $B$, respectively, and $\pi_{A}-\pi_{B} \geq 0$ the difference between them. Further, let $w_{A}$ and $w_{B}$ be some additional benefits that accrue to country $A$ and $B$, respectively, if it attracts the firm, these capture the idea, apparently commonplace among policy makers, that inward FDI conveys 
external benefits to the wider economy, perhaps through a reduction in per-capita cost of provision of public goods or inputs ${ }^{35}$, increases in wage income ${ }^{36}$, to generate technological spillovers and other external effects. And denote by $\sigma_{A}$ and $\sigma_{B}$ be the shares in the firm owned by citizens of country $A$ and $B$. Thus respectively, welfare in country $i$ is

$$
\begin{gathered}
\sigma_{i}\left(\pi_{i}+y_{i}\right)-y_{i}+w_{i} \text { if } i \text { attracts the firm } \\
\sigma_{i}\left(\pi_{-i}+y_{-i}\right) \text { if }-i \text { attracts the firm. }
\end{gathered}
$$

Assuming a suitable tie-breaking rule for the case in which a firm is just indifferent, one can characterize the equilibrium as follows: The country $i$ that loses just makes a bid for which it is indifferent whether to lose or win, which is the case if $y_{i}^{*}=\sigma_{i}\left(\pi_{i}-\pi_{j}+y_{i}^{*}-y_{j}^{*}\right)+w_{i}$. The winning country $j$ makes a bid that is just large enough to win against this bid, i.e., it bids $y_{j}^{*}=\pi_{i}+y_{i}^{*}-\pi_{j}$. Note that this latter condition implies $\pi_{i}-\pi_{j}+y_{i}^{*}-y_{j}^{*}=0$, and, hence, $y_{i}^{*}=w_{i}$, whereas $y_{j}^{*}=\pi_{i}-\pi_{j}+w_{i}<w_{j}$. This equilibrium has attractive features. First, the outcome is efficient: the firm allocates where it generates the higher welfare. Second, both the bids and the equilibrium allocation is independent of ownership shares in the firm. Intuitively, the winning country makes a bid that is just large enough to attract the firm, i.e., for which $\pi_{i}-\pi_{j}+y_{i}-y_{j}=0$. This condition is sufficient, however, for making the owners of the firm just indifferent about whether the firm locates in $A$ or $B$.

Allocative efficiency of the bidding equilibrium can though be destroyed by additional considerations. Kessing, Konrad and Kotsogiannis (2009), for instance, apply a very similar auction framework with two countries making bids for a foreign direct investment. One is a unitary country with a government that has essentially the same objective function as above. The other is a federal union in which several layers of government share the tax revenue that can be collected if the investment occurs in this country. This may cause a vertical fiscal externality inside the country, leading to an excessively high tax burden and taxation on the downward sloping part of the Laffer curve. In addition, while the governments at the different layers share a common interest in the bidding process they face a collective good problem when making their contributions to the country's overall bid. Vertical fiscal externalities and free-riding problems within the federal union generate a disadvantage for the federal union in a bid competition with a unitary country.

\footnotetext{
${ }^{35}$ See, e.g., Black and Hoyt (1989).

${ }^{36}$ Among these contributions is Haaparanta (1996).
} 
A further, large group of effects is related to the dynamic nature of investment, particularly in a multi-period framework. The analysis of King, McAfee and Welling (1993) alludes to some of these effects. First, the location choice of a firm may involve sunk costs and may reduce the firm's mobility, making it exposed to the host government that may then be tempted to extract from this firm. This is true not only if the firm becomes fully immobile, but also if some capital investment is made that is immobile or loses some of its value if it is relocated. As a result, and unless there are other means to overcoming this hold-up problem, governments may compensate firms for the extraction of tax revenue that comes later by making upfront subsidies. Also, a government of a country may incur cost of investing in infrastructure in order to increase the profitability of a firm should it locate in this country. If countries cannot coordinate as regards their investment choices, this may cause a noncooperative equilibrium with asymmetric investment choices in which one country invests much and the other country little. ${ }^{37}$

Bidding for firms occurs in a set-up in which foreign direct investment may have a number of externalities, and some of these make foreign direct investment beneficial for the host country and increase its willingness to bid for such investment. In similar spirit, Haufler and Wooton (1999) analyse the competition between two countries for a foreign owned monopolist and show that a large home market benefits that country if there are trade costs. The role of trade cost and market size is also important in the context of other types of imperfect competition and this paper can be seen as the starting point of a large literature that explores these effects. ${ }^{38}$

\subsection{Preferential regimes}

In its report on Harmful Tax Competition the OECD (1998) pays particular attention to practices by which countries may attribute different tax rules to the same type of business activity, typically attributing a lower tax rate to the more mobile activity, and a higher tax rate to the less mobile activity. For this practice the expression preferential regimes' has been coined, focussing and emphasizing the lower rates for the mobile tax base. Considered from the perspective of the public choice school, the same phenomenon may, of course, be called extortionary taxation of an immobile tax base. But sticking to the OECD term, what exactly is

\footnotetext{
${ }^{37}$ An elegant means to overcome the problem of opportunistic behavior of the host government ex post is Janeba (2000), discussed above.

${ }^{38}$ This literature includes Raff (2004), Bjorvatn and Eckel (2006), Ferrett and Wooton (2010b), Becker and Fuest (2010) and Haufler and Wooton (2010).
} 
the theory behind preferential regimes? And in particular, do they-as the OECD report presumed-necessarily aggravate the inefficiencies associated with international tax competition?

This can be addressed by broadening the benchmark model and assuming that, rather than one tax base, there are two tax bases. Denote the quantities of these tax bases that locate in country $i$ as $k_{i}$ and $\kappa_{i}$, respectively, and let $t_{i}$ and $\tau_{i}$ be the unit taxes applied to these tax bases at source. Generally, the quantities are functions of these tax rates: $k_{i}\left(t_{i} ; t_{-i}\right)$ and $\kappa_{i}\left(\tau_{i} ; \tau_{-i}\right)$ with $i \in\{1,2\}$, and where ${ }_{-i}$ denotes the respective tax rate in the other country (with possible generalizations towards more than two countries). These tax bases generally react to tax rate changes. Much like the literature on third-degree price discrimination in oligopoly (Holmes 1989), there are two major effects on tax bases. The first is that from overall taxation, which we may measure at a point of symmetry by $\partial k_{i}(t, t) / \partial t$. For instance, if savings are taxed more heavily universally, savings may go down. Second, there is an effect from changes in one country's tax, such as $\partial k_{i}\left(t_{i}, t_{-i}\right) / \partial t_{i}$, or $\partial k_{i}\left(t_{i}, t_{-i}\right) / \partial t_{-i}$.

We do not survey the whole literature here, but we re-establish two general insights. First we show that, whatever is the given fixed tax policy of the other country, a country can increase its tax revenue by tax rate differentiation. This revenue may be denoted as

$$
T_{i}=t_{i} k_{i}\left(t_{i} ; t_{-i}\right)+\tau_{i} \kappa_{i}\left(\tau_{i} ; \tau_{-i}\right)
$$

To see this, focussing on situations in which first-order conditions describe optimized choices and interior equilibrium, suppose first that country $i$ must tax both tax bases with the same uniform rate $t_{i}=\tau_{i}=z_{i}$. Its first-order condition is

$$
k_{i}+z_{i} \frac{\partial k_{i}}{\partial z_{i}}+\kappa_{i}+z_{i} \frac{\partial \kappa_{i}}{\partial z_{i}}=0
$$

The tax revenue emerging in the solution with uniform taxation can however unilaterally be further increased if the other country sticks to its choices of $t_{-i}$ and $\tau_{-i}$, irrespective of what these choices were: At $t_{i}=\tau_{i}=z_{i}$, we find

$$
\frac{\partial\left(\left(z_{i}+e\right) k_{i}\left(z_{i}+e ; t_{-i}\right)+\left(z_{i}-e\right) \kappa_{i}\left(z_{i}-e, \tau_{-i}\right)\right)}{\partial e}=k_{i}+z_{i} \frac{\partial k_{i}}{\partial z_{i}}-\kappa_{i}-z_{i} \frac{\partial \kappa_{i}}{\partial z_{i}} .
$$

This term is generically different from zero if the tax bases $k_{i}$ and $\kappa_{i}$ have different elasticities, suggesting that either an increase in $e$ or a decrease in $e$, and hence a 
differentiation in rates, can increase tax revenue in country $i$. This is well known from the theory of third-degree price discrimination of monopoly.

In the context of competition between countries, a further, strategic effect comes into play. If a country is known to choose differentiated tax rates rather than a uniform tax rate, the anticipation of its choices by the competing country causes a strategic reaction there. This leads to the second main question which we partially address. How does a world in which all countries nay apply a preferential regime differ from one in which they are constrained to apply a uniform regime? Are preferential regimes, in that sense, necessarily a harmful form of tax competition?

When preferential treatment is permitted, the first-order conditions for tax revenue maximization are

$$
k_{i}+t_{i} \frac{\partial k_{i}}{\partial t_{i}}=0 \text { and } \kappa_{i}+\tau_{i} \frac{\partial \kappa_{i}}{\partial \tau_{i}}=0
$$

and the resulting tax revenues are

$$
T_{i}^{P}=-k_{i}^{2} /\left(\partial k_{i} / \partial t_{i}\right)-\kappa_{i}^{2} /\left(\partial \kappa_{i} / \partial \tau_{i}\right)
$$

If on the other hand both countries apply uniform taxation, maximization of tax revenue in country $i$ yields

$$
T_{i}^{U}=-\left(k_{i}+\kappa_{i}\right)^{2} /\left(\frac{\partial k_{i}}{\partial z_{i}}+\frac{\partial \kappa_{i}}{\partial z_{i}}\right)
$$

Keen (2001) compares the implied equilibrium tax revenues in these two cases for the case of symmetric countries, assuming also that $k_{i}\left(t_{i}, t_{-i}\right)=k_{i}\left(t_{i}-t_{-i}\right)$, and $\kappa_{i}\left(\tau_{i}, \tau_{-i}\right)=\kappa_{i}\left(\tau_{i}-\tau_{-i}\right)$, essentially removing the effect of the general tax level for the aggregate tax base from the picture. For this case, the difference in a country's tax revenues between the Nash equilibrium with all countries applying uniform taxation $\left(T^{U}\right)$ and when countries may deploy preferential regimes $\left(T^{p}\right)$ is

$$
T_{i}^{U}-T_{i}^{P}=\frac{k_{i}^{2} \kappa_{i}^{2}}{k_{i}^{\prime} \kappa_{i}^{\prime}\left(k_{i}^{\prime}+\kappa_{i}^{\prime}\right)}\left(\frac{k_{i}^{\prime}}{k_{i}}-\frac{\kappa_{i}^{\prime}}{\kappa_{i}^{\prime}}\right)^{2} \leq 0,
$$

with $k_{i}^{\prime} \equiv \partial k_{i}(0) / \partial t_{i}$ and $\kappa_{i}^{\prime} \equiv \partial \kappa_{i}(0) / \partial \tau_{i}$, with equality holding only if $k_{i}^{\prime} / k_{i}=\kappa_{i}^{\prime} / \kappa_{i}$, that is, only, if there is no difference in elasticities in the two tax rates. In the general case in which 
elasticities differ, however, revenue is unambiguously higher when preferential regimes may be deployed: in that sense, they actually make tax competition less harmful. Intuitively, if countries must choose a uniform tax, then the high elasticity of the more elastic tax base (say, $k_{i}$ ) makes it more costly to impose a higher tax rate on the less elastic tax base $\left(\kappa_{i}\right.$, in this case) and leads to tax rate moderation. Discriminatory taxation leads to lower taxes on the more elastic tax base, but it also allows for a higher tax rate on the less elastic tax base-the flipside of preferential treatment is discrimination. Equation (51) shows that this latter effect dominates under certain conditions.

This result, running exactly counter to an commonplace presumption against preferential regimes of various kinds. as triggered much further consideration-see, for instance, Bucovetsky and Haufler (2007), Haupt and Peters (2005), Janeba and Peters (1999), and Janeba and Smart (2003)—some of which can be seen as providing a robustness check of Keen's result along a number of dimensions. The departure from the benchmark model that yields the largest divergence in results maintains the assumption of symmetry between countries and two tax bases, but assumes that $\kappa_{1}=\kappa_{2}=\kappa$ is completely inelastic up to a maximum tax rate of $\bar{\tau}$ in each of the countries, at which the owners of the tax base make use of a disposal option and scrap the tax base, and the existence of a perfectly elastic tax base of $2 k$ that floats freely between the two countries and locates in the country that has the lower tax rate. This capital locates symmetrically between the two countries if the tax rate applying to this tax base is the same in both countries. In this case, the equilibrium with preferential taxation is characterized by $t_{1}=t_{2}=0$ and $\tau_{1}=\tau_{2}=\bar{\tau}$. Both countries make use of their monopoly power as regards their immobile tax base, but they face cut-throat competition as regards the fully mobile tax base. In case of uniform taxation, an equilibrium in pure strategies does not exist. However, an equilibrium in mixed strategies exists. For symmetric countries, this mixed strategy equilibrium is characterized by uniform tax rates $z_{i}$ and $z_{i}$ that are random draws from a distribution that has a cumulative distribution function $F(z)=1+\frac{\kappa}{2 k}-\frac{k \bar{\tau}}{2 k z}$ and support $\left[\frac{2 k+\kappa}{K}, \bar{\tau}\right]$. The expected tax revenue in this equilibrium is equal to $\kappa \bar{\tau}$ for each of the two countries. Accordingly, preferential treatment generates exactly the same tax revenue as uniform taxation in the equilibrium. ${ }^{39}$

The results on preferential tax regimes are reminiscent of those on third-degree price discrimination in inter-firm competition. This literature first concentrated on third-degree price discrimination of a monopolist who serves several distinguishable customer groups [see, for instance, Schmalensee (1981)]. Here, price discrimination never yields monopoly profits

\footnotetext{
${ }^{39}$ Existence and uniqueness of this equilibrium has been obtained in the context of duopoly with loyal customer groups by Narasimhan (1988).
} 
lower than for uniform pricing, and as Holmes (1989) discusses, this carries over to collusive duopoly. Holmes (1989) main analysis concentrates on non-cooperative price competition between two firms. Each firm produces one product. The two products are imperfect substitutes. There are two sets of customers and each firm offers its product to both sets of customers. He distinguishes between uniform price competition, in which case each firm chooses the same offer price in both markets, and discriminatory pricing, in which case each firm chooses one offer price in each of the markets. To make the translation to preferential tax competition, the firms that set prices are replaced by governments which set taxes that are similar to fees charged on the tax base for operating in the respective country. This structural similarity is noted in some of the tax literature, most notably by Janeba and Smart (2003).

\subsection{Information exchange and implementation of the residence principle}

As noted in Section 2.1, it is the residence principle-not the source principle, which most of the formal literature reviewed here presumes-that is the international norm for personal-level taxation of capital income, ${ }^{40}$ and which continues to be important at corporate level too. Its implementation, however, can be problematic, for two reasons. One is that residence country taxes are generally not imposed until income is repatriated there, so that the real liability can be reduced by retaining funds abroad. A number of countries seek to address this through "controlled foreign corporation" (CFC) legislation, which enables them to bring into tax income remaining abroad-albeit generally only income that is "passive" in the sense of not arising from immediate business activities. Deferral, nonetheless, remains a key instrument of international tax planning (though not of course the only one). The second difficulty, seen as primarily arising at individual level, is simply the risk that taxpayers will not reveal to their home authorities income arising in abroad. The most obvious remedy for this is for the tax authorities to provide their counterparts abroad with information on the income arising in their country to residents of others. Fostering such information sharing has been the focus of considerable (indeed unprecedented) action in recent years, ${ }^{41}$ described in the next subsection, and attracted some theoretical interest too.

\footnotetext{
${ }^{40}$ With some exceptions: capital gains related to real estate, for instance, are generally taxable only where that real estate is located.

${ }^{41}$ The practicalities of information sharing are outlined in Keen and Ligthart (2006), though this predates the recent expansion of information agreements,
} 
Much of the literature on information exchange has focused on the question of whether countries might choose to provide such information voluntarily. ${ }^{42}$ At first sight, it might seem that those which are net recipients of income undeclared to the investors' home authorities would not, since by providing information they would enable the residence country to levy additional taxation and so make themselves less attractive a location for such funds. Strategic considerations, however, again come into play, a point first stressed by Bacchetta and Espinosa (2005). For if it can commit to providing such information-and double tax treaties and tax information exchange agreements may provide a vehicle for doing so-a low tax country enables the residence country to charge a higher tax rate than would otherwise be the case, which in itself tends to increase the inflow of capital that it receives-an effect that counteracts and may outweigh the directly harmful impact. ${ }^{43}$

To see this, consider again a world of just two countries, with $t_{2}>t_{1}>0$. In the high tax country 2 , there is a fixed amount of saving $S$ that can be invested in either country, in amounts $s_{1}$ and $s_{2}$, the former incurring expected (non tax-deductible) costs of $c\left(s_{1}\right)$, with $c$ increasing and strictly convex; there are no savings in the low tax country (to avoid the complication of cross-hauling of savings). The authorities in country 1 collect tax at the rate $t_{1}$ on all savings located there, and will provide information to the authorities in country 2 only on some proportion $\lambda$ of their residents' savings there; these are then liable to additional tax in country 2 of $t_{2}-t_{1}$ (credit being given for taxes paid abroad). Assuming the gross rate of return to be the same in both countries, country 2 investors will allocate their savings to as to minimize the sum of tax paid and transaction costs incurred, which is given by

$$
t_{2}(S-s)+(1-\lambda) t_{1} s_{1}+\lambda t_{2} s_{1}+c\left(s_{1}\right)
$$

the first term being the tax paid on savings retained at home, the second that paid on income abroad that is successfully concealed, the third paid on income abroad that is reported and so ultimately subject to the full home rate. Maximizing this to trade off the tax advantage of saving abroad against the transactions cost of doing, savings allocated abroad, $s_{1}\left(\lambda, t_{1}, t_{2}\right)$, are

\footnotetext{
${ }^{42}$ Some papers have compared in this setting information exchange and the imposition of withholding taxes by the low tax country, following Huizinga and Nielsen (2003). This is motivated largely by particularities of the EU Savings Directive, under which countries may either provide information or impose a withholding tax: in practice, may countries do both (double tax agreements for instance, typically providing for both information exchange and withholding taxes).

${ }^{43}$ Eggert and Kolmar (2002) consider the case in which tax rates and the extent of information sharing are chosen simultaneously, showing that the equilibrium degree of information sharing is then indeterminate.
} 
an increasing function $h\left[\beta\left(\lambda, t_{1}, t_{2}\right)\right]$ of the tax saved by doing so per unit of saving, given by $\beta \equiv(1-\lambda)\left(t_{2}-t_{1}\right)$. Thus

$$
\frac{\partial s_{1}}{\partial t_{2}}=(1-\lambda) h^{\prime}(\beta)>0
$$

so that, as one would expect, the amount saved abroad increases with the tax rate at home; similarly, it decreases with both the foreign tax rate and the extent of information sharing. For simplicity, assume that revenue rather welfare is the object of policy. In country 1 , this is simply

$$
R_{1}=t_{1} s_{1}\left(\lambda, t_{1}, t_{2}\right)
$$

while in country 2 it is

$$
R_{2}=t_{2} s_{2}+\lambda\left(t_{2}-t_{1}\right) s_{1}=t_{2} S-\left\{\lambda t_{1}+(1-\lambda) t_{2}\right\} s\left(\lambda, t_{1}, t_{2}\right) .
$$

With the degree of information sharing determined at the first stage of the game, each country chooses its tax rate taking as given both $\lambda$ and the tax rate of the other country. The tax rate chosen in the high tax country in particular, is thus $t_{2}\left(\lambda, t_{1}\right)$. Suppose then that the low country commits to a small increase in the extent of information sharing $\lambda$, From (55), the revenue impact in the high tax country, noting that the effect of any induced change in its own tax rate vanishes as an envelope property, is

$$
\frac{d R_{2}}{d \lambda}=\left(t_{2}-t_{1}\right) s-\left\{\lambda t_{1}+(1-\lambda) t_{2}\right\} \frac{\partial s_{1}}{\partial \lambda}
$$

and so is unambiguously positive: there is a gain both from increased taxation of any amount of income invested abroad and a reduction in the extent of such investments. For the low tax country 1 , matters are more complex. Revenue there being $t_{1} s_{1}\left[\lambda, t_{1}, t_{2}\left(\lambda, t_{1}\right)\right]$, the effect is given by

$$
\frac{d R_{1}}{d \lambda}=t_{1}\left\{\frac{\partial s_{1}}{\partial \lambda}+\frac{\partial s_{1}}{\partial t_{2}} \frac{\partial t_{2}}{\partial \lambda}\right\}
$$

Here the first term is the direct, adverse effect on the low tax country: it becomes less attractive as a venue for tax evasion. The second is the strategic effect: to the extent that the fuller information induces the high tax country to increase its tax rate-as is plausible, but not 
assured without further restriction of functional forms - this pushes more evasion into the low tax country. The overall impact of the low tax country is thus in principle unclear.

It can be, however, that the strategic effect dominates. Indeed in the simple structure above this, under plausible conditions, is sure to be the case. To see why, suppose that the high tax country reacts to increased information sharing by raising its own tax rate just enough to leave the tax saved by investing abroad unchanged in the face of the higher $\lambda$. With $\beta$ and hence the amount of saving allocated abroad unchanged, this leaves revenue in the low tax country as it was initially. Recalling (53.b), however, the higher $\lambda$ means that savings invested abroad are now less responsive than they were to the tax set by country 2 , which tips the balance of country 2's considerations towards increasing its tax rate further-pushing savings further in country 1 ' direction, and implying that it is ultimately better off. ${ }^{44}$

This is of course a strong and quite special result. Fuller treatments allow for the adjustment of country 1's tax rate too, and endogenize the choice of tax rates (relating them in particular to country size, with the standard conclusion that rates tend to be lower in smaller countries), allow for cross-hauling of savings, and explore the implications of differential tax treatment of residents and non-residents. While the strategic effect continues to play an important role, it clearly becomes much less powerful when there is more than one low-tax country: greater information sharing by one will then be met in part by a shifting of savings to other low tax countries, to that the impact on the tax-setting decisions of the high tax country will be greatly muted. The most robust result is probably the most obvious: there can be a sharp divergence of interests, with high tax countries much more certain to gain from mutual information exchange than low tax. ${ }^{45}$

\footnotetext{
${ }^{44}$ The result follows more formally by writing

$$
\partial R_{1} / \partial t_{2}=S-(1-\lambda) s_{1}(\beta)-(1-\lambda)\left(\beta+t_{1}\right) h^{\prime}(\beta)
$$

and noting that, for given $t_{1}$ and $\beta$, satisfaction of the necessary condition $\partial R_{1} / \partial t_{2}=0$ at $\lambda=0$ implies that $\partial R_{1} / \partial t_{2}>0$ at any $\lambda>0$. So long as $R_{1}$ is convex in $t_{1}$ (as is the case, for example, if the cost function $c$ is quadratic), the higher $\lambda$ must therefore be associated with a higher choice of $t_{2}$.

${ }^{45}$ The last observation perhaps suggests it might be Pareto-improving for the low-tax jurisdiction to receive some of the proceeds of the additional tax raised as a consequence of the information it provides. Keen and Ligthart (2006) show that his can indeed be the case, if the countries concerned are sufficiently asymmetric, even though such transfers may, perhaps surprisingly, reduce total revenue collected (by increasing the incentive for the low tax country to attract would-be evaders, since they then have less to fear if the evaders are caught). As a more practical caveat, it should be noted too that tax considerations of the kind in the models discussed here are not the only reason for concealing assets abroad.
} 


\section{4. "Tax havens"}

Though widely used, the precise meaning of the term 'tax haven' is elusive, and even in the practical world of policy there is no agreed definition., A low or zero tax rate on some activities or forms of income is clearly a necessary ingredient, but is not enough to capture common usage: very resource-rich countries, for example, may simply not need tax rates at anything like levels found elsewhere, and have little interest in how that affects capital or other cross-border flows. Beyond low taxation, the term carries the connotations that it is paper rather than real economic activity that is attracted, and moreover that these are jurisdictions which encourage, or at least inadequately discourage, tax avoidance or evasion that undermines tax revenues of other countries, perhaps through secrecy laws or other restrictions that preclude their sharing information. ${ }^{46}$ But quite what the standard of adequacy should be, of course, is by no means clear. Where the line lies that defines a tax haven remains hazy, but three features seem to capture the essence: low taxation that is seemingly not a reflection of high revenue, relative to needs, from other sources; the attraction of profitshifting and other tax arbitrage activities more than real activity; and imperfect sharing of information.

\section{Which countries become tax havens?}

The theory set out above carries the strong prediction that it is smaller countries which are more likely to become, in this broad sense, tax havens. They are more likely to set low tax rates that encourage profit-shifting and tax arbitrage, as seen in section 2.4, and, having low tax rates, it was seen in the preceding section that they are likely to have least to gain from information sharing.

The empirical evidence broadly matches this prediction. Dharmapala and Hines (2009) identify 41 countries as 'tax havens' and compare these with nonhavens. Their descriptive statics suggest that tax havens are, relative to nonhavens, small as regards population and area, are more likely to be islands and provide an institutional framework that is characterized, in broad terms, by good governance. These descriptive results are supported also by their multivariate analysis, suggesting that there is a strong positive correlation with governance quality, and a negative correlation with population size. These findings are also in line with those of Slemrod (2008), who offers an explanation based on the concept of

\footnotetext{
${ }^{46}$ Dharmapala and Hines (2009), for example, define as "a state or a country or territory where certain taxes are levied at a low rate or not at all while offering due process, good governance and a low corruption rate." But may would argue that it is bad governance-in the form of unwillingness to share tax information-that is a hallmark of tax havens.
} 
commercialization of a country's sovereignty: commercialization of state sovereignty for the purpose of tax haven activities has benefits that are not closely related to population size. However, the status as tax haven may have a cost in terms of "integrity" or "reputation", and this cost may be strongly correlated with population size, or the size of regular economic activity in the respective country.

\section{Are tax havens good or bad?}

The term 'tax haven' has clear pejorative overtones—one reason why policy makers have found an agreed definition so hard to find-but the recent literature has begun to focus on whether their existence and activities might not have beneficial effects. The question is closely related to the wider one of whether tax competition itself can be welfare-improving (political economy aspects of which are taken up in Section 4): after all, in any asymmetric equilibrium, some country will have the lowest tax rate, and in that sense look like a tax haven; and, at that level of generality, there may or may not exist a Pareto-superior outcome in which it sets a higher tax rate. The importance of pure arbitrage activities in the tax haven context does, however, raise distinct issues. ${ }^{47}$

One constructive way of looking at tax havens as specific players in the context of tax competition rather than as especially small ordinary countries is the structure that is mapped in Figure 10. This shows a number of 'nonhaven' countries on the right hand side. These provide an environment for real sector activity and host production facilities for firms. Some firms are fully immobile and locate their business completely in nonhaven countries. Others are mobile and make a location decision, choosing where and how much capital to locate. The right-hand side of the diagram can then be interpreted as corresponding to the benchmark ZMW model. Apart from "real" production decisions, firms may use other means to relocate accounting profits from one country to another. This may also happen between the nonhaven countries, but this is the point where haven countries enter into the picture. As they typically have a real sector that is negligible in comparison to the financial business they host, or have means to separate these two types of activities, they have an interest in firms shifting their taxable profits from nonhaven countries, in return for low tax payments or small fees. ${ }^{48}$ Tax havens compete with each other regarding the quality of their concealment or profit shifting

\footnotetext{
${ }^{47}$ Dharmapala (2009) is an overview of the theoretical and empirical literature that analyze the consequences and existence of tax haven countries.

${ }^{48}$ As pointed out in Schön (2005), a tax haven may successfully raise revenue even in case the nominal tax rate on profits is zero. This may be due to fees or levies on the financial service industry that facilitates multinational companies' operations in the tax haven.
} 
services, and in how much they charge for these. Some, presumably the larger and more international, firms in the nonhaven countries then have a choice along a second dimension. They must determine how much of their tax base to shift. This decision is similar to the condition of tax avoidance or tax evasion, as there will be a direct cost associated with the "fees" charged by the haven, the cost of setting up the appropriate international firm structure, and potentially the economic cost from adjustments required for the actual business operations. There may also be an indirect cost, given that the ordinary countries may take countermeasures to such shifting activities. ${ }^{49}$ It is this broader framework that work has identified several partial but important effects, some of which highlight detrimental effects of tax havens, while others point to possibly beneficial effects.

Figure 10: Interactions within and between havens and nonhavens

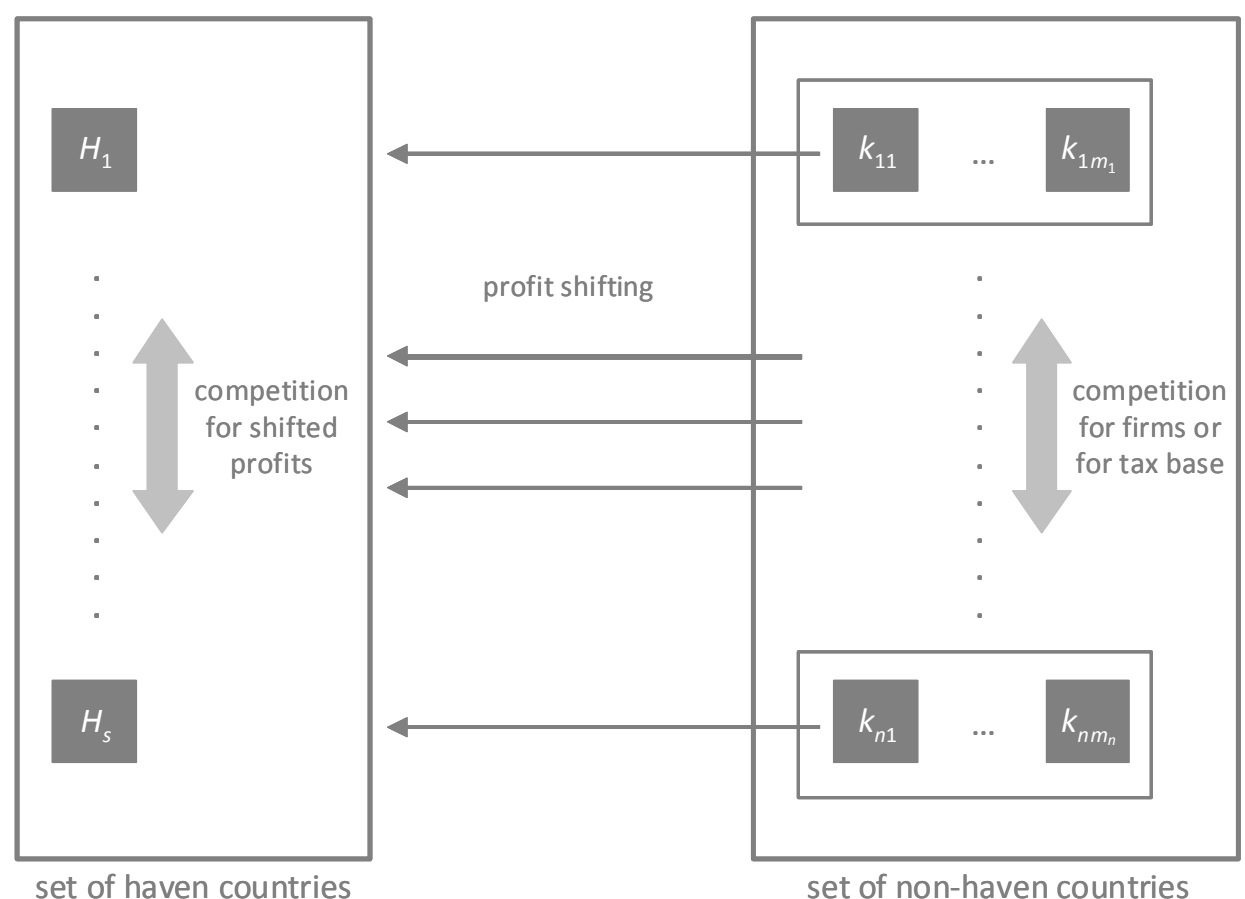

Slemrod and Wilson (2009) adopt this perspective and show that the provision of tax reduction services by haven countries can be undesirable for several reasons. They increase the marginal cost of public funds. Also, they involve some resource cost: just as with tax avoidance activities in a standard tax compliance model that are pursued with the help of tax consultants, tax payers should be willing to expend up to 99 cents to avoid the marginal \$1 additional dollar in taxes, causing social waste of 99 cents at the margin. A further insight of this paper is on the role of the direct shifting cost. If this cost is increased (for instance due to

\footnotetext{
${ }^{49}$ This perspective makes tax havens similar or comparable to tax consultancy companies who offer legal means to reduce the tax burden and charge a fee for this service, and who may face competition among each other.
} 
relaxed competition between tax havens), this generally reduce the amount of shifting and may even reduce the total amount of associated cost. Less shifting implies a broadening of the tax base and, thereby reduces the marginal cost of public funds. An element that adds to the analysis of the relationship between the tax office, tax payers and a sector of tax consultants in this analysis is the role of competition between 'ordinary' countries that may take place along the lines of tax rates or the intensity of enforcement effort.

Hong and Smart (2010) highlight a different effect by which, to the contrary, profit shifting to zero-tax jurisdictions can have beneficial side effects. In their framework the 'nonhaven' country has a mobile and an immobile sector. It can tax profits of each of these sectors with the same corporate income tax rate. The profit in the immobile sector is fully taxed. The mobile sector can shift a share of its profits to a zero-tax jurisdiction, using thin capitalization. A key assumption is that the amount of profit that can be shifted is proportionate to the capital invested, due to exogenous constraints, such as thin-capitalization rules. Generous allowances for profit shifting drive a wedge between the effective tax rates paid by the domestic firms that cannot engage in profit shifting and those faced by those using internationally mobile capital, reducing the effective tax rate for the latter. Generous opportunities for profit shifting allowances this have effects very similar to discriminatory taxation of the domestic (immobile) and mobile sectors. If the small open economy they consider could perfectly and costlessly control the amount of profit shifting through the laxness of its thin capitalization rules, it has two independent fiscal instruments at its disposal which is very similar to having two independent corporate tax rates, one for mobile and one for immobile capital—as analyzed in Section 3.2 above. Their analysis is related to the theoretical insights in Desai, Foley and Hines (2006a). They also consider tax havens as a means for profit shifting. This profit shifting reduces the effective corporate tax rates for firms, and therefore increases the net-of-tax marginal return on real investment in nonhaven countries. They conclude that this effect may dominate other, possibly detrimental effects of tax havens for investment in nonhaven countries. Their companion paper Desai, Foley and Hines (2006b) show that there is a positive business activity of firms in nonhaven countries and their activities in haven countries.

Johannesen (2010) explores another dimension of the change in the nature of tax competition that emerges from the existence of tax havens. He starts with an analysis of tax competition between $n$ countries, with a representative multinational firm that can locate and re-locate real production (an exogenously given amount of physical capital) between them. It can also shift accounting profits between countries, at some cost. He identifies asymmetric equilibria in which some countries charge high taxes and lose some tax base through profit 
shifting, while others set low taxes that attract a considerable amount of shifted profits. Tax rates are not zero even in the low-tax countries. When introducing a set of tax havens that by definition choose zero taxes and do not allow for real production, if these have a sufficient capacity, they absorb all the profit shifting, and essentially make the low-tax strategy unprofitable for those countries that would be low-tax countries in the asymmetric equilibrium without tax havens, leading to a symmetric behavior among the nonhaven countries. The tax havens deflect competition that took place between nonhaven countries towards competition between nonhaven and haven countries, and this outcome can yield higher tax revenue for the nonhaven countries in the equilibrium.

\section{Closing down tax havens}

Although few drew any strong links between the activities of tax havens and the 2009 financial crisis, at their London summit that year the G20 leaders put substantial new strength into the OECD work on encouraging widespread information exchange. Much of this effort has focused on encouraging tax havens to sign information exchange agreements (TIEAs), in order to make the concealment of taxable income more difficult, and peer reviews to ensure both that the legal mechanisms to do this are in place and that these arrangements are implemented in practice. Johannesen and Zucman (2012) survey these events and use data of the Bank of International Settlements on total deposits, held by residents from one country at banks in 14 tax havens, to measure the impact of TIEAs on deposit holdings. They find that signing an agreement between a nonhaven and a haven tends to reduce the deposits from the nonhaven in this haven country, but provide strong evidence that it also tends to shift these reductions to other havens, rather than to repatriate them.

Elsayyad and Konrad (2012) study a competition framework in which attempts are made to convince tax havens subsequently to close down their operations, for instance, by agreeing to, and practicing information exchange on tax relevant information with nonhaven governments. They show that this process may work well initially in a framework with a large number of tax havens. In this early stage, what each tax haven can earn from offering these concealment services is low, due to intense competition between the large number of existing havens. However, once a large number of tax havens has exited from this business, competition between the havens remaining relaxes, and the rents accruing to them for their services go up as a consequence. It then becomes ever more difficult to convince those remaining tax havens to exit, suggesting that the initial success that was visible in 2009 and 2010 may be bard to complete. Moreover, the outcome may then be one in which a smaller set of havens is operative, charging higher fees and acquiring a larger share of the accounting profits that 
generate from business activity in nonhaven countries. Using Zucman's (2011) estimate for total world financial wealth located in tax havens and applying their static competition model straightforwardly, the sum of profit losses of the first 34 of the 35 tax havens listed by the OECD (2000) sum up to 986 bn USD, compared to 490.8 bn. USD for the last haven almost 17 times as high as for each of the all previous havens. If the process stops short of completion, the outcome can be worse from the point of welfare for the nonhaven countries than the initial state with much competitive pressure among haven countries.

\subsection{Formula apportionment}

The incentive for companies to use transfer pricing and other devices to shift profits between jurisdictions - and for governments to design their tax systems to affect that incentivewould be removed if, instead of seeking to identify profits earned in particular jurisdictions, tax were simply levied on the aggregate of a multinationals' profits over all jurisdictions. ${ }^{50}$ 'Formula apportionment' is an alternative to either residence of source principles that goes some way in this direction, by using indicators of the extent of a company's activities in particular countries ('apportionment factors') to attribute to each a share of those aggregate profits, which it may then tax at whatever rate it chooses. This is the norm for state-level corporate taxation in Canada and the U.S. for instance (generally using as apportionment factors some combination of the shares of sales, payroll and assets located in each state) and which has been proposed by the European Commission, as a 'common consolidated corporate tax base' (CCCTB) for the EU. ${ }^{51}$

With a single apportionment factor $\alpha$, the total tax payable on a multinational's earning total profit of $\Pi\left(\alpha_{1}, \ldots \alpha_{n}\right)$ under such a system is

$$
\Pi\left(\alpha_{1}, \ldots, \alpha_{n}\right) \sum_{i=1}^{n}\left(\frac{\alpha_{i}}{\sum_{k=1}^{n} \alpha_{k}}\right) t_{i}
$$

\footnotetext{
${ }^{50}$ Nielsen, Raimondos-Møller and Schjelderup (2003) show, however, that formula apportionment may not eliminate transfer pricing incentives when subsidiaries of a controlling parent compete in oligopolistic markets. An additional motive then comes into play, which may reinforce tax considerations: if the subsidiary take that transfer price as the basis for its decision making, the centre may manipulate it as a commitment device to improve product market outcome.

${ }^{51}$ Adoption would be optional by country and by company, and with equal weight on assets, sales and payroll). On the CCCTB debate, see Sørensen (2004b), Bettendorf, Devereux, van der Horst and Loretz (2011).
} 
Supposing $\Pi$ to be strictly concave in the vector $\alpha_{i}$, the $\alpha_{i}$ would be chosen in the absence of taxation (or with tax levied directly on aggregate profit) so that $\partial \Pi / \partial \alpha_{i}=0$, for all $i$. Under formula apportionment, however, cross-country differences in tax rates distort these choices, with $\partial \Pi / \partial \alpha_{i}<0$ in countries where the tax rate is below the $\alpha$-weighted average, and conversely where it is above: broadly speaking, whatever the factor in the apportionment, it will tend to be reallocated from high to low tax countries. ${ }^{52}$

Of particular interest here is that revenue-seeking governments will have generally have an incentive to set tax rates with a view to manipulating those decisions. ${ }^{53}$ Suppose for instance that capital is used as the sole apportionment factor, and consider a multinational with some fixed amount of capital $2 \kappa$ to allocate between just two countries. Then it will do so to maximize after-tax profits

$$
\Pi \equiv\left[\Pi\left(k_{1}\right)+\Pi\left(2 \kappa-k_{1}\right)\right]\left(1-T\left(t_{1}, t_{2}, k_{1}\right)\right)
$$

where we again assume that 'true' profits can meaningfully be ascribed to countries and that the two countries are identical, and where the average tax rate

$$
T\left(t_{1}, t_{2}, k_{1}\right) \equiv \frac{t_{1} k_{1}+t_{2}\left(2 \kappa-k_{1}\right)}{2 \kappa}
$$

is endogenous to the investment decision. The solution to the firm's optimization problem leads to an allocation of capital $k_{1}\left(t_{1}, t_{2}\right)$ with the property that, where $t_{1}=t_{2}=t$,

$$
\frac{d k_{1}}{d t_{1}}=\frac{\Pi(\kappa)}{(1-t) 2 \kappa \Pi^{\prime \prime}(\kappa)}
$$

Again taking the objective to be revenue maximization, country 1 (say) then chooses $t_{1}$ to maximize $t_{1}\left(\Pi\left(k_{1}\right)+\Pi\left(2 \kappa-k_{1}\right)\right) k_{1}$; the necessary condition for which, using (61), implies that in symmetric equilibrium

$$
\frac{t^{F A}}{1-t^{F A}}=-\frac{(2 \kappa)^{2} \Pi^{\prime \prime}(\kappa)}{2 \Pi(\kappa)} \equiv \Delta^{F A}
$$

${ }^{52}$ Gordon and Wilson (1986) provide a detailed analysis of how formula apportionment can affect firm behavior, including through incentives to merge or dissolve. The analysis here follows Keen (1999).

${ }^{53}$ On other aspects of and practical experience with formula apportionment, see Weiner (2005). 
This outcome is clearly inefficient, since any higher common tax rate would yield both countries greater revenue.

More striking, however, is the comparison with the non-cooperative outcome under source taxation. In this case, total tax paid by the multinational is $t_{1} \Pi\left(k_{1}\right)+t_{2} \Pi\left(2 \kappa-k_{1}\right)$, and, by steps analogous to those leading to (62), the symmetric equilibrium tax rate has tax rates

$$
\frac{t^{s}}{1-t^{s}}=-\frac{2 \Pi(\kappa) \Pi^{\prime \prime}(\kappa)}{\left(\Pi^{\prime}(\kappa)\right)^{2}}
$$

so that comparing with (62),

$$
\frac{t^{F A}}{1-t^{F A}}-\frac{t^{s}}{1-t^{s}}=\frac{2 \Pi^{\prime \prime}}{\left(\Pi^{\prime}\right)^{2} \Pi}\left[\Pi(\kappa)^{2}-\left(\Pi^{\prime}(\kappa)\right)^{2} \kappa^{2}\right]<0,
$$

the inequality being from strict concavity of $\Pi$. Tax competition thus leads to an unambiguously lower equilibrium tax rate under formal apportionment tan under source taxation, and so, in that sense, to unambiguously more intense tax competition. To see the intuition for this, suppose that initially both countries charge the same tax rate. Under source taxation, attracting an additional unit of capital raises revenue of $t_{1} \Pi^{\prime}(\kappa)$, reflecting the marginal product of that capital; under formula apportionment, however, it raises additional revenue of $t_{1} \Pi(\kappa) / 2 \kappa$, reflecting - because the country is taking a share in aggregate profits, wherever earned-the average profit rate $\Pi(\kappa) / \kappa$. So long as the average rate of return exceeds the marginal, the incentive to attract capital is thus greater under formula apportionment.

This comparison of regimes is of somewhat unnatural in itself, in that there is assumed to be no scope for manipulating liability under the source regime other than by relocating real activities: the profit-shifting to which formula apportionment is seen as a possible response is thus absent. What the result does suggest is that formula apportionment can be preferred only if the distortions to firms' and governments' behaviour that profit-shifting leads to are sufficiently large to outweigh what would otherwise be an adverse strategic effect. Introducing the possibility of transfer pricing, at some cost to the multinational, into a framework similar to that above, Nielsen, Raimondos-Møller and Schjelderup (2010) provide a fuller treatment of the issue that elaborates on the circumstances, which turn on the level of profitability and the ease of transfer pricing, under which profit-shifting concerns dominate and formula apportionment consequently lead to a Pareto-superior non-cooperative outcome. 


\section{Political economy and agency issues}

There has long been debate as to whether international tax competition is good or bad from a welfare perspective. In the workhorse model tax competition is certainly bad. If tax rates choices are made at the central level, any decentralized equilibrium set of tax rates could equally well be implemented-at least, leaving aside the time consistency issue discussed in Section 2-but many tax rate combinations that cannot emerge in the decentralized setting are available to a central planner, making the central planning outcome at least as good as the decentralized outcome. Hence, coordinated tax rate choices-complemented as need be with international transfers of tax revenue-are at least as good, in a Pareto sense, as decentralized choices, and, as there are several externalities at work in the context of tax rate choices on the country level, will generally be Pareto-superior to the decentralized outcome. ${ }^{54}$

The comparison between a decentralized tax competition equilibrium outcome and a centrally coordinated solution in the context of fully benevolent government is evidently not an adequate comparison. If it were, for the same reason all private market economies should be transformed back into centrally planned economies. Both centralized political decision making and decentralized decision making suffer from a number of problems other than the possible externalities between decentralized decision makers. And this needs to be taken into consideration for an evaluation of independent national tax policies. Many of these problems have to do with the fact that policy decisions are not well described as the choices of a benevolent dictator who maximizes the utility of a representative citizen in the respective country. Political decision making by countries accounts for distributional conflict inside the country. Special interest groups may lobby for their preferred tax policy. The electoral process, on the other hand, gives the median voter a key role. Further, if the current government implements decisions that reflect the current preferences of its constituency, then this causes severe commitment problems for the government. And perhaps most importantly, power is delegated to governments, and this generates a number of accountability problems between the government and its constituency, even if there were no divergence of interests inside this constituency. This accountability issue has been central to the debate about whether tax competition may serve as a second-best policy, correcting for some of the inefficiencies that may emerge from the accountability problem. We start with a consideration of this latter problem.

\footnotetext{
${ }^{54}$ This reasoning is most prominently made in Sinn's (1997) selection principle, who basically argues that governmental tasks should be centralized if the activities of one country government generate externalities to other countries.
} 


\subsection{Tax competition and Leviathan}

There is a long standing tradition in the public choice literature to the effect the tax competition is not, as the analysis in Section 2 tends to suggests, a source of inefficiency, but, to the contrary, that, when other limits on their actions are weak, serves a valuable social purpose in constraining leviathans: policy makers who are inherently inclined to raise public revenue to serve their own rather than society's wide interests. To Brennan and Buchanan (1980, p.186), for instance, “..tax competition among separate units...is an objective to be sought in its own right." The view of policy makers diverting all revenue to their own use is, of course, extreme. So too, however, is the assumption in the preceding sections that they are concerned only with the general social good.

Edwards and Keen (1996) set out a variant of the ZMW model that blends the two views. Everything remains as in the symmetric version of the model analysed in Section 2.1, except that now policymakers are assumed to maximize some function $V(W, C)$ that reflects both the amount of tax revenue that they are able to divert to their own use, $C$, and, perhaps through concerns of re-election or revolt, the welfare $W$ of the taxpayer (all non-policymakers being assumed identical, and as described in Section 2.1). The policy maker's problem can then be broken down in to two stages. At the first, $C_{i}$ is taken as given, and the tax rate $t_{i}$ chosen so as to maximize the citizen's welfare, now given by

$$
W_{i}=f_{i}\left(k_{i}\right)-f_{i}^{\prime}\left(k_{i}\right) k_{i}+\rho c_{i}+G_{i}\left(t_{i} k_{i}-C_{i}\right)
$$

The solution to this gives $W\left(C_{i}\right)$, and the second stage of the problem is then that of choosing $C_{i}$ to maximize $V\left(W\left(C_{i}\right), C_{i}\right)$.

Consider then the effects of a coordinated small increase in the tax rate charged by each country, starting from the Nash equilibrium. This, it is readily shown and easy to believe, certainly makes the policymakers in each country better off. But what of the citizens? For this, note first that with $C_{i}$ fixed the first stage of the policy makers problems is formally the same problem as that in Section 2.1, so that (10) will again hold in the symmetric equilibrium:

$$
G^{\prime}(t * c)=\frac{1}{1+E_{k}}<1
$$

And the first part of equation (5) will also continue to hold, though now $d G$ is less than $c d t$ to the extent that part of the additional revenue that this reform yields is spent on $C$ instead. So: 


$$
d W=\left(G^{\prime} c\left(1-\frac{d C}{d(t c)}\right)-k\right) d t
$$

and the citizen's welfare increases if only if

$$
\frac{d C}{d(t c)}<E_{k}
$$

meaning that the policymakers' marginal propensity to consume on the item that benefits only themselves exceeds the (absolute value of) the elasticity of the tax base with respect to its own tax rate. The former is essentially an aspect of policy makers' preferences, and the latter can be thought of as increasing in the intensity of tax competition. One implication of (67) is thus that a coordinated tax increase is more likely to benefit the citizenry, all else equal, the more intense is tax competition.

A limitation of the Edwards-Keen model is that the form of policymakers' preferences and the nature of 'wasteful' spending $C$ is left unspecified: one person's waste is another's socially worthwhile spending. The issue ultimately, is one of distributional politics. This aspect is pursed further by Eggert and Sørensen (2008), who take $C$ to be rents paid to public sector workers by politicians anxious to secure their support in a probabilistic voting setting. An appealing feature of this framework is that there is in principle an optimal degree of tax competition: too little and rents are excessive, too much and under-provision of a beneficial public good dominates the gain from rent-destruction. Interestingly, their simulations suggest that this optimal degree of tax competition may be fairly low, leading them to conclude that: “...tax competition...seems a badly targeted remedy against political distortions, compared to domestic institutional reform such as restrictions on campaign contributions by lobby groups." 55

\subsection{Voters' choices}

Apart from benevolent government or selfish dictators, voting and the political process are important elements of political decision making, and this also holds for the choice of taxes. Several of the approaches have been used to describe democratic decision making have been applied to tax rate choices in a framework with tax competition. Persson and Tabellini (1992), Brückner (2001) and Fuest and Huber (2001) consider a median voter framework, while Ihori and Yang (2009) consider a citizen-candidate model.

\footnotetext{
${ }^{55}$ Eggert and Sørensen (2008, p.1154).
} 
A general insight from these models is that the political process may distort the intrajurisdictional tax rate choice away from that which a benevolent planner would have chosen, and this political distortion has to be compared with those that are introduced through the various fiscal externalities in the context of tax competition. To illustrate this in the context of the linearized framework, suppose that voters in a country differ only in their shares in the capital that is owned by each single voter. Suppose further that, as one would expect, the median voter in each country has less than the mean ownership of capital: $c_{m}<c$. These assumptions directly yield the reply functions $t_{i}\left(t_{j}\right)$ from (25) as

$$
t_{i}^{m}\left(t_{j}\right)=\frac{(1+2 \lambda)(K-A+2 a)-2 c_{m}}{3+4 \lambda}+\frac{1+2 \lambda}{3+4 \lambda} t_{j}
$$

A median voter's choice changes the intercept in the reply function, and for $c_{\mu}<c$, this reinforces the effect of tax competition. This yields reply functions $t_{i}^{m}\left(t_{j}\right)$ that are obtained from $t_{i}\left(t_{j}\right)$ by an upward shift, leading to an equilibrium with higher taxes. Other deviations of median voter preferences from those defined by a welfare maximizing planner may have similar effects. For instance, if the median voter has a lower (higher) valuation of the public good than the $\lambda$ of the benevolent government, then this has ambiguous effects. It makes the slope of the reply function less steep, but it also changes the intercept in a less predictable way.

An alternative view of electoral politics, and one that also captures the self-interest of policy makers that motivates the Edward-Keen model, is explored by Besley and Smart (2007). They consider a world in which there are two types of politicians-some pure leviathans, concerned only with the surplus $C$ they can extract from themselves, some wholly benevolent-competing for office in a world with a two-period term limit. Voters do not directly observe politicians' types, and while they can observe the taxes they pay and the public services they enjoy, they cannot observe the cost of providing those services or, hence, the surplus that the incumbent policymaker extracts for themself. There are then broadly two types of outcome, depending on the parameters of the model. One possibility is that Leviathan incumbents 'go for broke,' extracting as much revenue as they can when in office and accepting that in doing so they will reveal their identity as Leviathans, and consequently not be re-elected (a separating equilibrium). The other possibility is that Leviathan incumbents will restrain the amount of revenue they raise so as to mimic the behavior of a benevolent policy maker faced with an adverse cost shock, and so improve their chances of being reelected and extracting as much surplus as they can in a final period of office (a pooling equilibrium). 
Within this framework, Besley and Smart (2007) directly address the question of interest here: might an increase in the efficiency of the tax system-such as a coordinated increase in the tax rate in circumstances of international tax competition-reduce voter welfare (evaluated before the type of the first-period incumbent is known)? They show that it could. Such an increase in efficiency makes it more attractive for Leviathan to mimic a benevolent policy maker - the latter would now choose a higher level of provision of public good provision, which enables the former to extract more rent by pretending that its cost has proved high-so that electoral process becomes less effective at removing leviathans, thereby creating more risk of abuse in the final term of office. This source of loss is greater the higher is the likelihood that a candidate with no record of office would prove to be benevolent. ${ }^{56}$ For this reason-and counter perhaps to simple intuition-a coordinated increase in tax rates is more likely to reduce voter welfare the fewer politicians are potential leviathans.

\subsection{Delegation and lobbying for tax rate choices}

Instead of choosing the tax rate in order to maximize national welfare, the "decision maker" in country $i$ might delegate the choice of $t_{i}$ to an agent who follows their own agenda. Median voter choice of a representative government is one example of this approach to political decision making, in which the decision is delegated to a decision maker who maximizes an objective function that differs from the social welfare function. Depending on the incentives that can be given to the delegate, this may lead to somewhat extreme forms of delegation. For instance, suppose that country 2 anticipates that country 1 will delegate decision making in a way that generates a reply function $\hat{t}_{1}\left(t_{2}\right)$. It may them delegate the decision in an extreme way: $t_{2} \equiv \operatorname{argmax}_{t_{2} \in[0,1]} W_{2}\left(t_{1}, \hat{t}_{2}\left(t_{1}\right)\right)$. I.e., country 2 chooses the most preferred combination $\left(t_{1}, t_{2}\right)$ on the opportunity locus generated by $\hat{t}_{1}\left(t_{2}\right)$ in Figure 11 . But then $\hat{t}_{1}\left(t_{2}\right)$ is typically not the optimal delegation decision from the perspective of country 1 . It turns out that simultaneous delegation by the two countries may actually lead to an extreme delegation: $\hat{t}_{1} \equiv t^{*}$ and $\hat{t}_{2} \equiv t^{*}$. The Nash equilibrium is, perhaps surprisingly, also an equilibrium of this simultaneous delegation game.

\footnotetext{
${ }^{56}$ It is also greater the lower is the voter's discount rate, since then the present value cost of a future unrestrained Leviathan is greater.
} 
Figure 11: Perfect commitment and tax competition.

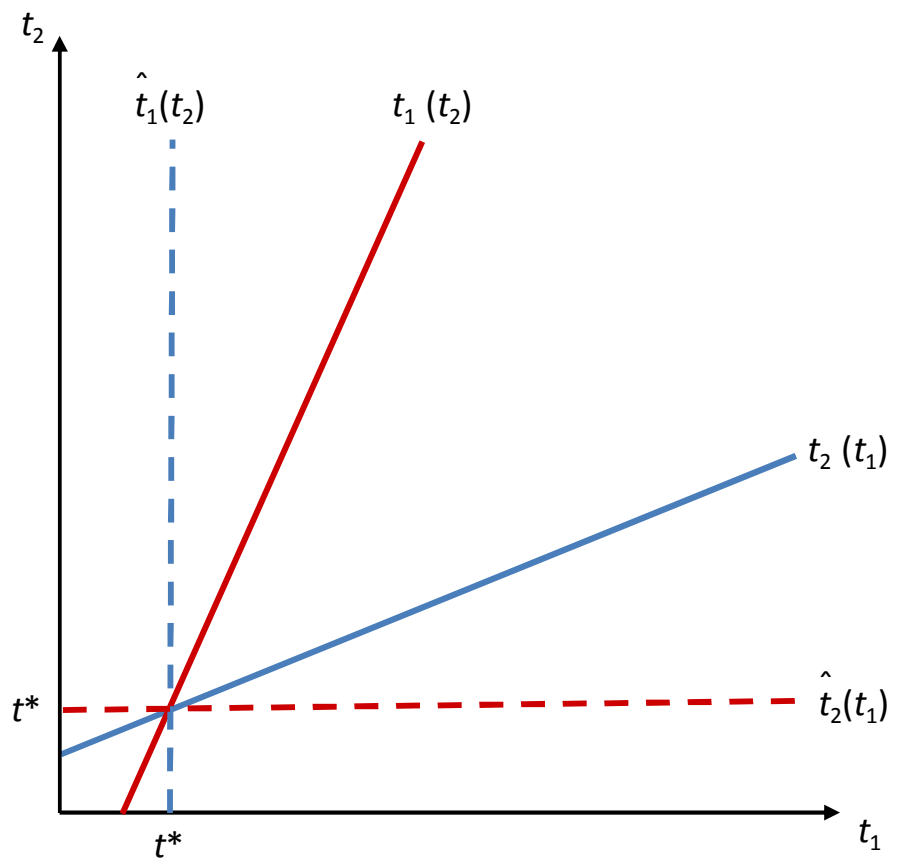

Brückner (2001) compares the strategic incentives to delegate decision making in the context of tax competition with a context in which the delegates coordinate on a cooperative outcome. If cooperation is anticipated, the decision maker who chooses the national delegate can also affect the outcome by the incentives given to the delegate. As he shows, this may cause a median voter appoints a delegate who is interested in low taxes.

Lobbying activities by some powerful groups may also affect the outcome of tax competition. Just as the median voter is likely to be less capital rich than the mean per capita amount of capital ownership, so citizens who own above average quantities of capital may not passively concede to the median voter outcome. Instead, they may lobby in the political process, trying to shift the reply function "downward" towards lower capital taxes. Applied to the workhorse model here, this should foster the effects of tax competition. Chirinko and Wilson (2010) report evidence suggesting that business campaign contributions in a country may affect the tax reaction function and influence tax policy.

\section{Concluding Remarks}

The literature reviewed here has produced a range of elegant and in some cases powerful results. It suggests, for instance, that the agreement of minimum tax rates at levels somewhat above the lowest in the observed outcome is likely to be a fruitful path to coordinating away 
from inefficient outcomes than is agreeing on common rates. ${ }^{57}$ It would be too much to expect conclusions to be unqualified, and they are not: it has also been seen, for instance, that adoption of a minimum rate has less clear cut effects in a Stackelberg game, and can undermine 'good' equilibria in a repeated game context. The literature does, nonetheless, provide a coherent basis for contributing to and perhaps also shaping policy debates.

These results do a better job, however in explaining why concerted action may be difficult than in suggesting, even in broad terms, what actions might be both desirable and feasible. It stresses, for instance, the importance of asymmetries between countries, and the potential limitations of less than globally coordinated measures. But it gives little useful guidance on how these might be overcome, or on such practical issues as whether the countries of Eastern Africa should put substantial effort into coordinating tax incentives among themselves. Perhaps most fundamentally, it has not answered the basic question raised by OECD (1998): How can one distinguish tax competition that is 'harmful' from that which is not? Progress has been made, but not yet enough to confidently determine whether, for instance, the presumption should be against or in favour of preferential regimes. Further advance may require not only deeper empirical understanding and perhaps more use of calibrated simulations, but less simplistic views of the international tax regime itself. The risk, not for the first time, is that the world will move more quickly than the theory.

\footnotetext{
${ }^{57}$ Effective or statutory, depending on the context, and assuming agreement on a common base.
} 


\section{References}

Agrawal, D. (2011), “The tax gradient: do local sales taxes reduce tax differentials at state borders?" Mimeo (University of Michigan).

Altshuler, R., and T.J. Goodspeed (2002). "Follow the leader? Evidence on European and U.S. tax competition”, Departmental Working paper 200226 (Department of Economics, Rutgers University).

Andersson, F., and K.A. Konrad (2003), "Human capital investment and globalization in extortionary states", Journal of Public Economics 87(7-8):1539-1555.

Auerbach, A.J. (2006), “The future of capital income taxation”, Fiscal Studies 27(4):399-420.

Bacchetta, P., and M.P. Espinosa (1995), "Information sharing and tax competition among governments", Journal of International Economics 39(1-2):193-121.

Baldwin, R.E., and P. Krugman (2004), "Agglomeration, integration and tax harmonisation", European Economic Review 48(1):1-23.

Baretti, C., B. Huber, and K. Lichtblau (2002), "A tax on tax revenue: the incentive effects of equalizing transfers: evidence from Germany", International Tax and Public Finance 9:631649.

Becker, J., and C. Fuest (2010), "EU regional policy and tax competition", European Economic Review 54(1):150-161.

Besley, T.J., and M. Smart (2007), "Fiscal restraints and voter welfare", Journal of Public Economics 91(3-4):755-773.

Bettendorf, L., M. Devereux, A. van der Horst, and S. Loretz (2011), "Corporate tax reform in the EU: weighing pros and cons, policy briefing", (Centre for Business Taxation, University of Oxford).

Binet, M-E. (2003), "Testing for fiscal competition among French municipalities: granger causality evidence in a dynamic panel data model", Papers in Regional Science 82(2):277289.

Bjorvatn, K., and C. Eckel (2006), "Policy competition for foreign direct investment between asymmetric countries", European Economic Review 50(7):1891-1907.

Black, D.A., and W.H. Hoyt (1989), "Bidding for firms", American Economic Review 79(5):1249-1256.

Blonigen, B.A., and R.B. Davies (2004), "Do bilateral tax treaties promote foreign direct investment?" In: J. Hartigan, ed., Handbook of International Trade Volume II: Economic and Legal Aspects of Trade Policy and Institutions (Blackwell Publishers, Boston).

Boadway, R., and M. Hayashi (2001), "An empirical analysis of intergovernmental tax interaction: the case of business taxes in Canada", Canadian Journal of Economics 34(2):481-503. 
Boadway, R., and M. Keen (1998), "Evasion and time consistency in the taxation of capital income", International Economic Review 39(2):461-476.

Boadway, R., and J-F. Tremblay (2011), "The evolution of fiscal federalism since Tiebout", Journal of Public Economics, forthcoming.

Brennan, G., and J. M. Buchanan (1980), “The power to tax: analytical foundations of a fiscal constitution" (Cambridge University Press).

Brochner, J., J. Jensen, P. Svensson, and P.B. Sørensen (2007), "The dilemmas of tax coordination in the enlarged European Union", CESifo Economic Studies 53(4):561-595.

Broner, F., A. Martin, and J. Ventura (2010), "Sovereign risk and secondary markets", American Economic Review 100(4):1523-1555.

Brückner, M. (2001), "Strategic delegation and international capital taxation", ZEI Working aper B 22-2001, ZEI-Center for European Integration Studies (University of Bonn).

Brückner, J.K. (2003), "Strategic interaction among governments: an overview of empirical studies", International Regional Science Review 26(2):175-188.

Bucovetsky, S. (1991), "Asymmetric tax competition", Journal of Urban Economics 30(2):167-181.

Bucovetsky, S. (2009), “An index of capital tax competition”, International Tax and Public Finance 16(6):727-752.

Bucovetsky, S., and A. Haufler (2007), "Preferential tax regimes with asymmetric countries", National Tax Journal 60(4):789-795.

Büttner, T. (2003), "Tax base effect and fiscal externalities of local capital taxation: evidence from a panel of German jurisdictions", Journal of Urban Economics 54(1):110-128.

Cai, H., and D. Treisman (2005), "Does competition for capital discipline governments? Decentralization, globalization, and public policy", American Economic Review 95(3):817830.

Cardarelli, R., E. Taugourdeau, and J-P. Vidal (2002), “A repeated interactions model of tax competition", Journal of Public Economic Theory 4(1): 19-38.

Carlsen, F., B. Langset, and J. Rattsø (2005), "The relationship between firm mobility and tax level: empirical evidence of fiscal competition between local governments", Journal of Urban Economics 58(2): 273-288.

Catenaro, M., and J-P. Vidal (2006), "Implicit tax co-ordination under repeated policy interactions", Louvain Economic Review 72(1):5-17.

Chirinko, R.S., and D.J. Wilson (2010), "Can lower tax rates be bought? Business rent-seeking and tax competition among U.S. states", National Tax Journal 63(4):967-994. 
Clausing, K.A. (2007), “Corporate tax revenues in OECD countries”, International Tax and Public Finance 14(2):115-133.

Conconi, P., C. Perroni, and R. Riezman (2008), "Is partial tax harmonization desirable?", Journal of Public Economics 92(1-2):254-267.

Deneckere, R., and C. Davidson (1985), "Incentives to form coalitions with Bertrand competition”, RAND Journal of Economics 16(4):473-486.

Desai, M.A., F. Foley, and J R. Hines Jr. (2006a), "Do tax havens divert economic activity?" Economics Letters 90:219-224.

Desai, M.A., F. Foley, and J.R. Hines Jr. (2006b), "The demand for tax haven operations", Journal of Public Economics 90:513-531.

Devereux, M.P. (1992), "The Ruding Committee Report: an economic assessment", Fiscal Studies 13(2):96-107.

Devereux, M.P., R. Griffith, and A. Klemm (2002), "Corporate income tax reforms and international tax competition”, Economic Policy 17(35):449-495.

Devereux, M.P., B. Lockwood, and M. Redoano (2008), "Do countries compete over corporate tax rates?” Journal of Public Economics 92(5-6):1210-1235.

Dharmapala, D. (2009), "What problems and opportunities are created by tax havens?" Oxford Review of Economic Policy 24(4):661-679.

Dharmapala, D., and J.R. Hines Jr. (2009), "Which countries become tax havens?” Journal of Public Economics 93:1058-1068.

Dhrymes, P.J. (1978), Mathematics for Econometrics (Springer-Verlag, New York).

Edwards, J., and M. Keen (1996), "Tax competition and Leviathan", European Economic Review 40(1):113-134.

Eggert, W., and M. Kolmar (2002), "Residence-based capital taxation in a small open economy: why information is voluntarily exchanged and why it is not", International Tax and Public Finance 9:465-482.

Eggert, W., and P.B. Sørensen (2008), "The effects of tax competition when politicians create rents to buy votes", Journal of Public Economics 92:1142-1163.

Elsayyad, M., and K.A. Konrad (2012), "Fighting multiple tax havens", Journal of International Economics 86:295-305.

Fenge, R., and M. Wrede (2007), "EU financing and regional policy: vertical fiscal externalities when capital is mobile", FinanzArchiv 63(4):457-476.

Ferrett, B., and I. Wooton (2010a), "Tax competition and the international distribution of firm ownership: an invariance result", International Tax and Public Finance 17(5):518-531. 
Ferrett, B., and I. Wooton (2010b), "Competing for a duopoly: international trade and tax competition", Canadian Journal of Economics 43(3):776-794.

Fuest, C. (2005), "Economic integration and tax policy with endogenous foreign firm ownership", Journal of Public Economics 89(9-10): 1823-1840.

Fuest, C., and B. Huber (1999), “Can tax coordination work?” Finanzarchiv 56(3-4): 443-458.

Fuest, C., and B. Huber (2001), "Tax competition and tax coordination in a median voter model”, Public Choice 107(1-2):97-113.

Fuest, C., B. Huber, and J. Mintz (2005), "Capital mobility and tax competition: a survey", Foundations and Trends in Microeconomics 1(1):1-62.

Genschel, P., and P. Schwarz (2011), "Tax competition: a literature review", Socio-Economic Review 9:339-370.

Gérard, M., H. Jayet, and S. Paty (2010), “Tax interaction among Belgian municipalities: do interregional differences matter?” Regional Science and Urban Economics 40(5):336-342.

Gordon, R.H. (1986), "Taxation of investment and savings in a world-economy", American Economic Review 76(5):1086-1102.

Gordon, R.H., and J.R. Hines Jr. (2002), "International taxation", In: A. J. Auerbach and M. Feldstein eds., Handbook of Public Economics, Vol. 4:1935-1995.

Gordon, R.H., and J.D. Wilson (1986), “An examination of multijurisdictional corporate income taxation under formula apportionment”, Econometrica 54(6):1357-1373.

Gresik, T. A. (2001), "The taxing task of taxing transnationals", Journal of Economic Literature 39(3):800-838.

Haaparanta, P. (1996), "Competition for foreign direct investment", Journal of Public Economics 63(1):141-153.

Hamilton, J.H., and S.M. Slutsky (1990), "Endogenous timing in duopoly games: Stackelberg or Cournot equilibria", Games and Economic Behavior 2(1):29-46.

Haufler, A., and I. Wooton (1999), "Country size and tax competition for foreign direct investment", Journal of Public Economics 71(1):121-139.

Haufler, A., and I. Wooton (2006), "The effects of regional tax and subsidy coordination on foreign direct investment", European Economic Review 50(2):285-305.

Haufler, A., and I. Wooton (2010), "Competition for firms in an oligopolistic industry: the impact of economic integration", Journal of International Economics 80(2):239-248.

Haupt, A., and W. Peters (2005), "Restricting preferential tax regimes to avoid harmful tax competition", Regional Science and Urban Economics 3585:493-507. 
Hayashi, M., and R. Boadway (2001), "An empirical analysis of intergovernmental tax interaction: the case of business income taxes in Canada", Canadian Journal of Economics, 34(2):481-503.

Holmes, T.J. (1989), "The effects of third-degree price discrimination in oligopoly", American Economic Review 79(1):244-250.

Hong, Q., and M. Smart (2010), "In praise of tax havens: international tax planning and foreign direct investment", European Economic Review 54(1):82-95.

Huizinga, H. (1995), "The optimal taxation of savings in an open economy", Economics Letters 47(1):59-62.

Huizinga, H., and G. Nicodème (2006), "Foreign ownership and corporate income taxation: an empirical evaluation”, European Economic Review 50(5):1223-1244.

Huizinga, H., and S.B. Nielsen (1997), "Capital income and profit taxation with foreign ownership of firms", Journal of International Economics 42(1-2):149-165.

Huizinga, H., and S.B. Nielsen (2002), "The coordination of capital income and profit taxation with cross-ownership of firms", Regional Science and Urban Economics 32(1):1-26.

Huizinga, H., and S.B. Nielsen (2003), "Withholding taxes or information exchange: the taxation of international interest flows", Journal of Public Economics 87(1):39-72.

Huizinga, H., and S.B. Nielsen (2008), "Must losing taxes on saving be harmful?" Journal of Public Economics 92(5-6):1183-1192.

Ihori, T., and C.C. Yang (2009), "Interregional tax competition and intraregional political competition: the optimal provision of public goods under representative democracy", Journal of Urban Economics 66(3):210-217.

Jacobs, J.P.A.M., J. E. Ligthart, and H. Vrijburg (2010), "Consumption tax competition among governments: evidence from the United States", International Tax and Public Finance 17(3):271-294.

Janeba, E. (2000), "Tax competition when governments lack commitment: excess capacity as a countervailing threat", American Economic Review 90(5): 1508-1519.

Janeba, E., and W. Peters (1999), "Tax evasion, tax competition and the gains from nondiscrimination: the case of interest taxation in Europe", Economic Journal 109(452):93101.

Janeba, E., and M. Smart (2003), "Is targeted tax competition less harmful than its remedies?" International Tax and Public Finance 10(3):259-280.

Johannesen, N. (2010), "Imperfect tax competition for profits, asymmetric equilibrium and beneficial tax havens", Journal of International Economics 81:253-264.

Johannesen, N., and G. Zucman (2012), "The end of bank secrecy? An evaluation of the G20 tax haven crackdown", Working paper 2012-04 (Paris School of Economics, Paris). 
Kanbur, R., and M. Keen (1993), "Jeux sans frontières: tax competition and tax coordination when countries differ in size", American Economic Review 83(4):877-892.

Karkalakos, S., and C. Kotsogiannis (2007), “A spatial analysis of provincial corporate income tax responses: evidence from Canada", Canadian Journal of Economics 40(3):782-811.

Keen, M. (1999), "EMU and tax competition", Mimeo (International Monetary Fund, Washington, DC).

Keen, M. (2001), "Preferential regimes can make tax competition less harmful", National Tax Journal 54(4):757-762.

Keen, M. (2002), "Some international issues in commodity taxation", Swedish Economic Policy Review 9(2002):41-45.

Keen, M., and C. Kotsogiannis (2002), "Does federalism lead to excessively high taxes?" American Economic Review 92(1):363-370.

Keen, M., and C. Kotsogiannis (2004), "Tax competition in federations and the welfare consequences of decentralization”, Journal of Urban Economics 56(3):397-407.

Keen, M., and J.E. Ligthart (2006), "Information sharing and international taxation: a primer", International Tax and Public Finance 13(1):81-110.

Keen, M., and M. Mansour (2010), "Revenue mobilisation in sub-saharan Africa: challenges from globalisation II-corporate taxation”, Development Policy Review 28(5):573-596.

Keen, M., and M. Marchand (1997), "Fiscal competition and the pattern of public spending", Journal of Public Economics 66(1):33-53.

Keen, M., and D. Wildasin (2004), "Pareto-efficient international taxation", American Economic Review 94(1):259-275.

Kehoe, P.J. (1989), "Policy cooperation among benevolent governments may be undesirable", Review of Economic Studies 56(2):289-296.

Kelders, C., and M. Koethenbuerger (2010), "Tax incentives in fiscal federalism: an integrated perspective", Canadian Journal of Economics 43(2):683-703.

Kempf, H., and G. Rota Graziosi (2010), "Endogenizing leadership in tax competition: a timing game perspective", Working paper 299 (Banque de France, Paris).

Kessing, S., K.A. Konrad, and C. Kotsogiannis (2006), "Federal tax autonomy and the limits of cooperation", Journal of Urban Economics 59(2):317-329.

Kessing, S., K.A. Konrad, and C. Kotsogiannis (2009), "Federalism, weak institutions and the competition for foreign direct investment", International Tax and Public Finance 16(1):105123. 
King, I., P. R. McAfee, and L. A. Welling (1993), "Industrial blackmail: dynamic tax competition and public investment", Canadian Journal of Economics 26(3):590-608.

Kiss, Á. (2011), "Minimum taxes and repeated tax competition", IEHAS Discussion Papers 16/2011, In: International Tax and Public Finance (Institute of Economics, Hungarian Academy of Sciences, Budapest), forthcoming.

Konrad, K.A. (2009), "Non-binding minimum taxes may foster tax competition", Economics Letters 102(2):109-111.

Konrad, K.A., and D. Kovenock (2009), "Competition for FDI with vintage investment and agglomeration advantages", Journal of International Economics 79(2):230-237.

Konrad, K.A., and K.E. Lommerud (2001), "Foreign direct investment, intra-firm trade and ownership structure", European Economic Review 45(3):475-494.

Konrad, K.A., and G. Schjelderup (1999), "Fortress building in global tax competition", Journal of Urban Economics 46(1):156-167.

Kotsogiannis, C. (2010), "Federal tax competition and the efficiency consequences for local taxation of revenue equalization", International Tax and Public Finance 17(1):1-14.

Kydland, F.E., and E.C. Prescott (1980), "Dynamic optimal taxation, rational-expectations and optimal control", Journal of Economic Dynamics and Control 2(1):79-91.

Lipsey, R.G., and K. Lancaster (1956), "The general-theory of 2nd best", Review of Economic Studies 24(63):11-32.

Lockwood, B. (1997), "Can international commodity tax harmonisation be Pareto-improving when governments supply public goods?” Journal of International Economics 43:387-408.

Lockwood, B. (2004), "Competition in unit vs. ad valorem taxes", International Tax and Public Finance 11(6):763-772.

Marceau, N., S. Mongrain, and J.D. Wilson (2010), "Why do most countries set high tax rates on capital?" Journal of International Economics 80(2):249-259.

Mintz, J., and M. Smart (2004), "Income shifting, investment, and tax competition: theory and evidence from provincial taxation in Canada", Journal of Public Economics 88(6):11491168.

Mintz, J., and H. Tulkens (1986), "Commodity tax competition between members of a federation: equilibrium and efficiency”, Journal of Public Economics 29:133-172.

Mintz, J., and H. Tulkens (1996), "Optimality properties of alternative systems of taxation of foreign capital income", Journal of Public Economics 60:373-399.

Mintz, J., and A. Weichenrieder (2010), "The indirect side of direct investment: multinational company finance and taxation", (MIT Press Cambridge, MA). 
Narasimhan, C. (1988), "Competitive promotional strategies”, Journal of Business 61(4):427449.

Nielsen, S.B. (2001), "A simple model of commodity taxation and cross-border shopping", Scandinavian Journal of Economics 103:599-623.

Nielsen, S.B., P. Raimondos-Møller, and G. Schjelderup (2003), "Formula apportionment and transfer pricing under formula apportionment", Journal of Public Economic Theory 5:419437.

Nielsen, S.B, P. Raimondos-Møller, and G. Schjelderup (2010), "Company taxation and tax spillovers: separate accounting versus formula apportionment", European Economic Review 54:121-132.

Ohsawa, Y. (1999), "Cross-border shopping and commodity tax competition among governments", Regional Science and Urban Economics 29:33-51.

Organisation for Economic Cooperation and Development (1998), Harmful Tax Competition: An Emerging Global Issue (OECD, Paris).

Organisation for Economic Cooperation and Development (2000), Towards Global Tax Cooperation: Progress in Identifying and Eliminating Harmful Tax Practices (OECD, Paris).

Overesch, M., and J. Rinke (2009), "Competition from low-wage countries and the decline of corporate tax rates: evidence from European integration", World Economy 32(9):13481364.

Parry, I.W.H. (2003), "How large are the welfare costs of tax competition?" Journal of Urban Economics 54(1):39-60.

Peralta, S., X. Wauthy, and T. van Ypersele (2006), "Should countries control international profit shifting?" Journal of International Economics 68:24-37.

Peralta, S., and T. van Ypersele (2005), "Factor endowments and welfare levels in an asymmetric tax competition game", Journal of Urban Economics 57(2):258-274.

Peralta, S., and T. van Ypersele (2006), "Coordination of capital taxation among asymmetric countries", Regional Science and Urban Economics 36(6):708-726.

Persson, T., and G. Tabellini (1992), "The politics of 1992: fiscal policy and European integration", Review of Economic Studies 59:689-701.

Raff, H. (2004), "Preferential trade agreements and tax competition for foreign direct investment", Journal of Public Economics 88(12):2745-2763.

Revelli, F. (2003), "Reaction or interaction? Spatial process identification in multi-tiered government structures", Journal of Urban Economics 53(1):29-53.

Ruding, O. (1992), Conclusions and Recommendations of the Committee of Independent Experts on Company Taxation: Report of the Committee of Independent Experts on 
Company Taxation, Commission of the European Communities, Official Publications of the EC, ISBN 92-826-4277-1, March 1992.

Salant, S.W., S. Switzer, and R.J. Reynolds (1983), "Losses from horizontal mergers: the effects of an exogenous change in industry structure on Cournot-Nash equilibrium", Quarterly Journal of Economics 98:185-199.

Schmalensee, R. (1981), "Output and welfare implications for monopolistic third-degree price discrimination", American Economic Review 71:242-247.

Schön, W. (2005), "Playing different games? Regulatory competition in tax and company law compared”, Common Market Law Review 42:331-365.

Schön, W., and K.A. Konrad, eds., (2012), Fundamentals of Transfer Pricing in Law and Economics, Springer, Heidelberg.

Sinn, H-W (1997), “The selection principle and market failure in systems competition”, Journal of Public Economics 66(2):247-274.

Slemrod, J. (2008), "Why is Elvis on Burkina Faso postage stamps? Cross-country evidence on the commercialization of state sovereignty", Journal of Empirical Legal Studies 5(4):683712 .

Slemrod, J., and J.D. Wilson (2009), "Tax competition with parasitic tax havens", Journal of Public Economics 93:1261-1270.

Sørensen, P.B (2004a), “International tax coordination: regionalism versus globalism”, Journal of Public Economics 88(6):1187-1214.

Sørensen, P.B. (2004b), "Company tax reforms in the European Union”, International Tax and Public Finance 11:91-115.

Sørensen, P.B. (2007), "Can capital income taxes survive? And should they?" CESifo Economic Studies 53(2):172-228.

Vanistendael, F. (1992), “The Ruding Committee Report: a personal view”, Fiscal Studies 13(2):85-95.

Vrijburg, H., and R.A. de Mooij (2010), Enhanced Cooperation in an Asymmetric Model of Tax Competition, CESifo Working Paper No. 2915.

Wang, Y-Q (1999), "Commodity taxes under fiscal competition: Stackelberg equilibrium and optimality”, American Economic Review 89(4):974-981.

Weightman, G. (2007), The Industrial Revolutionaries (Grove Press, New York).

Weiner, J. (2005), "Formulary apportionment and group taxation in the European Union: insights from the United States and Canada", Taxation paper 8/2005 (European Commission). 
Wildasin, D.E. (1988), "Nash equilibria in models of fiscal competition", Journal of Public Economics 35(2):229-240.

Wildasin, D.E. (1991), "Some rudimentary duopolity theory", Regional Science and Urban Economics 21(3):393-421.

Wildasin, D.E. (2003), "Fiscal competition in space and time", Journal of Public Economics, 87(11):2571-2588.

Wildasin, D.E., and J.D. Wilson (1998), "Risky local tax bases: risk-pooling vs. rent-capture", Journal of Public Economics 69:229-247.

Wilson, J.D. (1986), “A theory of international tax competition”, Journal of Urban Economics 19(3):296-315.

Wilson, J.D. (1991), "Tax competition with interregional differences in factor in factor endowments", Regional Science and Urban Economics 21(3):423-451.

Wilson, J.D. (1999), “Theories of tax competition”, National Tax Journal 52(2):269-304.

Wilson, J.D., and E. Janeba (2005), "Decentralization and international tax competition", Journal of Public Economics 89(7):1211-1229.

Wilson, J.D., and D.E. Wildasin (2004), "Capital tax competition: bane or boon”, Journal of Public Economics 88(6):1065-1091.

Winner, H. (2005), "Has tax competition emerged in OECD countries? Evidence from panel data", International Tax and Public Finance 12(5):667-687.

Wrede, M. (1999), “Tragedy of the fiscal common? Fiscal stock externalities in a leviathan model of federalism", Public Choice 101(3-4):177-193.

Zodrow, G.R. (2003), "Tax competition and tax coordination in the European Union", International Tax and Public Finance 10(6):651-671.

Zodrow, G.R. (2010), “Capital mobility and tax competition”, National Tax Journal 63(4):865902.

Zodrow, G.R., and P. Mieszkowski (1986), "Pigou, tax competition and the underprovision of local public goods", Journal of Urban Economics 19:356-370.

Zucman, G. (2011), “The missing wealth of nations: evidence from Switzerland, 1914-2010”, Working paper 2011-07 (Paris School of Economics, Paris). 